Florida International University FIU Digital Commons

6-12-1998

\title{
Icelandic occupational therapists' attitudes toward educational and professional issues
}

Elín Ebba Ásmundsdóttir

Florida International University

DOI: $10.25148 /$ etd.FI14032360

Follow this and additional works at: https://digitalcommons.fiu.edu/etd

Part of the Occupational Therapy Commons

\section{Recommended Citation}

Ásmundsdóttir, Elín Ebba, "Icelandic occupational therapists' attitudes toward educational and professional issues" (1998). FIU Electronic Theses and Dissertations. 1328.

https://digitalcommons.fiu.edu/etd/1328

This work is brought to you for free and open access by the University Graduate School at FIU Digital Commons. It has been accepted for inclusion in FIU Electronic Theses and Dissertations by an authorized administrator of FIU Digital Commons. For more information, please contact dcc@fiu.edu. 
FLORIDA INTERNATIONAL UNIVERSITY

Miami, Florida

ICELANDIC OCCUPATIONAL THERAPISTS' ATTITUDES TOWARD EDUCATIONAL AND PROFESSIONAL ISSUES

A thesis submitted in partial satisfaction of the requirements for the degree of

MASTER OF SCIENCE

IN

OCCUPATIONAL THERAPY

by

Elín Ebba Ásmundsdóttir

1998 
To: Dean DeLois Weekes

College of Health Sciences

This thesis, written by Elín Ebba Ásmundsdóttir, and entitled Icelandic Occupational Therapists' Attitudes Toward Educational and Professional Issues, having been approved in respect to style and intellectual content, is referred to you for judgment.

We have read this thesis and recommend that it be approved.

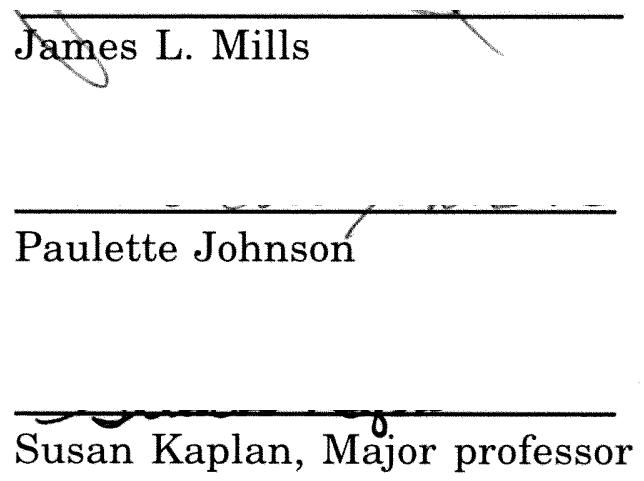

Date of Defense: June 12, 1998

The thesis of Elín Ebba Ásmundsdóttir is approved.

Dean DeLois Weekes College of Health Sciences

Dr. Richard L. Cantpbell

Dean of Graduate Studies

Florida International University, 1998 
I dedicate this thesis to my husband Jon Kjell Seljeseth and my mother Sólrún Yngvadóttir, who have shown me, in a hundred different ways, what love is. 


\section{ACKNOWLEDGMENTS}

I wish to thank Florida International University for their collaboration with the University of Iceland, and particularly Dr. Gail Hills, Ph.D., OTR, for her contribution to Icelandic occupational therapy.

I thank Dr. Patricia Scott, Ph.D., OTR, for her constructive comments as my main advisor in the early phase of the study. Although our collaboration was shorter than expected, it surely made a difference. I wish her all the luck in the future.

I thank Professor James L. Mills, MHA, MSED, OTR, for his skills in health promotion, Dr. Paulette Johnson Ph.D., for guiding me gently through chapter four, and Dr. Susan Kaplan Ph.D., OTR, for stepping in as my main adviser. Her knowledge, expertise and personality made this all seem so easy. 


\author{
ABSTRACT OF THE THESIS \\ ICELANDIC OCCUPATIONAL THERAPISTS' \\ ATTITUDES TOWARD EDUCATIONAL \\ AND PROFESSIONAL ISSUES \\ by \\ Elín Ebba Ásmundsdóttir \\ Florida International University, 1998 \\ Miami, Florida \\ Professor Susan Kaplan, Major Professor
}

The entire population of Icelandic occupational therapists were surveyed concerning characteristics and attitudes toward professionalism and educational goals. There were 87 questionnaires sent out and 80 (92\%) were returned and used for analysis. This data will have a positive impact upon the development of the first Icelandic occupational therapy curriculum.

Icelandic occupational therapists, in general, value academic skills over technical skills, are active in their association, willing to take on duties for the advancement of the profession and are interested in conducting research. The attitudes of the Icelandic occupational therapists were generally quite uniform. T- tests and one-way ANOVAs $(\mathrm{p}<.05)$ revealed some significant differences in a number of attitudes by education level, length of professional experience and country of education. The results show the importance of providing Icelandic occupational therapy practitioners with the opportunity to take part in research. This study will serve as a foundation for future studies on Icelandic occupational therapists and provide reference data for later comparison. 


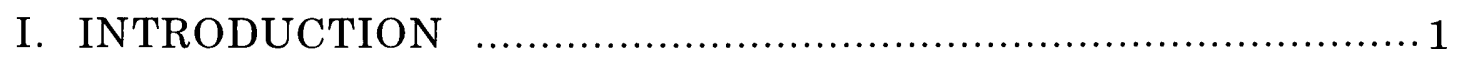

Occupational Therapy in Iceland ....................................... 1

Statement of the Problem …........................................ 7

Purpose of the Study ................................................. 7

Research Questions ............................................ 8

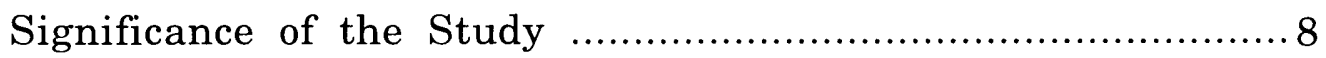

Definitions ........................................................ 9

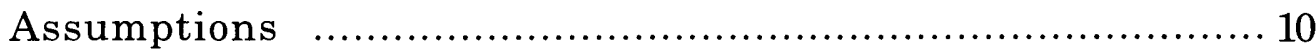

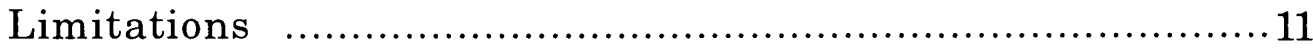

II. LITERATURE REVIEW …............................................ 12

Perspective of the Professions …....................................12

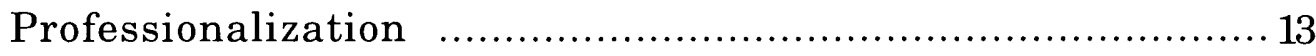

The Professionalization of Occupational Therapy ................. 15

Future Perspectives for the Occupational Therapy Profession ... 29

Research in the Occupational Therapy Profession ................. 31

Studies Regarding Professionalism ................................. 34

Studies with Respect to Education ................................. 38

Research in Chronological Order ................................5 52

Self Report ..........................................................5 55

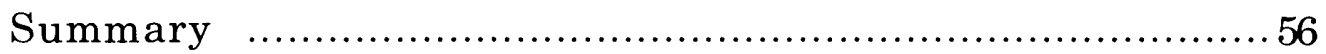

III. RESEARCH PROCEDURES …................................... 58

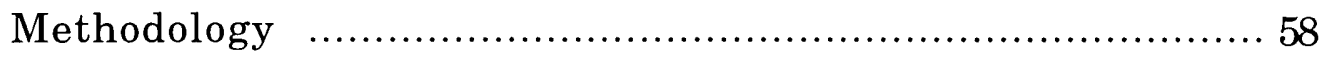

Research Questions ....................................... 58

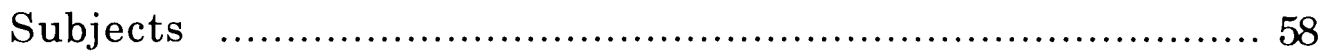

Study Design ........................................................ 59

Procedure ............................................................ 59

Instrument Development ...................................... 60

Statistical Analysis ......................................... 64

Limitations ........................................................... 65 


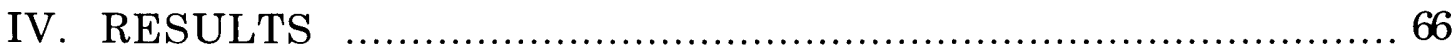

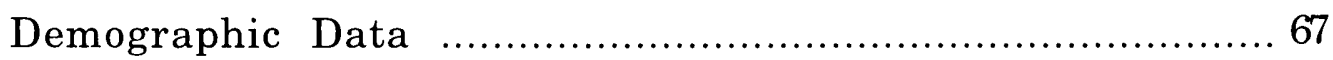

Attitudes Toward Professionalism …................................. 71

Professional Interests, Productivity and Commitment ..............72

Attitudes Toward Professional Commitment and Concerns ....... 77

Attitudes Regarding Educational Goals ............................. 82

Preparation for Practice ............................................. 82

Emphasis in Areas of Education .................................. 84

Preferences Regarding Changes in the

Occupational Therapy Practice ...................................... 86

Attitudes Toward Scope of Practice ................................. 88

Attitudes Toward Educational Issues ................................. 88

Important issues for the Occupational Therapy Profession ....... 92

Summary of Significant Differences Between Groups .............. 92

Summary f.................................................... 98

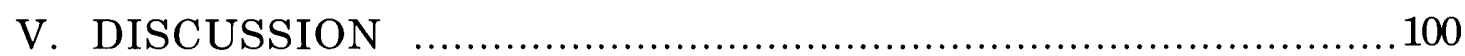

Research Questions ............................................... 100

Application of Theory ............................................ 102

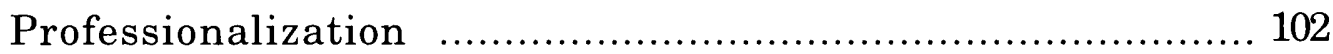

Comparing the Study to Previous Studies ............................ 104

Implication of the Study ......................................... 113

Limitation of the Study ............................................ 114

Further Studies .................................................... 114

Conclusion ............................................................. 115

LIST OF REFERENCES ................................................ 116

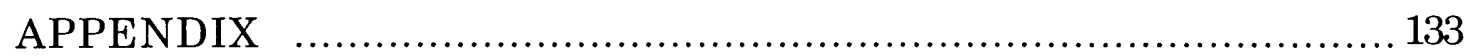




\section{LIST OF TABLES}

TABLE 1: Research Chart in Chronological Order ........................ 53

TABLE 2: Percentage of Occupational Therapists Engaged in

Professional Activities for the Last Five Years 73

TABLE 3: Means and Percentages Regarding Therapists' Attitudes

Toward Professional Commitment 78

TABLE 4: Means and Percentages Regarding Attitudes

Toward Professional Concerns 81

TABLE 5: Means and Percentages Regarding Attitudes

Toward Preparation for Occupational Therapy

Practice

TABLE 6: Means and Percentages Regarding Attitudes

Toward Emphasis in Occupational Therapy Education 85

TABLE 7: Means and Percentages Regarding Attitudes

Toward Change in the Occupational Therapy

Practice

TABLE 8: Means and Percentages Regarding Attitudes

Toward Scope of Practice

TABLE 9: Means and Percentages Regarding Attitudes

Toward Educational Concerns

TABLE 10: Means and Percentages of Respondents' Choices for Important Issues for the Occupational Therapy Profession ..93

TABLE 11: Significant Differences on Attitudes by Educational Level .... 94

TABLE 12: Significant Differences on Attitudes by Length of Experience .96

TABLE 13: Significant Differences on Attitudes by Country of Education 


\section{CHAPTER I}

\section{Introduction}

\section{Occupational Therapy in Iceland}

The introduction of the first occupational therapy curriculum in Iceland at the University of Akureyri occurred in autumn, 1997. In this regard, there is now a unique opportunity to shape the future of the occupational therapy profession in Iceland. Occupational therapy in Iceland is at the present characterized by female domination, lack of recognition, lack of autonomy, lack of differentiation from other similar professions and lack of political involvement. Icelandic therapists have missed, up to now, a common base from which to define their role and professional identity (Pálmadóttir, 1996b). Icelandic occupational therapists need to increase their autonomy, gain a stronger professional identity and participate in organizational decisions that affect the health and well-being of the community members.

The main goal of this study is to describe Icelandic occupational therapists' current level of professional identification and to ascertain their views of professionalism. Furthermore, it might serve as a foundation for future studies on Icelandic occupational therapists and provide reference data for later comparison. This study may be an important tool to start constructing bridges between practitioners and academicians, as Yerxa (1991) suggests as a necessity for the growth of the occupational therapy profession.

Iceland is an island in the North Atlantic between Europe and North America. The country has only 278 thousand inhabitants. It is a Nordic country along with Sweden, Denmark, Norway, Faroe Islands, Greenland, Finland, and Åland. Health service is a public matter in all the Nordic countries. As reported in the Nordic Medico Statistical Committee 
(NOMESCO, 1996), they have well-developed hospital and outside hospital medical care services with advanced specialist treatment.

The Ministry of Health and Social Security is responsible for general administration of health affairs in Iceland. Health service is provided in accordance with legislation and mainly financed by taxes from the Central Government, either directly or through the state run compulsory health insurance scheme. The Government provides about $84 \%$ of the expenditures for health service (NOMESCO, 1996). In Iceland, a specified amount is charged for treatment and for purchase of pharmaceutical products; whereas, expenses due to hospitalization are covered by the health insurance program.

In 1994, Iceland had 294 physicians per 100,000 inhabitants. As a comparison Norway had 225, Denmark 279 and Sweden 261. Qualified nurses in Iceland were 550 per 100,000 inhabitants compared to Norway that had 780, Denmark 706 and Sweden 808 (NOMESCO, 1996). Health statistics (1995) reported 82 physical therapists per 100,000 inhabitants. As a comparison, Norway had 101, Denmark 86 and Sweden 81. In 1996, Iceland had 31 occupational therapists per 100,000 inhabitants (Pálmadóttir, 1997) compared to Denmark who had 70 and Sweden who had 67 occupational therapists.

Occupational therapy is part of the allied health department at the University of Akureyri. Today the department only includes one other profession, nursing, which started in 1987 (Gunnarsson, 1997). The plan is to include other health professions in the future (Halldórsdóttir, 1997). The two universities in Iceland collaborate in many ways concerning faculty, long distance learning, lecturing and publishing (Gunnarsson, 1997). The occupational therapy program will offer a four-year program for the bachelor's degree and a master's program for occupational therapists will 
be provided in collaboration with Dalhousie University in Halifax, Canada in the near future (Halldórsdóttir, 1997). The University of Akureyri and its staff maintain close contacts with academic institutions abroad. A master's program for the nursing profession has already been initiated; it is in collaboration with Manchester University in Great Britain.

According to information collected in 1995 (Pálmadóttir, 1996a), 84\% of the Icelandic occupational therapists completed their education in the Scandinavian countries: Denmark, Sweden and Norway. More than half of Iceland's occupational therapists, $55 \%$, are educated in Denmark (Pálmadóttir, 1996a). Occupational therapy education in Denmark and Norway provides students with a diploma, not a bachelor's degree. Therapists with a diploma have had difficulty being admitted to graduate studies and the occupational therapy practice area in the United States. The Essentials of the American Occupational Therapy Association statement the requirements for minimum standards for a baccalaureate education are based on a broad foundation of liberal arts, sciences and research (AOTA, 1991). Most diploma-trained Icelandic occupational therapists are educated with little emphasis on liberal arts, sciences and research.

The fact that all Icelandic occupational therapists have been educated overseas has had both positive and negative effects on the profession. On the positive side, it has made Icelandic occupational therapists broad-minded and capable of sharing many different experiences. On the other hand, they have had very little formal education on how current occupational therapy practice relates to Icelandic culture and society. New occupational therapists who return to Iceland after education abroad are relatively unfamiliar with the Icelandic health care system. Another disadvantage of having all occupational therapists educated in foreign countries is that the profession has not developed an 
Icelandic vocabulary of its own. The number of occupational therapists in Iceland is increasing slowly, around three percent each year. In 1995, there were only 65 employed, seven of whom were working outside the capital, Reykjavík. Fourteen were not employed, adding up to a total number of 79 occupational therapists. In addition to the therapists living in Iceland, there are 25 living permanently abroad with no plans of returning to Iceland (Pálmadóttir, 1996b). In the beginning of 1998 there were 87 occupational therapists registered, ten of them working outside the capital city.

The first occupational therapist started practice in mental health in 1945. From 1945, various foreign occupational therapists visited Iceland and stayed for short periods of time until 1974 when the second Icelandic therapist started to work. The Icelandic Occupational Therapist Association is quite young, as it was founded in 1976 by eight occupational therapists. It is a member of the World Federation of Occupational Therapists (WFOT), the Committee of Occupational Therapists for the European Communities (COTEC) and participates actively within the cooperation that exists among the Nordic occupational therapy associations (Pálmadóttir, 1996b). Most occupational therapists in Iceland are employed by hospitals and rehabilitation centers. The profession has not established a reimbursement contract with the Social Security Institute, and clients in need of occupational therapy are referred to a hospital or a rehabilitation center. According to Pálmadóttir (1996b), there were no occupational therapists practicing within the state school system, in institutions for the elderly, or in the community providing home care services. At this time, about $50 \%$ of the therapists were working in the somatic area, while the others were working in mental health, geriatrics, pediatrics or mixed settings (Pálmadóttir, 1996a). 
Icelandic occupational therapists have primarily been engaged in presenting themselves to the public and to other health professions, along with trying to attract the government's attention regarding the need for and value of occupational therapy. When new regulations are made concerning health issues in Iceland, occupational therapy services are usually left out (Pálmadóttir, 1996a). Occupational therapy is definitely not a visible profession in Iceland, and most Icelanders do not know what services professional practitioners provide. Knowledge is usually limited to experiences regarding their own treatment or treatment received by a family member or a friend. However, visibility in the professional literature is increasing. Between 1976 and 1985 there were only 20 articles about occupational therapy published in journals other than the occupational therapy journal; these were mainly providing information about the profession. The number of articles doubled from 1986 to 1995 and the focus was no longer merely explaining occupational therapy (Pálmadóttir, 1996a). The authors got more involved in broader tasks like societal debate and informing the public of new theories.

At the time when Icelandic occupational therapists started establishing themselves as professionals in Iceland, occupational therapy was undergoing changes regarding education and philosophy, particularly in the United States. There has been a worldwide debate going about the importance of research and validation in the profession (Christiansen, 1983). When financial resources in health care decrease, competition and responsibility among those who provide service increases (Barris \& Kielhofner, 1985). The occupational therapy profession needs personnel who can critically generate and evaluate scientific knowledge (Yerxa, 1983). American occupational therapists are now focusing on producing more professionals with master's and/or doctoral degrees. Barris and Kielhofner 
(1985) imply that the most critical need in occupational therapy is an integrated plan of graduate level education. Educational level is a critical variable to be able to develop and validate knowledge and practice technology.

Academic entry-level preparation has a greater balance of theoretical course content (Colman, 1990) while a technical entry-level preparation has more emphasis on practical experience. The terms training and competency based curricula are usually code words for a technical, recipebased approach to teaching rather than a knowledge-based education producing reflective practitioners (Yerxa, 1995). Yerxa (1982) stated that American occupational therapists were vulnerable when moving into new areas of practice due to short periods of education. This applies to Icelandic occupational therapists even today, since more than half of them are educated in diploma programs not always at the university level. However, Icelandic occupational therapists have always been extremely enthusiastic about gaining professional knowledge and when a well known occupational therapist visits Iceland, like Antje Price, 1982, Deborah R. Labovitz, 1987, Gary Kielhofner, 1993, Nedra Gillette, 1995, Anita Bundy, 1996, Jane BearLehman, 1996 and Barbara O'Shea, 1997, it is common that around $80 \%$ of the therapists attend their seminars or workshops.

Establishing a bachelor's program in Iceland, grounded in solid theory, will hopefully encourage the undergraduates to continue graduate studies abroad. A large number of Icelandic academicians, approximately 90\%, have obtained their final degrees abroad (University of Iceland, 1995). It is believed that higher levels of education may create stronger leaders which is an important step for shaping the profession's future. If there is going to be a meaningful development of the profession, feedback and interaction between educators and working occupational therapists are 
necessary. "The leader and the excellent practitioner need each other to promote change that will move the profession in a positive direction" (Burke \& DePoy, 1991, p. 1031). Occupational therapy needs both a scientific approach when conducting research and an artistic method when making clinical observations (Kelly, 1996).

\section{Statement of the Problem}

As an island between the two large continents of Europe and North America, Iceland has substantial communication with both sides. During the last several years, Icelandic occupational therapists have been influenced by the debate as to whether occupational therapy should remain a technical profession or become an academic one. If the current and future attitudes of Icelandic therapists are that techniques are more important than ideas and occupational therapy is perceived as a technical profession, the profession may lose potential leaders to other professions (Yerxa, 1991).

\section{Purpose of the Study}

The survey is intended to reveal an overall view of the demographic characteristics of Icelandic occupational therapists and how they relate to their profession. The main goals of the survey are to ascertain Icelandic occupational therapists' attitudes toward professionalism, to examine the extent to which occupational therapy practitioners exhibit characteristics of professionals, for example, commitment to own profession, emphasis on academic expertise rather than technical and attitudes toward educational concerns. The survey intends to reveal possible differences in opinion between therapists regarding professionalism, educational goals as compared to variables such as educational level, professional experience 
and country of graduation. By revealing the therapists' attitudes to professional issues, the results of the study might determine the state of the ongoing professionalization process. Furthermore, it could serve as a foundation for information on Icelandic occupational therapists in general which could be expanded later with further studies.

\section{Research Questions}

1. What are the demographic characteristics of Icelandic occupational therapists?

2. What are the Icelandic occupational therapists' attitudes regarding professionalism and educational goals?

3. Is there a relationship between therapists' educational level, years of experience and country of graduation with respect to their attitudes toward professionalism and educational goals?

\section{Significance of the Study}

The occupational therapists taking part in this survey will not only supply valuable information, but they may also be encouraged to consider and reflect upon aspects of the profession that otherwise would have been neglected. In this way, I believe that the survey can help increase professional awareness among Icelandic occupational therapists.

Gathering data on attitudes concerning professionalism and specifying the current level of professional identifications make it possible to assess the profession's strengths and weaknesses. It should also help the founders of the occupational therapy curriculum to identify shortcomings that need to be addressed immediately. Decisions made regarding Icelandic occupational therapy education will affect the practice of occupational therapy over time. Fidler (1979) emphasizes that in order to make sound 
decisions about educational goals, the current identity of occupational therapists must be known. This study might further serve as a valuable tool for initial interactions between academicians and practitioners.

Furthermore, the survey should reveal possible differences between therapists regarding professional and educational issues.

\section{Definitions}

Academic discipline- "The primary function of an academic discipline is the creation of knowledge: identifying common elements among varied phenomena, finding relationships between concepts, developing and testing theory" (Mosey, 1981, p. 124).

Autonomy- The condition or quality of being self-governed (Funk \& Wagnalls, 1964).

Attitudes- "Tendency or orientation of the mind" (Flexner \& Hauck, 1987, p. 99).

Bachelor's degree- "A degree awarded by a college or university to a person who has completed undergraduate studies, also called baccalaureate" (Flexner \& Hauck, 1987, p. 150).

Characteristic- "Character: The aggregate of features and traits that form the individual nature of some person or thing; one such feature or trait; characteristic" (Flexner \& Hauck, 1987, p. 346).

Diploma- "A document given by an educational institution conferring a degree on a person or certifying that the person has satisfactorily completed a course of study" (Flexner \& Hauck, 1987, p. 558).

Liberal education- "An education based primarily on the liberal arts, emphasizing the development of intellectual abilities as opposed to the acquisition of professional skills" (Flexner \& Hauck, 1987, p. 1108). "Concerned chiefly with broadening the mind, not simply with technical or 
professional training” (Cowie, 1989, p. 717).

Occupational therapy- "Occupational therapy is the art and science of directing an individual's participation in selected tasks to restore, reinforce, and enhance performance; facilitate learning of those skills and functions essential for adaptation and productivity; diminish or correct pathology; and promote and maintain health" (AOTA, 1991, p. 1080). Profession- "An occupation that properly involves a liberal education or its equivalent, and mental rather than manual labour; especially one of the three learned professions, law, medicine, or theology" (Funk \& Wagnalls, 1964, p. 1006). "A vocation requiring knowledge of some department of learning or science" (Flexner \& Hauck, 1987, p. 1544).

Professionalism- "Professional character, spirit or methods; the standing practice, or methods of a professional" (Flexner \& Hauck, 1987, p. 1544). Professionalization- Meaning the organization of work and the role of expertise. It requires formal training and autonomy, which is central to professional status in work (Beckman, 1990).

Technical- "Belonging or pertaining to an art, science, or the like:

'technical skill'; peculiar to or characteristic of a particular art, science, profession, trade, etc." (Flexner \& Hauck, 1987, p. 1950). "Involving the mechanical arts and applied sciences" (Cowie, 1989, p. 1319).

\section{Assumptions}

1. Icelandic occupational therapists will respond to the questions and answer them truthfully.

2. Icelandic occupational therapists are concerned with similar issues as occupational therapists in the United States and other western countries. 3. Issues regarding occupational therapy research and literature in the United States and other western countries are relevant to Icelandic 
occupational therapists.

\section{Limitations}

The study is designed to cover a broad range of aspects briefly rather than examining specific areas in detail. Since this is a self-report questionnaire, it is not possible to explain unexpected misunderstandings to the respondents. The findings apply to the practice of occupational therapy in Iceland, any inferences about relevance to other countries must be made with caution. 


\section{CHAPTER II \\ Literature Review \\ Perspective of the Professions}

The earliest meaning of the term profession was religious and referred to a proclamation of faith. When the connotations of the term changed from religious to secular, it first included medicine and law, later evolving to include many other occupations. The term is a reminder of the way in which each succeeding generation used the examples of history in order to define, organize and communicate their particular expertise and cultural authority (Brown, 1992).

The words profession and professional were used by new secular groups to establish authority for their own purpose (Brown, 1992) and the meaning has changed. With the passage of time, the word has attained a different meaning and refers to various kinds of practice and knowledge (Selander, 1990). Sociologists have not been entirely successful in establishing definitions and as the conditions of professional work have changed in recent decades, the predominant pattern of a professional has also changed (Collins, 1990). It has been heavily debated how the term profession should be defined, which occupations should be included and by what criteria occupations should be called professions (Freidson, 1983). Some occupational groups claim they are professionals since they have a unique knowledge base, though it might be practically oriented. Most people who have completed mastery of an academic oriented research basis call themselves professionals and so do people in control of the mechanisms of power in society (Selander, 1990). One recent definition of professional is workers whose qualities of detachment, autonomy and group allegiance are more extensive than those found among other workers. These qualities include a high degree of systematic knowledge, strong community 
orientation and loyalty (Brown, 1992). Another definition is that a professional is a university educated person who uses exclusive technologies based on scientific knowledge to constitute and meet the demands of society and patients (Collins, 1990). Freidson (1983) concluded that a unified definition for the term professional may not be found.

Professions should be viewed in a historical perspective and it is improper to treat professions like they are a generic concept rather than an evolving historic concept (Freidson, 1983).

Professionalization

The change in character of work in twentieth-century America led to professionalization of many occupations, professionalization meaning the organization of work and one's expertise. Professional status requires formal training and autonomy (Beckman, 1990). Sociologists have different opinions on what is the main goal for professionalization: to maximize power, wealth and status within the occupational groups (Beckman, 1990; Collins, 1990); or to close in on the established professions who have been especially successful in controlling the market conditions (Collins, 1990); or a desire for specific knowledge and exclusive practically oriented competence (Selander, 1990). The older professions established models which other occupations are trying to accomplish. They surround their work with an ideological covering and their work is carried out from high motives of altruism, glory, or moral, spiritual or aesthetic commitment (Collins, 1990).

A strong and influential profession may encourage, even foster the development of new troups which seek professional status to carry out tasks which are too time-consuming or may be considered inappropriate to the skill of the parent profession. Nevertheless, at the point when these immature professions reach maturity and challenge the established ones, 
they are usually kept in their place by lack of autonomy. In spite of this, the practitioners of the emerging professions continue with their work and development, ultimately aiming for total professional autonomy (Wallis, 1987). Higher education has been used as an aid to increase status, but frequently without reaching the level of the established professions (Collins, 1990). The process of professionalization may occasionally include scientification. This reflects the fact that more occupations are now obtaining an abstract base of knowledge to achieve their own research competence. Scientification grants the occupations the ability to produce theoretical and empirical knowledge relevant to their own practice (Selander, 1990). Professionalization has exhibited particularly strong roots in industrial nations strongly influenced by Anglo-American institutions (Freidson, 1983).

Semi-professions. A study of semi-professions revealed characteristics that distinguish semi-professions from real professions (Etzioni, 1969). Semi-professionals are characterized by the incompleteness of their knowledge base and weakness of their professional ideology. The practice of semi-professions does not have a unique theoretical base. The theoretical knowledge and technical skills of semi-professionals are poorly defined. The period of training is relatively short, five years or less, and skills are more of a technical nature. There is a high rate of turnover among members and a lack of solidarity. The semi-professions are often controlled by the established professions or bureaucracies. Special areas of competence are not well defined and members can not claim monopoly on their work. Among the semi-professions, supervision, administration and directing are the most monetary rewarded tasks. However, in true professions (e.g. physicians) task performance, not organizational positions brings the main monetary rewards (Etzioni, 1969). 
Kelly (1996) pointed out that differentiating between professionals and semi-professionals could be gender related, those that can be called professionals tend to have typical male behaviors, and those who are called semi-professionals are associated with female behaviors. Miller (1992) looked at male and female behaviors from the perspective of Yin and Yang from ancient Chinese culture. Males are associated with Yang; expansive, demanding, aggressive, competitive, rational and analytic. Females are associated with Yin; contractile, conservative, responsive, cooperative, intuitive and integrative.

Elzinga (1990) claims that male domination has affected both the perspective and the theoretical content of scientific literature. Many service occupations are dominated by women and face special difficulties in their pursuit of professionalization. Women's studies and discussions relating to feminist epistemology have given rise to a notion of gender bias in science. Griffin (1988) also underlined a male bias in the definitions of the professions. When striving for recognition, going through the phase of scientification and preparing the way for professionalization, Elzinga (1990) states that women must have in mind the:

... continuation of a rationalization process with extreme functional differentiation in the labour process, perpetuating social differences in status between male- and female-dominated occupations, and between high and low wage groups in society as a whole. (p. 157)

\section{The Professionalization of Occupational Therapy}

Physicians enjoy a long-standing recognition of their professional status and still monopolize the market of medicine. They dominate the power structures of hospitals and health care and defend that position by referring to their special expertise. In modern hospitals there are a wide 
range of occupational groups today that make independent claims of professionalism, making use of science to exercise their skills. Nurses, occupational therapists, physiotherapists and other occupational groups are defining their knowledge in terms of scientific specialities, pressing for new arrangements, whereby, some of them can go on to training for research. The course of development in the nursing occupation is sketched as four stages that can be applied to occupational therapy: (1) calling, (2) semiprofessionalization, (3) scientification and (4) technification to professionalization (Elzinga, 1990).

Since the beginning, occupational therapy has developed under the patronage, guardianship and control of medicine (Wallis, 1987). Numerous progressive occupational therapists have contributed to the debate around the professionalization process of occupational therapy. In 1979, Fidler responded to the issue of professionalism and occupational therapy. She compared the professions and semi-professions, adopting the views of sociologist Etzioni (1969), who outlines criteria that define professionals and professions. Among these criteria are rigorous, prolonged education and apprenticeship; an organized, refined and specialized body of knowledge; trust from society; a code of ethics and autonomy. Fidler's conclusion was that occupational therapists and occupational therapy education must change if practitioners in the field intend to become full-fledged professionals.

The goal of professionalization according to Gillette and Kielhofner (1979) was autonomy, the freedom to be self-determining and selfregulating in carrying out a range of services needed by society. In their view, the occupational therapy profession should provide services that are needed resting on the development and validation of an abstract body of knowledge and not available from any other source. They stressed the 
importance of the profession being bound together by a shared vision, a paradigm. This paradigm determines a profession's purpose, the nature and scope of its practice, the content of its educational curriculum, its research interest, the assumptions about the nature of its phenomena of interest, consistently identified problems and accepted methods of solutions. They emphasized that the paradigm must be implicated in the specialization process for a successful development; they were concerned how specialization would interfere with the professionalization of occupational therapy and the survival of the profession. The specialization process would also determine whether occupational therapy developed as a technical discipline or a profession (Gillette \& Kielhofner, 1977).

Mosey (1981) described a model of a profession, including occupational therapy, as having philosophical assumptions, an ethical code, a theoretical foundation, a domain of concern, legitimate tools, and principles of practice upon which the profession was founded. "The structure of a model is similar for all professions; the content of each profession's model differentiates one profession from another. Professional models are not, however, stagnant but evolve with time" (p. 52). She stated that the profession's models also incorporate their own perception of identity, relationship to other professions and association with the society to which they are responsible (Mosey, 1981).

Professions develop under the pressures of numerous and often contrary social forces. Professions are the ways in which complex sets of skills are taught to individuals so that they can support themselves, sustain those skills, and have status in their communities while serving an important social need. Professions therefore have both internally and externally directed goods and goals. (Engelhardt, 1983, p. 140) 
Fleming, Johnson, Marina, Speregel, and Townsend (1986) described characteristics of successful professions as necessary goals for the occupational therapy profession. The occupational therapy education should be organized in a hierarchical structure and based on academic disciplines. The profession has its own applied science, possible diversification of functions and existence of evaluation and treatment procedures unique to the profession (Fleming et al., 1986).

Wallis (1987) stressed that professions form professional associations to draw up selfgovering rules and their association draws up a code of ethics to regulate the standards and behavior of their members. The professions define their own sanctions of offenders and negotiate and collaborate with the State and other groups in the society to maintain and extend their status. Professions may form pressure groups to initiate changes in social policy/public policy and may monitor and evaluate the effects of changed policies (Wallis, 1987).

Breines (1988) suggested that since the occupational therapy profession is female dominated, the question of professionalism should be readdressed. Instead of diminishing the qualities of women, one should appreciate them. Professional characteristics, such as ongoing knowledge acquisition, devotion in teaching others, continuously updating education and an ongoing sense of responsibility to the patients and to the profession should be exhibited (Breines, 1988). Rogers (1982) recommended adapting sponsorship relations between occupational therapists to stimulate leadership development for the occupational therapy profession. A sponsorship is built on a concept of intraprofessional and interprofessional support which has been lacking in the female professions. Women establish fewer mentor relationships than men. Distrust and competitiveness among woman themselves discourages cooperative 
interaction (Rogers, 1982). In Green's (1991a) opinion, the drive for professionalization during the past years might be an act to salve insecurities and lack of status among occupational therapists and reflect these needs when competing with other health groups (Green, 1991b).

West (1992) identified several professional issues important for the development of occupational therapy: medical control, licensure, entry-level degrees, treatment media, maintenance of competency, professional autonomy and the status of occupational therapy as a profession. The occupational therapy profession in the United States is included among the allied health professions. Half of the curricula in occupational therapy education is offered at the undergraduate level, in contrast with the graduate degree requirement of the learned professions, for example, medicine, law and clergy (West, 1992). More than $40 \%$ of accredited occupational therapy professional education programs are organized within schools or colleges of health-related professions, health-related sciences, health sciences, or allied health (AOTA, 1991), several of whose associated curricula graduate technicians and technologists rather than professionals (West, 1992). Irvine and Graham (1994) argued:

... the conflict between authors over the professional status of occupational therapy reveals a substratum of tangles viewpoints and assumptions about how professions should be defined, which occupation should be called professions and by what criteria occupations are to be assessed as professions. (p. 10)

Their conclusion was that the problem is an uncritical agreement of the so called trait theory, that is based on a list of characteristics said to distinguish professions from other forms of occupations. They recommended that if the occupational therapy profession was to develop as a profession one needs to reconceptualize occupational therapy, 
emphasizing its power relations and structure. "Trait theory describes profession as a logical, rational and natural outcome of claims to ownership of selected traits, rather than of power relation in society" (Irvine \& Graham, 1994, p. 16).

Taylor (1995) examined the history and development of the occupational therapy profession alongside the general position of women in society. Occupational therapy is female dominated considered to be woman's work; very few males study to become occupational therapists. Among the consequences of being a female dominated discipline is a lack of strong professional identity, not being valued or possessing little power within the treatment team and low priority among practitioners on research activity. Although occupational therapy has become more scientific and objective, the objective science is derived from a malecentered tradition which suppresses the thinking and knowledge of women. Adoption of scientific approaches to treatment may endow occupational therapists with increased status in the male gender oriented world of medicine and health service management. Women have other qualities to contribute such as caring, social skills and intimacy. Scientific approaches must not constrain these qualities. Feminism also offers an opportunity to find a renewed value in its original base in activity and the importance of relationships for health and well-being (Taylor, 1995).

Yerxa (1995) explained that a true profession possesses considerable autonomy in the provision of its services. A profession demonstrates its professionalism by exercising control over its own education, practice and accreditation. Most definitions of the word profession include the idea that a profession establishes and maintains its own practice, education and standards on the basis of its unique body of knowledge (Yerxa, 1995). An autonomous profession determines what services to offer, who is in need of 
these services, for what problem or conditions, guides decision making by an ethical code held in common with all other members of the profession and determines the manner and amount of reimbursement for services (Gillette \& Kielhofner, 1979). On the contrary, lack of autonomy makes it difficult to shape the profession's future (Parham, 1987). In the history of occupational therapy in the United States, the profession has sought to maintain a balance of autonomy and cooperation in its relationship to medicine. American occupational therapists have been struggling to maintain control over the entry-level education programs and professional standards (Colman, 1992). Full autonomy is usually granted only to those who are considered independent professionals, like physicians, psychologists and Ph.Ds. Some health care specialists, like social workers and nurses, have been able to gain autonomy without a doctoral degree through the use of licensure laws (Fleming, 1985). "Occupational therapists both receive from and make referrals to appropriate health, educational, or medical specialists" (AOTA, 1991, p. 1080). The Icelandic law of occupational authorization from 1977, $\S 5$ declares that, "an occupational therapist is not allowed to treat patients without consulting a physician" (Lög Idjuthjálfafelags Íslands, 1977, p. 1). More than twenty years ago, Mathewson (1975) stated that this "symbol of control is the sore point in the subordinate status of therapists" (p. 603). Bellner (1995) illustrated that occupational therapists may sense themselves as mere extenders of functions performed by the physician. This problem might reflect a longstanding socialization experienced by therapists, physicians and members of the general public. Physicians are taught to be responsible for all health care, including rehabilitation; are expected to have broad based authority. This image of the physician is actively reinforced by the literature, the media, and health-care institutions so that the public, as well as therapists, 
have internalized this kind of value system (Bellner, 1995). Yerxa (1995) states that a relationship exists between the profession's autonomy and the ability to serve and empower clients. The profession's autonomy affects the ability to develop new ideas and models of practice in the context of valuing patients' autonomy and self-direction (Yerxa, 1995).

Educational concerns in the occupational therapy profession. Gillette and Kielhofner (1979) suggested that educational programs should work toward development of curricula that first teach core concepts and identify the nature and values of occupation before examining the therapeutic modalities which emerge from this conceptual base. New ideas, research and education are primarily contributed by their academic programs (Yerxa, 1991). Education transmits the knowledge of new ideas to the next generation of occupational therapists and is a powerful tool for reducing vulnerability within the profession. Yerxa and Sharrott (1986) stressed that a professional person is a product of his or her education. They argued strongly for a liberal education granting the capability of thinking in broad categories, providing openness to new ideas and awareness of ethical implications in a technical, mechanistic world (Yerxa \& Sharrott, 1986). Yerxa (1975) emphasized that occupational therapy students should be socialized to behave in an autonomous and assertive manner in order to exercise self directed learning and to handle potential confrontations. In 1991, Yerxa further emphasised the importance of occupational therapy students understanding the significance of academic programs and their contribution to both the field and the practice. Yerxa (1982) claimed that, "in order to deal with the complexity of civilization and its institutions, occupational therapy students need a strong liberal education as the foundation for professional knowledge" (p. 404). Education in liberal arts is essential for defining a career, choosing a career and developing career 
skills (Pierce, 1984). Such education is desirable for occupational therapists in order to make the appropriate connections needed to develop a perspective that strengthens professional competence. "Unless occupational therapy students are liberally educated, they are not learning the assessment, integrative and synthesis skills they need for personal and professional growth and development" (Pierce, 1984, p. 238).

Professional socialization is a process that spans over a lifetime. An important part of the process is the attainment and maintenance of professional attitudes which starts at the very first day of professional education and continues throughout the professional career (Wallis \& Hutchings, 1990). The successfulness of this approach might be an indicator of the quality of education. The content of the profession's curricula, according to Sabari (1985), needed to attend more to attitudes and values that shaped the complexion of future professionals. Consistency of socializing influences is a critical factor in the formation of strong professional identity. Socializing influences encountered during professional education may have greater impact on students' future practice than the academic and clinical information they learn.

Educational programs should present a realistic picture of professional practice since students are likely to discard values that are not reinforced in clinical settings (Sabari, 1985).

Yerxa (1987) described research in occupational therapy as the scholarly pursuit of understanding not only about patients with extra challenges concerning adaptation, but better understanding of all humans in relationship to play, work, rest, self-maintenance, adaptational skills, use and organizing of time and meaning of occupation. In her opinion, one of the greatest dilemmas in the profession is that its members are perceived differently from collaborators in other health professions regarding 
practice, academia and research, and face, therefore, a risk of being misunderstood. However, the profession could capitalize on these differences as a resource to make a unique contribution to the body of knowledge that is devoted to better understanding of humans as occupational beings. She highlights that the profession needs to search for research methods that maintain the integrity of the human being. This means, however, it should not sacrifice the person on the altar of fragmented science. The risk is that the scientific community will not perceive these methods as scientific and that the research environment may therefore provide little support (Yerxa, 1987).

Ottenbacher (1990) noted that in the mature professions there is widespread support among membership for research activities and a clear understanding that:

... the discipline cannot advance without the small number of researchers who work in the empirical gardens sowing the seeds of tomorrow's technology and practice. (p. 8)

He examined whether occupational therapy programs were skill based or knowledge based curricula. Skill based curricula are reactive due to the emphasis of teaching specific technologies of treatment and preparing practitioners to meet immediate needs; research, therefore, is not an important component. Knowledge based curricula are proactive as a result of their orientation to the future. They prepare practitioners to meet the challenges of diversified and changing practice by focusing on the clinical reasoning skills; they cannot exist without research. Research provides the method for generating and refining clinical decision making and practice. Practitioners must have technical skills that arise from a clearly defined and well developed knowledge base that originate mainly from the discipline that guides and justifies the practice and the academic 
association with the university (Ottenbacher, 1990).

Van Deusen (1993) stated that very few recognize the existence of occupational therapy because the emphasis has solely been on the service function. Hagedorn (1995) expressed that the profession has difficulty in communicating, with clarity, the process and purpose of occupational therapy. In her opinion, the cause might be lack of confidence, pride and not being able to make positive statements about the profession. She believes that the key to professional development is ensuring that therapists are educated in a new version of "the three Rs": reasoning, reflection and research. Clinical reasoning requires conscious development and exploration because it holds the key to effective practice and to uncovering and communicating the often unstated rules and procedures used by experienced therapists (Mattingly \& Fleming, 1994). Reflective practice provides personal and professional development. The author is concerned about the measurement of the product of occupational therapy as it is most often intangible and phenomenological. It is difficult to measure the products of enablement, enhancement or empowerment since they depend on subjective perceptions of well-being, purpose, self-worth, or a meaningful, rewarding life. Because it is difficult to evaluate these things in scientific terms it is very tempting to fall back on measuring the things that are measurable (Hagedorn, 1995). Van Deusen (1993) warned strongly against attempting new research innovation in the field before being firmly grounded in the old research methodology. The social scientist Schön (1987) defined this professional dilemma as a choice between the high hard ground of practice, where problems have neat and tidy scientific solutions, and the swamps where more muffled problems are to be found. Researchers must choose whether they want to remain on the high ground where they can solve relatively unimportant problems according to the 
prevailing standards of rigour, or if they descend to the swamp of important but non-rigorous enquiry (Schön, 1987). Hagedorn (1995) states that research provides the profession with the scientific and academic justification for practice and the means of evaluation. It provides others with the assurance that what is done is effective and that innovations and outcomes are tested with objective rigour, but not merely by counting numbers. His recommendation is that occupational therapists should use the phenomenological paradigm and use this methodology to the profession's advantage (Hagedorn, 1995).

Scope of occupational therapy practice. According to Kielhofner and Burke (1977), 1900 to 1930 was the pre-paradigm period of occupational therapy. Its history was continuous with the Moral Treatment movement of 19th century America in psychiatric practice. The field originally embraced a paradigm of occupation which incorporated a holistic outlook focused on mind-body and person-environment unity. This paradigm recognized the power of participation in everyday occupation to influence mental and physical well-being (Kielhofner, 1992). In the 1940s, medicine placed increasing pressure on the field to abandon this paradigm in favor of a more scientific one that would theoretically and empirically justify its services. In 1950, a new paradigm emerged based upon the principles of reductionism (Kielhofner \& Burke, 1977). This new mechanistic paradigm stressed recognition of the inner mechanisms underlying the capacity for performance. It envisioned practice as the application of activities to reduce pathological states in these inner mechanisms (Kielhofner, 1992). This paradigm guided occupational therapy through the 1950s and 1960s. The field lost the sight of the meaning of occupation, the theme that united the field in the beginning and the profession became more technically orientated and lost its philosophical concept. As the philosophical and 
scientific framework faded out, a loss of identity and role confusion emerged, however, the field gained increased technology for remediating specific dysfunctions (Kielhofner, 1992). The new professional culture is currently seeking to capture the best of both previous paradigms, aiming toward a strong sense of professional identity,

... balancing holism with precise knowledge, and integrating themes spanning the body, mind, and the environment. These tasks are being done within the context of a recommitment to the field's focus on occupation. (Kielhofner, 1992, p. 44)

Creek and Ormston (1996) believed that the interaction between philosophy, practice and theory generates energy and motivation and drives the profession onward. Professional philosophy is the system of shared beliefs and values held by the profession's members which provide them with a common identity and regulates professional theory and practice. Occupational therapy theories might be in danger of being taken over by other powerful groups, such as medicine or psychology. To reduce the risk of this, it is important that skills, techniques, and modalities that the occupational therapy profession uses as intervention strategies are consistent with the central theme of occupational therapy philosophy (Creek \& Ormston, 1996). Occupation and purposeful activity are the profession's unique and distinguishing means of influencing health (West, 1992). The profession must take care to practice with a grounded theory base, focusing not just on tasks, but on practice integrated with philosophy and theory (Creek \& Ormston, 1996).

As occupational therapists move into new areas of practice, they may experience expansion into fields already claimed by established professions (Yerxa, 1982). These professions tend to be possessive regarding the content of their model and are not likely to share practice areas with other 
professions (Mosey, 1981). In order to protect their own professional territory, these professions might wish to discredit the roles and functions of occupational therapists. New territories encountered by occupational therapists, such as: maintenance of health, promotion of health, prevention of illness and prevention of disability (West, 1992), could also appeal to the established professions and they might prefer to provide these services themselves. The paradigm of the profession is, therefore, essential regarding specialization delivery in the discipline and must stem from the paradigm. Specialization is powerful, it helps the discipline to become more autonomous, to obtain an abstract body of knowledge, to be recognized, to be needed in the society and to be reimbursed. If specialty practice is developed primarily around the concepts of the subspecialities, for example medicine, and not around occupation, the specialities do not arise from and do not support and develop the paradigm (Gillette \& Kielhofner, 1979). West (1992) is concerned that specialty certifications in occupational therapy pediatrics is probably just the start on certifications within the profession. Though specialty is a strength, it is of major concern if it leads to disunity in the field.

Mocellin (1996a) evaluated some of the philosophical ideas and core concepts of occupational therapy which have emerged over the years. The author criticized the preliminary evaluations as not seriously analysed nor critiqued and that has caused philosophical and clinical problems for the practitioner. Occupational therapy is in danger because it is challenged by those outside the profession "who do not rely on historical reputation and tradition as valid and reliable factors in therapeutic outcomes" (p. 502). Mocellin (1996b) suggested that the foundation of the profession does not rest on the slogan "health through occupation" but on the field related to the learning and teaching skills. She states that these skills are important to 
provide the necessary foundation for the further advancement of the profession (Mocellin, 1996b).

Future Perspectives for the Occupational Therapy Profession

The increased number of health professions and a decreasing health budget might expand the competition between the professions further in the future. Which professions will strengthen their position depends on their awareness of development and the ability to adapt their services according to needs. Essentially, society asks how a profession can enhance the quality of life of community members, since payment for the services rendered by this particular emerging profession must be justified by their results. Although societies may support the development of a new profession to meet newly identified needs, more typically societies first seek the assistance from their existing profession (Mosey, 1981).

"The existence of a profession rests on recognition of its ability to provide a unique solution to some fundamental social problem" (Kielhofner, 1992 , p. 3). The use of complex problem-solving and autonomous decisionmaking in multiple settings is becoming more important in occupational therapy (Kielhofner, 1992). Traditionally, women and minorities have been attracted to health professions like occupational therapy at a baccalaureatelevel (Teske \& Spelbring, 1983). The educational trend in occupational therapy is moving from diplomas, certificates and bachelor's degrees toward master's and doctoral degrees. However today's entry-level master's degree remains a voluntary and optional decision for both beginning students and occupational therapy educational programs (West, 1992). The profession might experience that in the future a graduate degree may be necessary for entry level in occupational therapy practice (Pierce, Jackson, Rogosky-Grassi, Thompson, \& Menninger, 1987). Vogel (1991) identified three main problems of the occupational therapy profession as it moves into 
the 21st century: the debate between proponents of the profession's philosophical base, the fragmentation of the profession into technical specialities generated from lack of basic knowledge and differences in occupational therapists' perception of their own status (Vogel, 1991).

Bruhn's (1991) projection for the 21st century included the prediction that more occupational therapists will become self-employed and begin to market themselves. He also predicted that in the future more occupational therapists will be consultants, private practitioners and case or care managers. Van Deusen (1995) claims that whenever cost is an issue "the emphasis of health care is on practical results of intervention to offset health care expenses by patients' return to productive life-styles" (p. 833). Therefore, occupational therapists will play an essential role in the future using their evaluations of patients' productivity to integrate and decide what components need to be addressed for their maximum functioning (Van Deusen, 1995). Baum and Law (1997) imply that services framed within the medical model alone will face ongoing cuts, whereas services framed within a broader, community-based model will enable clients to be responsible for their own health and occupational function. They envision that occupational therapy practice will "focus on occupational performance; will be more client and family centered; and as a result, will be community based" (p. 286). They see the future for the profession in a collaborative form with clients removing environmental barriers together, thus, enabling occupational performance.

According to Yerxa (1991), her concern for the future is that low academic status among occupational therapists is the cause of frustration and discouragement in achievement. The occupational therapy profession must adapt to the academic environment by making legitimate contributions to the universe of knowledge and providing substantive 
foundation for research programs. It must represent an area of inquiry that is worthy of serious study and possess freedom to choose research directions not restrained by preconceived results. The profession's curriculum must be founded on liberal arts at the baccalaureate level and disciplinary knowledge at the graduate level. The education should be supervised by doctoral degree faculty members. If occupational therapy can not adapt to the academic environment in the future, the profession could end up as an endangered species (Yerxa, 1991).

Nelson's (1997) view of occupational therapy in the future and why it will survive is that its core is so basic to human health yet so flexible, and that "only those things will endure that are both fundamental to human nature and adaptable to a changing world" (p. 12). Nelson also accentuates the current trend that persons with disabilities perceive themselves as consumers of health care services. They are becoming more autonomous in making decisions about their lives and will not accept the authoritarianism that often accompanies the medical model. Tryssenaar's (1997) perspective is comparable to Nelson's (1997). He pointed out that twenty years ago mental health consumers' sole involvement was the patient role. Today however, the consumer movement is demanding collaboration with health care workers in their ongoing care. They are involved in the political area, program evaluation and some run their own treatment programs or collaborate with professionals in providing intervention (Tryssenaar, 1997).

\section{Research in the Occupational Therapy Profession}

This section is a summary of what the main areas of study are regarding professional and educational issues in the occupational therapy profession. The section is divided into two categories: studies regarding professionalism and studies with respect to education. Studies with respect 
to education are divided into three groups: educational concerns, scope of occupational therapy practice and studies on occupational therapy students. A research chart in chronological order is shown in Table 1.

The first category relates to characteristics connected to professionalism: Staying informed about professional developments (Bell \& Bell, 1972; Schlenz, Guthrie \& Dudgeon, 1995), autonomy (Bellner, 1995; Davis \& Bordieri, 1988; Graham \& Timewell, 1990; Madill, Brintnell, Stewin, Frizsimmons \& Macnab, 1986a; Lehmann, 1973), professional productivity (Clark, Sharrott, Hill, \& Campell, 1985; Gilkeson \& Hanten, 1984; Rogers \& Mann, 1980a, 1980b; Storm, 1990), career pattern (Madill, Brintnell, Stewin, Fitzsimmons \& Macnab, 1986b), value of theory developments (Barris \& Kielhofner, 1985; Van Deusen, 1981), perception of professional status (Bellner, 1996), and the nature of published professional material (Mountain, 1997; Ottenbacher \& Short, 1982).

The second category contains studies about education. The first group focuses on educational concerns: Inexperienced therapists' problems (Allen \& Cruickshank, 1977), factors contributing to leadership (Burke \& DePoy, 1991; Schemm \& Bross, 1995; Scott, 1985), factors influencing the development of master clinicians (DePoy, 1990), the role expectation and demographics of program directors (Dudek-Shriber, 1997; Miller, 1982), academic rewards (Parham, 1985), roles of academic chairpersons (Sieg, 1986), the ideology of psychosocial occupational therapists (Barris, 1984), knowledge of theories (Javetz \& Katz, 1989; Munoz, Lawlor, \& Kielhofner, 1993), clinical reasoning skills (Strong, Gilbert, Cassidy \& Bennett, 1995), factors leading therapists to cease practice (Rugg, 1996) or to become administrators or clinicians (Bailey, 1988), whether attitudes toward theory development is related to educational level (Van Deusen, 1985, 1986), perceptions about occupational therapy education (Fleming \& Piedmont, 
1989), the move from diploma to degree level (Gape \& Hewin, 1995) and attitudes held by co-workers on the importance of activities used in occupational therapy (Kaur, Seager \& Orrell, 1996).

The second group views the scope of practice in occupational therapy: Group work used in occupational therapy (Duncombe \& Howe, 1985, 1995), family involvement in practive (Humphry, González \& Taylor, 1993), motivation to enter private practice (McClain, McKinney \& Ralston, 1992), relationship between various factors in practice and job satisfaction (Bordieri, 1988; Brollier, Bender, Cyranowski \& Velletri, 1986; Brollier, 1985a, 1985b; Florian, Sheffer \& Sachs, 1985; Jacob, 1994; Taylor, Madill, \& Macnab, 1990), meaning therapists find in their practice (Hasselkus \& Dickie, 1990), involvement in research activities (Taylor \& Mitchell, 1990), experiences occupational therapist have in their practice (Finlay, 1997) and the role of occupational therapy and the practitioner (Adamson, SinclairLegge, Cusick \& Nordholm, 1994; Ambrosi \& Schwartz, 1995a, 1995b; Clark, Corcoran \& Gitlin, 1995; Engquist, Short-DeGraff, Gliner \& Oltjenbruns, 1997; Jenkins \& Brotherton, 1995a, 1995b; Moll \& Cook, 1997; Vogel, 1991).

The third group includes a number of studies on students: Characteristics of students in occupational therapy education programs (Madigan, 1985), speciality choice in occupational therapy (Ezersky, Havazelet, Scott, \& Zettler, 1989), learning styles of students and practitioners (Katz \& Heimann, 1991), efficacy of one method for teaching reasoning skills (Neistadt, 1992; Neistadt \& Smith, 1997), why students choose occupational therapy as a career (Rozier, Gilkeson, \& Hamilton, 1992), values held by occupational therapy students (Avi-Itzhak \& BenShem, 1993; DePoy \& Merrill, 1988; Katz, 1982), attitudes toward disabled people (Eberhardt \& Mayberry, 1995; Lee, Paterson, \& Chan, 1994; Lyons, 1991; Lyons \& Hayes, 1993), the influence of fieldwork on the professional 
socialization of occupational therapy students (Tompson \& Ryan, 1996), levels of psychological distress among occupational therapy students (Tyrell \& Smith, 1996), experiences in the psychiatric fieldwork (Lyons, 1997) and the impact of counselling skills training on interpersonal skills (Jeffery \& Hicks, 1997).

Studies Regarding Professionalism

Bell and Bell (1972) studied dimensions of professionalism among occupational therapists. Level of educational degree showed a moderately strong significant relationship with the therapist's use of the professional organization as a major referent. This included reading professional journals as well as attending local and national professional meetings. The implications were that individuals with higher degrees are more likely to stay informed about current theory, research and practice trends. They further demonstrated more characteristics generally associated with professionalism.

In Lehmann's survey (1973), occupational therapists mostly agreed that they needed more independence in their work. Furthermore, most of them did not approve of the requirement of physician's referrals or prescriptions for occupational therapy services.

Rogers and Mann (1980a, 1980b) studied the relationship between professional productivity and educational level. Their findings showed that therapists with a master's degree contributed more frequently to professional literature than those with a bachelor's degree. Graduate level therapists made greater contributions to practice, education, research, publications, and professional activities than undergraduates. They also found certain patterns of professional contributions to be associated with different graduate curricula, but not with undergraduate curricula.

Van Deusen (1981) surveyed newly certified occupational therapists 
regarding values on development of theory within the profession. The results showed that graduate level therapists valued theory development significantly more than undergraduates.

Ottenbacher and Short (1982) reviewed articles in the American Journal of Occupational Therapy from January 1970 to May 1980 to determine the nature of articles published during this period. Seven categories of articles were identified: descriptive, survey, case and field study, correlational, quasi-experimental, true experimental and practical. Data analysis revealed that there was a significant change of emphasis on categories before and after 1978. Articles that were of quasi-experimental nature increased and articles of descriptive type decreased.

Gilkeson and Hanten (1984) studied 1000 therapists and graduates and undergraduates who had been practicing from 1 to 6 years. In this study, the only difference between the two groups was that graduates published more, although occupational therapists in general published little. Master's level therapists had greater belief in knowledge of research methodology than undergraduates. This extensive survey found that both groups spent similar amounts of time consulting and supervising. No difference was detected between graduates and undergraduates regarding research activities. Graduates had more confidence in their professional capabilities and demonstrated more characteristics generally associated with professionalism.

The Barris and Kielhofner study (1985) concluded that "purely quantitative measures of differences between undergraduates and graduates may not be sufficient criteria for comparison" (p. 117). In their opinion, studies that examine attitudes or values regarding professionalization and observed feelings of competence related to job performance may be better indicators of differences among therapists. They 
suggested that undergraduates may be more interested in developing practical skills whereas, graduates seem more receptive to examination of theoretical issues. According to Davidson (1981), valuing theory has a developmental sequence beginning with valuing theory application, then research and finally theory-building.

Clark et al. (1985) examined occupational therapists educated from one single school over a period of ten years. They found differences between therapists with different degrees similar to those found by Rogers and Mann (1980a, 1980b) regarding professional productivity; graduate therapists had published more, presented more at national conferences, and they spent more time engaged in research activities and research papers than undergraduates. Master's degree students were more likely to believe in the importance of using a theoretical frame of reference to guide practice than the therapists educated at the baccalaureate level.

Madill et al. (1986b) did a career pattern study of two groups of occupational therapists in Alberta, Canada. The groups were those that had left the profession or were not working and those that were working both in traditional and non-traditional settings. The data showed from the career histories that five career patterns were most common: interrupted career, geographic relocation, the planned career, the negative employment experience and job availability.

Davis and Bordieri (1988) surveyed perceived autonomy and job satisfaction among occupational therapists and found that ratings were moderately high. Results showed that perceived autonomy positively related to job satisfaction and career development, a finding also obtained in a survey by Madill et al. (1986a).

Graham and Timewell (1990) surveyed 136 Australian occupational therapists and explored their perception of autonomy and status. The 
authors' conclusion was that the occupational therapy profession had a high opinion of its status and autonomy and believed that the profession had a unique set of skills. The authors further implied that there might be reason to question the foundation for this professional self-image.

Storm (1990) investigated the qualitative and quantitative differences in productivity among occupational therapists with various educational backgrounds. Four hundred therapists responded and the results indicated that the most significant relationship between type of education and productivity is found in the doctoral group. There was also a significant difference between entry level and postprofessional master's groups in course of work and perceived benefits of education.

Bellner (1995) studied the perception occupational and physical therapists had of their working conditions in the context of ongoing professionalization. Seven hundred Swedish occupational and physical therapists were surveyed nationwide, equally represented. The results indicated most of the therapists experienced job satisfaction and professional self-concept and that, in this area, physical therapists were ahead of occupational therapists. The data revealed that a minority of occupational therapists and only half of physical therapists admitted clinical autonomy, indicating that only a few therapists admitted the full capacity to think and make decisions independently. The study attempted to clarify the work-situational barriers that therapists might experience on their way to increased professional status and autonomy. The conclusion was that therapists did not seem to take on full responsibility for their professional development and field of competence, nor to make their expert knowledge explicit. On the basis of the results, the author suggested as a possible explanation that most of the therapists are extenders of function performed by the physician, something that constitutes a principal barrier 
to full professional status.

Schlenz et al. (1995) explored the prevalence of burnout among forty occupational therapists and physical therapists and evaluated the relationship between burnout and professional development activities. The study revealed that professional development activities may augment feelings of personal accomplishment and minimize burnout.

Bellner (1996) investigated 364 occupational therapists and 346 physical therapists in Sweden regarding their perception of professional status. She wanted to know if the transfer of their education to a university level had made a difference in their perception of their own professional status and that of others. Physical therapists tended to perceive increased professional status both from team members and themselves while occupational therapists tended to perceive a decreased status. The author's suggested explanation is that university schooling and certification reinforce a positivistic knowledge base which is more prevalent in physical therapy than occupational therapy and that leans toward a more humanistic knowledge base.

Mountain (1997) did an analysis of the content of papers in the British Journal of Occupational Therapy over an eight-year period from 1989 to 1996. The findings were that the majority of published papers were descriptive in nature with physical disability as the major research topic. Policy-related material was poorly represented and so were papers concerning evidence of clinical effectiveness.

Studies with Respect to Education

Educational concerns. The goal of Allen and Cruickshank's (1977) study was to collect information that could later be reproduced in simulations for the classroom. It focused on problems of inexperienced therapists and identified, for example: problems obtaining other 
professionals' respect and understanding of the role of occupational therapy, difficulties in presenting the profession and little knowledge about systems and authorities.

Miller (1982) examined the role expectations of 48 program directors. The results indicated areas of agreement and disagreement about the chairperson's role expectation and highlighted areas of potential conflict, for example, deans and faculty members had different expectations for occupational therapy program directors than the program directors had for themselves.

A study by Barris (1984) sought to answer the question of how the ideology of psychosocial occupational therapists related to their role practices in various work settings. Their findings were that there was a widespread prevalence of occupational behavior practices among occupational therapists, despite the subjects' claims of differing in ideologies. This study was conducted as an educational needs assessment for occupational therapy.

Gape and Hewin's (1995) survey on British occupational therapists focused on the move from diploma to degree level. The respondents were occupational therapists in education, clinical practice and management. The results indicated that concern exists within the profession regarding levels of qualification. The main differences in judgment of the two training levels were the inclusion of a research element in the degree level.

Parham (1985) examined academic rewards in occupational therapy education through a survey of baccalaureate and postbaccalaureate programs. Analysis of the sample showed that occupational therapy faculty were younger, held lower academic ranks and degrees and were less often tenured than most faculty in higher education. Publication rates of occupational therapy faculty were about $20 \%$ lower than of other faculty. 
The occupational therapy academic reward systems did not emphasize publications as highly as traditional academic professions did.

Scott's (1985) study of factors that contributed to leadership among female occupational therapists identified shared experiences in childhood, adolescence and early adulthood. The leaders were more likely to identify with their fathers' personality and temperament and they were expected by their mothers to be employed full-time throughout their life.

Van Deusen's $(1985,1986)$ studies aimed to determine if occupational therapists' attitudes toward theory development are related to their level of education or to their length of professional experience. Data supported a developmental sequence for theory valuing similar to Davidson's suggestions (1981). Results indicated that both longevity of practice as well as level of education were associated with priorities for theory development. Sieg (1986) discussed the roles and functions of occupational therapy academic chairpersons using job analysis format. From her research she identified three basic functions of program directors: data functions, people functions and thing functions.

Bailey (1988) wanted to establish if certain variables could indicate whether an occupational therapist would choose an administrative or a clinical role. She found differences in demographics and values held by occupational therapy administrators and clinicians. Degree, male mentoring, speciality in physical disabilities and high values of capability were among the predictors of administrators.

Fleming and Piedmont (1989) gathered data from 811 therapists concerning perception of the profession's state and its educational system. According to this study, occupational therapists felt that the status of the profession should be improved and that education needed a change. However, there were significant differences in opinion about how to achieve 
these goals, depending on academic degree and years in practice. The survey showed that occupational therapists needed recognition for the service they contributed, both by third party payers, the general public and by other health professionals.

Javetz and Katz (1989) examined occupational therapy practitioners' knowledge of theories in Israel. The results of this study expressed a need for further articulation of theory in clinical practice, as well as improved preparation for education of the reflective practitioner.

DePoy (1990) aimed to describe the characteristic of master occupational therapy clinicians. The findings suggested that mastery is a combination of selected personal traits, creative and flexible judgment, the use of occupation as the foundation for practice and a strong commitment to the practice.

Burke and DePoy (1991) examined the relationships of mastery, excellence and leadership of ten master occupational therapy clinicians. The findings proved these variables to be independent of one another, although they share some characteristics.

Munoz, Lawlor, and Kielhofner (1993) conducted a survey of occupational therapists who utilized the Model of Human Occupation (MOHO) as their primary practice model to examine how they applied concepts of this model to describe the occupational functioning of their clients. The findings suggested that therapists valued the holistic approach of MOHO. They often incorporated other practice models into it, occasionally ignoring conceptual differences between models.

In Schemm's and Bross' study (1995) of mentorship experiences of occupational therapy leaders, 53 respondents completed a questionnaire that was distributed at an annual meeting of the Committee of State Association Presidents. The results indicated that the leaders were 
frequently exposed to role models, were assisted by sponsors, were mentored by other occupational therapists and served as mentors themselves.

Strong, Gilbert, Cassidy, and Bennett (1995) examined 19 participants and their approaches to the clinical reasoning processes. Two groups were compared, expert occupational therapists and post-clinical fourth-year occupational therapy students. The most valued skill for the experts was good communication, whereas the students rated knowledge of and understanding of disability highest. The experts were mostly concerned with gaining understanding of the patients and how the illness affected them while the students considered pragmatic factors on treatment to be of most importance.

Kaur's et al. (1996) study of 64 mental health staff members on a psychiatric unit investigated, for example, their attitudes to the importance of therapeutic activities and communication between occupational therapy and other disciplines. Occupational therapy was generally seen in a positive light, but there was confusion of roles between occupational therapy and other disciplines. Although the main functions of occupational therapy were understood, other staff were not confident about what occupational therapy could do and needed better communication between the disciplines.

Rugg (1996) investigated the feasibility of identifying the factors that influenced British occupational therapists' decisions to practice or cease to practice within one year of qualification. The study suggested that occupational therapists seemed to experience difficulty in their early practice with an apparent mismatch between their expectations and experience of practice.

Dudek-Shriber (1997) established a basic demographic profile of occupational therapy program directors. The study investigated the 
leadership of occupational therapy program directors, the organizational health of their departments and the relationships between them. The result was that both director and faculty respondents rated their departments high in organizational health.

Scope of occupational therapy practice. Brollier's study (1985a) examined what factors were associated with job satisfaction. When various situational and leadership factors were combined, one of the results indicated that occupational therapists in mental health care are less satisfied at work than therapists involved with other client populations. However, Cottrell's (1990) pilot study of occupational therapists in mental health suggests that this is not related to their perception of their own work performance, since respondents rated most of the professional tasks listed in the questionnaire as good or excellent.

In another study, Brollier (1985b) explored the effects of managerial leadership of hospital-based occupational therapy directors on their occupational therapy staff members' job satisfaction. Leadership behaviors were tested and correlated with staff job satisfaction. The findings revealed that leadership styles of the directors influenced staff's job satisfaction considerably more than in similar studies from other fields. Directors and their staff members showed major differences in their ratings of the directors' leadership styles. The average director viewed herself as a competent managerial leader while the average occupational therapist experienced the director as being a fairly mediocre managerial leader.

Duncombe and Howe (1985) gathered descriptive data on group work in occupational therapy from a sample of 120 therapists in all areas of practice. Sixty percent of these occupational therapists used groups in their therapy; verbal groups were used significantly less than activity groups.

Florian et al. (1985) explored the relationship between work load 
demands and job satisfaction of occupational therapists in Israel. The findings revealed that occupational therapists in Israel spend most of their work time giving treatment and even administrators spend over $50 \%$ of their time in treatment. They concluded, that in this sense, occupational therapy is primarily a treatment oriented discipline.

Brollier et al. (1986) did a pilot study of job burnout among hospitalbased occupational therapists. Managers and supervisors were then compared with staff therapists. Managers reported higher levels of burnout, specifically in the areas of depersonalization and emotional exhaustion.

Bordieri's study (1988) examined job satisfaction among occupational therapists. Ratings of job satisfaction factors differed as a function of the respondent's primary work role. A sense of achievement, interpersonal relations and being valued by others were identified as a positive work incentive and source of job satisfaction in occupational therapy.

A qualitative pilot study by Hasselkus and Dickie (1990) gathered data regarding the meaning therapists find in their practice. The following themes of meaning were derived from the data: making a difference, being valued by others, sense of initiative, sense of inventiveness and agreeableness. Expanding on this method, the researchers collected experiential narrative data to develop a deeper understanding of the nature of working in occupational therapy (Hasselkus \& Dickie, 1994).

Taylor and Mitchell (1990) studied occupational therapists to determine their perceived roles and attitudes regarding research. The sample was 270 clinicians whose primary or secondary employment function was direct patient service. The results indicated a strong belief in the importance of research in the profession. However, the objects reported a minimal involvement in research due to limited time, money and skill. 
Collaboration with experienced researchers was rated as highly desirable.

Taylor et al. (1990) observed values, salience and job satisfaction among male and female occupational therapists. There were no differences between the genders regarding job satisfaction. However, males endorsed risk and advancement more strongly than females. Females endorsed social relationships at a higher level than males. Males considered studying more important than females did in terms of participation, commitment, and role value. Female therapists tended to be more client oriented while male therapists were more management oriented in their work settings.

Vogel (1991) studied 348 occupational therapists, educators and students concerning the perceived role of the practitioner. The three groups agreed that the profession should be skilled in analyzing activities and that occupational therapy services should be covered by third-party payment, whereas treatment modalities and therapists' role characteristics revealed various opinions.

McClain and Ralston (1992) asked experienced American occupational therapists what motivated them to enter private practice, how they prepared themselves for the move, their perception of the risks and benefits before and after the move. According to the survey, autonomy was the most important motivating factor for the therapists moving into private practice.

Humphry et al. (1993) surveyed family-therapist involvement of 340 occupational therapists primarily practicing in the areas of physical disabilities, development disabilities or mental health and compared the subjects from these three areas of practice. Results indicated that area of practice affected the amount of contact with client's family, reasons for family-therapists interactions and attitudes about the family's abilities and 
involvements. Respondents in all three practice areas identified scheduling difficulties as the biggest issue affecting their involvement with their clients.

Adamson et al. (1994) explored the attitudes, values and orientation to professional practice of 378 Australian occupational therapists. Their findings indicated that the attitudes within the profession were oriented toward client and therapist interaction and client responsibility and holistic attitudes toward health care. Older therapists with more professional experience endorsed a more humanistic approach to therapy and were promoting the resources of the client more effectively than the younger, less experienced therapists.

In 1994 Jacobs studied optimal flow experience, a form of job satisfaction, in occupational therapy practitioners employed at physical rehabilitation facilities in New England. She found that flow experience occurred only an average 5.24\% during a five day work week. Flow experience mostly occurred when subjects were working with clients in some type of intervention; perceived autonomy and self-esteem were high during this time.

Ambrosi and Schwartz (1995a) examined how occupational therapy was represented in the New York Times during 1917-1925. The portrayal of the profession was favorable and it was illustrated as small but valuable, concerned with restoring patients to economic and social usefulness. At this time, there was a great demand in society for a profession that could assist physical and emotional disabled veterans and return them to productive lives. Occupational therapy was especially highly valued regarding mental illness. Ambrosi and Schwartz (1995b) stated that within the health care system every profession possessed the goal of returning patients to full functioning. As a comparison, only occupational therapists 
held that goal in 1917. The profession has had to struggle to define itself, and by adjusting to what the media valued in the early days, the opportunity to promote occupational therapy to the general public fell short.

A pilot study by Clark et al. (1995) examined how occupational therapists engaged family caregivers of elderly persons receiving home care services. A qualitative descriptive design was used to explore the behaviors of two occupational therapists when working with caregivers. The findings pointed out four types of interactions: caring, partnering, informing and directing.

Duncombe and Howe (1995) did a replication of their survey from 1985. The intention was to determine whether economic and demographic changes during the 10-year period altered the use of group treatment in the delivery of occupational therapy services. They concluded that occupational therapists continued to use group treatment in a variety of facilities and with many different groups. Changes were only seen in demographics, like the decrease in the number of therapists working in mental health settings.

Jenkins' and Brotherton's (1995a, 1995b) study aimed to obtain a definition, a function, competencies and vocational training and factors of successful intervention for the occupational therapy profession.

Furthermore, they wanted to receive specific detail on student training and post-qualification education and critical incidents. Their work had two phases: a semi-structured interview and an observation exercise. The population consisted of ten individuals from each of the following groups: occupational therapy practitioner group assistants, students, therapists graduated from diploma programs, graduates, educators, peer professionals, clients and administrators. The authors' finding was that occupational therapy is a practical profession with both practical and theoretical knowledge. The practical knowledge is often "uncodifiable, 
unordered and particularistic. It has personal validity, although little formal credibility" (1995a, p. 280). In contrast, theoretical knowledge advances a more structured and generalizable knowledge base of scientific validity. The thesis, "Occupational therapy: perspectives on the effectiveness of practice," implies that:

... professional effectiveness is not dependent only on the concept of reflection in and on action as espoused by Schön (1987) but, in effect, hinges on a 'community of practice' wherein learning is situated, ongoing and continuous and occurs in action, in discussion and in periods of personal reflection, purposively and incidentally. (Jenkins \& Brotherton, 1995a, p. 280)

The findings of their research was that occupational therapy "is a person service which penetrates clients' life-world contexts naturally" (1995a, p. 282). Occupational therapy is client focused, has a pragmatic orientation, and rests on contact and first-hand experience with clients and their work. Occupational practice does not revolve around abstract principles but on real life situations. Communication, as the critical key to a successful intervention was, endorsed by $82.5 \%$ of the interviewees (Jenkins \& Brotherton, 1995b).

Engquist et al. (1997) studied the role of occupational therapists with regard to clients' spirituality and established a baseline of occupational therapists' opinions and practices about spirituality and therapy on which future research could be built. The results of the study was that less than $40 \%$ of the respondents indicated that addressing clients' spiritual needs was within the scope of their profession and the majority reported that their academic training did not prepare them to address this issue.

Finlay (1997) did a quality study which explored how occupational therapists perceived their patients. Nine occupational therapists were 
interviewed. Warm and responsive patients were perceived as good patients, enabling the therapist to feel effective. Manipulative or threatening patients, resistant to change, were seen as bad patients. Difficult patients were viewed as positively challenging but hard work.

Moll and Cook (1997) explored the beliefs of occupational therapists working in mental health regarding the therapeutic value of "doing" as a treatment modality. They used observations on 11 occupational therapists as they conducted three to six regular scheduled therapy sessions in addition to interviews. Two main themes related to the value of activity emerged: beliefs of activity for the client and benefits in facilitating the process of therapy. The researchers concluded that occupational therapists working in mental health hold diverse beliefs about the value of doing in treatment.

Occupational therapy students. Katz's (1982) study revealed that graduate and undergraduate occupational therapy students were more uniform in their value preferences than a national sample of college educated adults. When comparing values among beginning occupational therapy students at the undergraduate and graduate levels, there were few significant differences. Madigan (1985) compared technical- and professional-level students from four occupational therapy educational programs in Illinois. Registered occupational therapists and certified occupational therapist assistants came from different backgrounds and though the two groups chose occupational therapy as a career for similar reasons, their work values and carrier goals were different.

DePoy and Merrill (1988) investigated values held by students in occupational therapy. The results indicated that the acquisition of professional values may be a development process which is not finished when students graduate. Ezersky et al. (1989) surveyed nine occupational 
therapy schools in New York to determine the factors affecting choice of speciality area after education. Primary factors were the fieldwork experience, the feeling of effectiveness in the specialty area and the perception of employment availability. Katz and Heimann (1991) did a study on learning styles among Israeli students and practitioners in five health professions, including occupational therapists. Their findings suggest greater variance in learning styles among the students as compared to practitioners.

Lyons (1991) studied if there were differences between occupational therapy students and business students at an Australian University in attitudes toward persons with disabilities and if attitudes varied between freshmen and those who had completed their education. Attitudes did not differ between the groups. However, those who had had contact with persons with disabilities beyond the context of a caregiver-care receiver relationship had significantly more positive attitudes toward disabled people. Neistadt (1992) examined the efficiency of one method for teaching diagnostic reasoning to occupational therapy students. The results suggested that in-class evaluations improved students' diagnostic reasoning skills. Rozier et al. (1992) studied why students choose occupational therapy as a career and found out that salaries, job availability, regular hours and prestige associated with the profession were the main reasons for choosing occupational therapy. Avi-Itzhak and BenShem (1993) examined work values and vocational choices in allied health and helping professions. Freshmen enrolled in occupational therapy were separated from the other freshmen choosing job-related aesthetics as most important and management as least important. Lyons and Hayes (1993) surveyed occupational therapy students and business students on their attitudes toward persons with psychiatric and others disabilities. There 
were no significant differences between groups concerning attitudes and both groups ranked persons with psychiatric disabilities as least favored. Lee et al. (1994) studied the effect of occupational therapy education on students' perceived attitudes toward persons with disabilities and found that attitudes became more positive after they commenced formal professional education. Eberhardt and Mayberry's (1995) study explored entry-level occupational therapy practitioners' equal status contact with and attitudes toward persons with disabilities. The results showed overall positive attitudes toward disabled persons. Tompson and Ryan (1996) did a qualitative study which focused on the role played by fieldwork in the professional socialization of four British occupational therapy students. Four major themes relating to professional socialization emerged during the study: the nature of professionalism, the concept of occupational therapy, learning the language of the professional and the shifting focus of the different levels of placements.

Tyrrell and Smith (1996) measured levels of psychological distress among a sample of Irish occupational therapy students. These students had similar psychological distress as found in students from four other university disciplines. Students who had unhealthy diets or who smoked had significantly higher levels of psychiatric symptomatology than the others. Jeffery and Hicks (1997) studied first-year undergraduate students to assess whether completion of counseling skill assignments had an impact upon a range of interpersonal skills in occupational therapy. Lyons (1997) did a phenomenological study to explore occupational therapy students' experiences in psychiatric fieldwork. Data was gathered from 16 female occupational therapy undergraduates. The study revealed that students had difficulties reconciling conflicting expectations with regard to emotional and social distance from persons who use mental health services 
and a need to assume authority and maintain control when working with them. Neistadt and Smith (1997) examined the effect of a 'classroom-asclinic' format using videotaped occupational therapy evaluations on students' diagnostic reasoning skills and found that experiencing a 'classroom-as-clinic' format identified significantly more occupational therapy problems.

\section{Research Chart in Chronological Order}

\section{Abbreviations for the Research Chart}

$\mathrm{P}=$ Professionalism

$\mathrm{A}=$ Autonomy

$\mathrm{Pp}=$ Professional productivity

$\mathrm{J}=$ Job satisfaction

$\mathrm{E}=$ Educational level

$\mathrm{Op}=$ Other professional issues

$\mathrm{S}=$ Students

$\mathrm{T}=$ Theories

$\mathrm{Sc}=$ Scope of practice

$\mathrm{M}=$ Master clinicians

$\mathrm{L}=$ Leadership

$\mathrm{F}=$ Faculty issues

$\mathrm{Oe}=$ Other educational issues 


\section{Table 1}

\section{Research Chart in Cronological Order}

\section{Authors}

Bell \& Bell

Lehmann

Allen \& Cruickshank

Rogers \& Mann a, b

Davidson

Van Deusen

Katz

Miller

Ottenbacher \& Short

Barris

Gilkeson \& Hanten

Barris \& Kielhofner

Brollier

Brollier

Clark et al

Duncombe \& Howe

Florian et al.

Madigan

Parham

Scott

Van Deusen

Brollier et al.

Madill et al.

Madill et al.

Sieg

Van Deusen

Baily

Bordieri

Davis \& Brodieri

DePoy \& Merrill

Ezersky et al

Fleming \& Piedmont

Javetz \& Katz

Cottrell

DePoy

Graham \& Timewell

Hasselkus \& Dickie

Storm

Taylor \& Mitchell

Taylor et al.

Professional

Educational

1972

1973

1977

1980

1981

1981

1982

1982

1982

1984

1984

1985

$1985 \mathrm{a}$

$1985 \mathrm{~b}$

1985

1985

1985

1985

1985

1985

1985

1986

$1986 \mathrm{a}$

$1986 \mathrm{~b}$

1986

1986

1988

1988

1988

1988

1989

1989

1989

1990

1990

1990

1990

1990

1990

1990
P

A<smiles>C1CCCC1</smiles>

$\mathbf{P} \quad \mathbf{P p}$

$\mathbf{P}$

$\mathbf{E}$

p

$\mathbf{p} \quad \mathbf{E}$

E Op

E

$\mathbf{s}$

$\mathbf{S}$

P

$\mathbf{P p}$

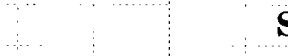

$\mathbf{P}$

Pp E

$\mathbf{P}$

$\mathbf{P}$

$\mathbf{P}$

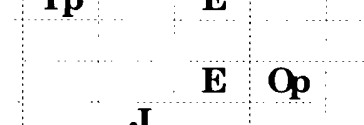

:

$\mathbf{F}$

J

$\mathbf{P p}$

$\mathbf{E}$

Sc

L

Sc

Sc

$\mathbf{S}$

A

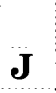

$\mathbf{P}$

A J

$\mathbf{J}$

$\mathbf{E}$

$\mathbf{T}$

M

Sc

$\mathbf{E}$

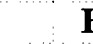

J

A

$\mathbf{J}$

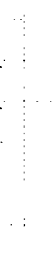

P

E

S

S

Sc

L

F

T

Sc

$\mathbf{T}$

J

P A

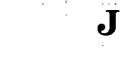

Sc

M

Sc

Sc

Sc 
Table 1

$\underline{\text { Research Chart in Cronological Order }}$

Authors

Bell \& Bell

Lehmann

Allen \& Cruickshank

Rogers \& Mann a, b

Davidson

Van Deusen

Katz

Miller

Ottenbacher \& Short

Barris

Gilkeson \& Hanten

Barris \& Kielhofner

Brollier

Brollier

Clark et al.

Duncombe \& Howe

Florian et al.

Madigan

Parham

Scott

Van Deusen

Brollier et al.

Madill et al.

Madill et al.

Sieg

Van Deusen

Baily

Bordieri

Davis \& Brodieri

DePoy \& Merrill

Ezersky et al

Fleming \& Piedmont

Javetz \& Katz

Cottrell

DePoy

Graham \& Timewell

Hasselkus \& Dickie

Storm

Taylor \& Mitchell

Taylor et al.

Professional

Educational

1972

1973

1977

1980

1981

1981

1982

1982

1982

1984

1984

1985

$1985 \mathrm{a}$

$1985 \mathrm{~b}$

1985

1985

1985

1985

1985

1985

1985

1986

$1986 \mathrm{a}$

$1986 \mathrm{~b}$

1986

1986

1988

1988

1988

1988

1989

1989

1989

1990

1990

1990

1990

1990

1990

1990
$\mathbf{P}$

A

$\mathbf{P}$

P

P

P

$\mathbf{P}$

$\mathbf{P}$

$\mathbf{P p}$

$\mathbf{P p}$

A

$\begin{array}{ll:l}\mathbf{P} & \mathbf{O P}\end{array}$

E

$\mathbf{S}$

$\mathbf{P} \quad \mathbf{E} \mathbf{O P}$

$\mathbf{P}$

$\mathbf{P}$

(a)

$\mathbf{P}$

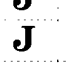

E
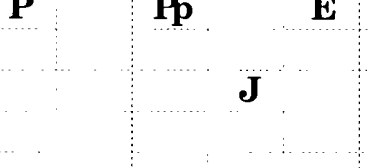

$\mathbf{E}$

A

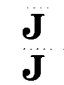

$\mathbf{P}$

A

$\mathbf{E}$

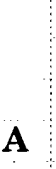

A
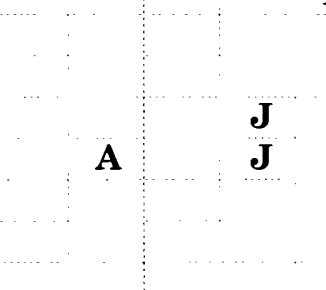

P

.

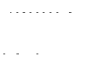

P A

$\mathbf{P p}$

E

$\mathbf{S}$

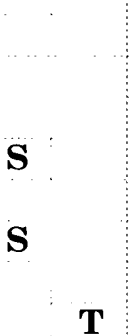

S

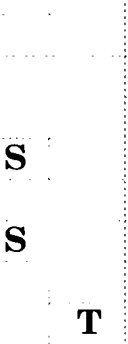

Sc

$\mathbf{L}$

$\mathbf{T}$

Sc

L

Sc

Sc

$\mathbf{S}$

F

Oe

F

T

L

Sc

$$
\text { J }
$$
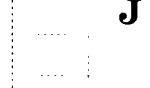

c

$\mathbf{T}$

Sc

M

Sc

Sc

Sc 


\section{$\underline{\text { Self Report }}$}

The use of a self-report scale is prevalent in research where information needs to be obtained directly from the interviewee. Although this is a very common research measurement, there is still a major concern among researchers about the validity of self-reported information. For example, how valid are surveys' measures of attitudes? Responses have been found to depend on variables such as: exact phrasing of the question, the sequence of questions, the nature of the response alternative and whether the subjects are given the option of answering neutrally or not (Schuman \& Presser, 1981).

Schwarz and Sudman (1996) discussed two interpretations of attitudes. One was that people have true attitudes on a topic and the goal is to find a way of assessing these attitudes. The other was that people do not have an attitude stored in memory, but rather construct one when asked to do so. Strong attitudes are those stored in memory, whereas weaker attitudes are those constructed from information that is accessible at a given point. When constructing valid survey measures of attitudes, care must be taken to minimize the effect the questions themselves might have on the attitude. Furthermore, the stability of attitude might affect the validity of a survey. Accuracy is an aspect of self-reported information that often is of concern. Survey respondents are often unreliable and inaccurate in answering what may seem to be straight forward questions (Schwarz \& Sudman, 1996).

There is always an element of uncertainty whether the subjects are answering truthfully, or if they are answering how they think they should answer. Sometimes respondents might answer according to their knowledge rather than their beliefs. The error of central tendency, respondents avoiding extremes, is a common occurrence with rating 
scales. Misinterpretation of the rating scales can produce unrepresentative survey results. Respondents occasionally tend to classify issues according to their general impressions, rather than according to the scale's meaning (Moser \& Kalton, 1971).

\section{$\underline{\text { Summary }}$}

Sociologists have listed characteristics said to distinguish professions from other forms of occupations. The traditional professions have been dominated by men and the so called semi-professions by women. In numerous authors' opinions, male bias is in the definitions of the professions, and characteristics associated to women have not been cherished either in the established professions or in the scientific world. Occupational therapy is a field were women are still in the majority. The field originally embraced a paradigm of occupation, however in the sixties, when the profession strived for more recognition and value in the medical world, it became more technically oriented and lost its philosophical ideas. In the last two decades the profession has returned to many of its original themes to recapture its identity to a more holistic orientation. In the last two decades American occupational therapists along with their fellow colleagues in the western world have consistently strived, not without disagreements though, toward reaching the goals needed to become a fullfledged profession. There are still many barriers, for example, the profession being female dominated, lack of autonomy and difficulty on conducting research that is valued in the scientific literature. The quantitative statistical methods that are respected do not measure the products of enablement, enhancement or empowerment when these depend on subjective perceptions. It is clear that consumers will have more influence on development of health care services in the future. They have 
become more autonomous in making decisions about their lives and are politically involved. As the expenses of health care steadily increases, the society demands a constant search for more cost effective solutions.

Occupational therapy can make significant contributions concerning this. If the profession is to grow, it needs an educational system that generates skilled clinicians, inventive researchers and leaders with political involvement. 


\section{CHAPTER III \\ Research Procedures \\ Methodology}

This descriptive research is intended to describe demographic characteristics of Icelandic occupational therapists and their attitudes toward professionalism and educational goals. It is also intended to detect if there is a relationship between variables, such as: educational level, experience in practice, country of graduation, attitudes regarding professionalism and educational domains.

Research Questions

1. What are the demographic characteristics of Icelandic occupational therapists?

2. What are the Icelandic occupational therapists' attitudes regarding professionalism and educational goals?

3. Is there a relationship between therapists' educational level, years of experience and country of graduation with respect to their attitudes toward professionalism and educational goals?

Subjects

The entire population of occupational therapists in Iceland was included in this study. The register from The Icelandic Occupational Therapy Association was used to ensure that all members received the questionnaire. The size of the occupational therapy population on February 1, 1998 consisted of 87 members, the majority living in Reykjavík, the capital. Among the subjects there were two males and two individuals over 60 years of age. The subjects were not asked to report gender or exact age since this could identify some of them and would conflict with the anonymous nature of the study. 
This is a quantitative-descriptive cross-sectional study. A survey questionnaire was used to gather information concerning several factors including demographic characteristics, provider responsibilities, type of professional education, length of practice, professional duties and professional productivity, commitment to the profession and attitudes toward educational and professional issues. The study investigated if two or more existing independent variables, such as: educational level, experience in practice and country of graduation, had an effect on dependent variables, such as: attitudes regarding professionalism and educational domains.

\section{Procedure}

The instrument was first reviewed by the Icelandic occupational therapy school committee to obtain design and face validity and determine if there was need to add further information. After their revision, the instrument was changed according to recommendations and several questions were added. It was pilot tested on seven physical therapists and revised based on their feedback. Questions obtained from other instruments were translated to Icelandic and later translated back to English by persons not familiar with the original phrasing of the questions. This was done to confirm that the meaning did not change through the translation process. Minor revisions had to be made to adapt to the Icelandic language, for example, there is no equivalent term for liberal arts in Icelandic; therefore, clinical reasoning, philosophy and ethics were used as substitutes. After final feedback from faculty at Florida International University (FIU), the instrument was completed and received an approval from the Human Subjects Committee at FIU. The Icelandic version was then approved by The Computer Committee of Iceland which is the review committee for studies involving human subjects in Iceland. 
Enclosed with the questionnaire was a letter explaining the purpose and confidentiality of the study. Most of the therapists, sixty members, received the questionnaire at a meeting on February 13th, 1998. The rest received the questionnaire along with a stamped and addressed envelope by mail. Within one week the return rate was around $60 \%$. After two weeks occupational therapists working on the larger institutions were contacted and reminded to reply. This resulted in a total response of $75 \%$. After four weeks the same places where contacted again and smaller workplaces also added. Out of the 87 questionnaires that were distributed, 80 were returned which resulted in a $92 \%$ return rate.

Instrument Development

The questionnaire (see Appendix) was developed by using parts of six other instruments used in research on occupational therapists (Barris \& Kielhofner, 1985; Clark et al., 1985; Fleming, 1985; Fleming \& Piedmont, 1989; Gilkeson \& Hanten, 1984; Vogel, 1991) along with questions designed specifically for this survey. Gilkeson and Hanten's (1984) instrument was pilot-tested and pretested for design and face validity. The validity of Clark's et al. (1985) items were established through a group process in which seven current students consensually agreed on the meaning of the respective items. Instruments by Barris and Kielhofner (1985), Fleming (1985), Fleming and Piedmont (1989), showed no reports on reliability or validity. Vogel's (1991) instrument was pilot-tested and revised several times. None of the instruments have been validated or proven reliable through systematic validity and reliability studies.

The first section of the questionnaire contains 22 background questions to collect demographic characteristics information. The second section contains two questions, 23 and 24, regarding educational issues. Question 23 includes ten items. Fleming and Piedmont's (1989) instrument: 
Perception of Current Occupational Therapy Education was used for the first nine items while the tenth was modified. Their instrument was developed to gather data on perception of the state of the profession and its educational system. Question 24 concerns how Icelandic occupational therapists define future educational goals. The question includes 11 items. The first eight items are provided by The Occupational Therapy Education Values Instrument developed by Barris and Kielhofner (1985). Their instrument was used to assess differences in theoretical commitment and application of theory on graduate and undergraduate level students and practicing therapists. The last three items, i, j, and k, were especially designed for this instrument.

The third section contains four questions (25-28) concerning interest in new developments in professional matters, continuing education and professional productivity. Gilkeson and Hanten's (1984) study was employed as a model for this section. Their instrument was used to compare possible differences between therapists with baccalaureate education and master's level therapists on job activities and responsibilities, professional productivity and professional growth.

The fourth section contains ten questions (29-38) concerning attitudes toward professional issues. Question 29 includes ten items and regards the respondents' opinion on changes needed in the profession. The question is supplied by Fleming and Piedmont's (1989) questionnaire. Questions 30 and 33 are statements regarding professionalism, question 31, scope of practice and 32 , educational concerns. Questions 30 e, f, h, 31 c, d, 32 a, e, 33 c, d, e, are provided by Clark's et al. (1985) instrument. Their instrument was developed to assess attitudes toward professional issues, professional organizational involvement and scholarly contributions. Questions $31 \mathrm{~b}, \mathrm{f}$, 33 a, g, i, are provided by Vogel's (1991) instrument: The Perceptions of the 
Practitioners' Role Questionnaire. Her instrument was used to study differences in attitudes on perceived roles of the practitioner among occupational therapy educators, practitioners and students. The concept for questions 32 b, c, d, b, f, g, came from Fleming's (1985) questionnaire draft \#2. Question 38 is provided by Barris and Kielhofner's (1985) questionnaire. The question includes 13 items and the respondents rank five selected items according to their importance for the occupational therapy profession. Questions 30 a, b, c, d, g, 31 a, 33 b, f, h, and 34-37 were designed particularly for this instrument with 34-37 developed by the Icelandic school committee.

Instrument. The first section (see Appendix) contains 22 questions regarding the therapists' background. Questions 1-5 address age range, marital status, provider responsibilities, caregiving duties and reasons for coming back to Iceland after graduation. Questions 6-16 concern length of professional experience, where education was completed, educational degree, current employment status, current work setting, the percentage of time spent working as an occupational therapist, how many occupational therapists are working at their workplace, current area of practice, educational duties at work and income as an occupational therapist. Questions 17-22 are questions regarding pause from practice for more than six months/for what reason, work in more than one specialty area/what speciality areas, the percentage of time spent working in other occupations and income from the different occupations, respectively.

The second section contains two questions, 23 and 24, regarding educational issues. Question 23 divides educational aspects into ten areas, and the respondents indicate how they feel their own education has prepared them in each area. Ratings are on a scale from 1 to 5 where 1 is none, 2 is poor, 3 is fair, 4 is good, and 5 is excellent. Question 24 lists 11 
different skills and attitudes concerning the occupational therapy profession and respondents indicate how much emphasis they feel each item should be given in the occupational therapy education. Ratings are on a scale from 1 to 5 where 1 is very little, 2 is little, 3 is average, 4 is much, and 5 is very much.

The third section contains four questions concerning interest in professional matters, continuing education and professional productivity. Questions 25-27 are questions on professional journal reading habits. In question 28, respondents list the number of articles they have published during the last five years, participation in workshops and seminars and if they have conducted workshops or held presentations on seminars.

The fourth section contains ten questions concerning attitudes toward professional issues. Question 29 lists ten aspects of occupational therapy practice and the respondents indicate how much change they think is needed regarding each area. Ratings are on a scale from 1 to 5 where 1 is none, 2 is little, 3 is some, 4 much, and 5 is very much. Question 30 contains statements regarding professional issues and respondents are to indicate how well the statements describe them. Ratings are on a scale from 1 to 5 where 1 is not at all, 2 is rather poorly, 3 is some, 4 is rather well, and 5 is very well. Questions 31 to 33 are statements regarding attitudes concerning scope of the profession, educational issues and professionalism. The respondents are to indicate how well the statements describe their opinion. Ratings are on a Likert scale from 1 to 5 where 1 is strongly disagree, 2 is mildly disagree, 3 is neutral, 4 is mildly agree, and 5 is strongly agree. Questions 34 to 37 address the need for a bridging course to obtain a BS degree, if they would be interested in such a course, if they consider themselves having adequate knowledge to teach or supervise students and if they are interested in providing these duties. Question 38 lists 13 issues 
regarding the occupational therapy profession. The respondents choose among these what they consider to be the five most important issues and rank order those according to their importance from 1 to 5 . Number 1 means most important, number 2 means second most important, and so on, number 5 meaning the least important of the five chosen issues.

Questions number 39 to 41 provide the respondents with an opportunity to comment on professional issues of their own choice. The interviewees are asked if they want to share opinions and ideas regarding the profession, the upcoming Icelandic occupational therapy curriculum and continuing education.

Statistical Analysis

Statistical summary measures, such as frequencies, percentages, means and standard deviations, were used to describe the data. Question response types used in the instrument are: fill in blanks, multiple choice, ranking scale and Likert scales. The summary measure is selected to the response type of each question. Questions offering a multiple choice response, for example, marital status, providing responsibilities, type of professional education, length of practice and professional duties are summarized as percentages. In this study, questions using Likert scales generally concern attitudes toward educational and professional issues. The percent of each choice and the mean score were computed for each question's response. One question applies a ranking scale and respondents rank specified professional issues according to their importance, from highest to lowest priority. When interpretating data, highest priority was given 5 points, second priority 4 points, third priority 3 points, fourth priority 2 points and the fifth priority 1 point. The percent of each issue and the mean score were computed for each question's response.

The independent variable of educational level was divided in two 
groups: group one included occupational therapists with diplomas $(\underline{\mathbf{n}}=55)$ and group two included occupational therapists with a BS or MS degree in occupational therapy or other professions and those studying for the MS $(\underline{\mathrm{n}}=25)$. Length of professional experience was divided into three groups: 0 - 5 years $(\underline{\mathrm{n}}=19) ; 6-11$ years $(\underline{\mathrm{n}}=25) ; 12$ years or more $(\underline{\mathrm{n}}=30)$. Country of education was categorized into three groups: The Nordic countries $(\underline{n}=68)$; U.S.A, Canada $(\underline{\mathrm{n}}=6)$; other countries $(\underline{\mathrm{n}}=6)$.

Chi-Square analyses were used when testing for relationships between professional productivity and commitment by education and professional experience and country of education. T-tests were used when comparing the means of attitudes toward professionalism and educational goals by educational levels. One way ANOVAs were used when comparing by professional experience and by country of education. Fisher's Least Significant Difference test was used to determine pairwise mean differences. Significance level was $\underline{p}<.05$ for all tests.

\section{Limitations}

None of the instruments used as guidelines for this study have been validated or proven reliable through systematic validity and reliability studies. Persons with occupational therapy backgrounds could not be used in the pilot testing nor in the translation process, since the whole population of occupational therapists were subjects and no occupational therapy students were available. Another limitation was that Icelandic occupational therapists have not yet developed a vocabulary of their own. These limitations could affect the face validity of the survey. This is a national survey and the findings do not necessarily apply to occupational therapists in other countries. 


\section{CHAPTER IV}

Results

The results of this study are presented in this chapter. The three following research questions were asked:

1. What are the demographic characteristics of Icelandic occupational therapists?

2. What are the Icelandic occupational therapists' attitudes regarding professionalism and educational goals?

3. Is there a relationship between therapists' educational level, years of experience and country of graduation with respect to their attitudes toward professionalism and educational goals?

The entire population of occupational therapists in Iceland $(\underline{\mathrm{N}}=87)$ were included in this study. Eighty (92\%) of the 87 members replied. The independent variable of educational level was divided in two groups: group one was occupational therapists with diplomas $(\underline{n}=55)$ and group two was occupational therapists with BS, MS in occupational therapy or other professions and those studying for MS ( $\underline{\mathbf{n}}=25)$. Length of professional experience was divided into three groups: $0-5$ years $(\underline{n}=19) ; 6-11$ years $(\underline{\mathrm{n}}=25) ; 12$ years or more $(\underline{\mathrm{n}}=30)$. Country of education was categorized into three groups: the Nordic countries $(\underline{\mathrm{n}}=68)$; U.S.A., Canada $(\underline{\mathrm{n}}=6)$; and other countries $(\underline{n}=6)$. T- tests were used to compare the means of attitudes toward professionalism and educational goals by educational levels. Oneway analyses of variance (ANOVA) were used for comparisons by professional experience and by country of education. Fisher's Least Significant Difference test was used to determine pairwise mean differences. Chi-Square analyses were used to compare professional productivity and professional commitment by educational level, professional experience and country of education. Significance level was 
$\underline{p}<.05$ for all tests.

\section{Demographic Data}

To answer research question one, frequencies and percentages are discussed for each demographic variable. The respondents did not answer all questions in the section of demographic data and the sample sizes ranged from 74 to 80 . Forty-three $(53.8 \%)$ of the subjects were between the ages of 30 to $39,29(36.3 \%)$ between 40 to 49 years, five (6.3\%) were younger than 30 years, and three (3.8\%) older than 50 years. Forty-two $(52.5 \%)$ were married, $21(26.3 \%)$ lived in a marriage-like relationship, $11(13.8 \%)$ were single, and six (7.5\%) divorced, widowed or had other marital status. Fiftythree $(67.9 \%)$ reported steady incomes, 47 (60.3\%) had lower incomes than their spouses, $11(14.1 \%)$ had similar incomes as their spouses, ten (12.8\%) had spouses with irregular income, and four (5.1\%) had higher incomes than their spouses. Seven (9\%) of the subjects reported living alone, six $(7.7 \%)$ were single parents and two $(2.6 \%)$ reported being the main provider in their household.

Concerning caregiving duties, the results revealed that there were 126 children altogether living at home with an age range from 0 to 24 years. Twenty-three (18.3\%) were three years of age or younger and $61(48.4 \%)$ of the children were ten years or younger. Twenty-six (32.9\%) of the subjects had two children, $16(20.3 \%)$ had three, 14 (17.7\%) had one child, three (3.9\%) had four, and 20 (25.3\%) had no children. Five (6.3\%) had one to three grown up children and one had six grandchildren. Fifteen (19\%) cared for a relative at least once a week and five (6.3\%) had other time consuming caregiving duties.

Forty-six (57.5\%) graduated as occupational therapists between the years 1981 and 1990, 20 (25\%) later than 1991, and 13 (16.2\%) between 1971 
and 1980. Forty-four (55\%) graduated in Denmark, 16 (20\%) in Sweden, eight $(10 \%)$ in Norway, five $(6.3 \%)$ in another European country, five $(6.3 \%)$ in the U.S.A., one in Canada and one in a country outside Europe and North America. Sixty-six (82.5\%) held a diploma, 12 (15\%) were bachelors in occupational therapy, two $(2.5 \%)$ were bachelors in other professions, three (3.8\%) held a master's degree in occupational therapy, three (3.8\%) a master's degree in an other profession, seven (8.8\%) were currently studying for a master's degree, and six (7.5\%) had other special education. As reason for returning to Iceland after graduation, 55 (70.5\%) answered that they always intended to come back, 51 (65.4\%) reported patriotism and family as reasons, 30 (38.5\%) had a position waiting for them in Iceland, 11 (14\%) reported that their spouse did not get work abroad, five $(6.4 \%)$ did not get work themselves abroad, $13(16.7 \%)$ had other reasons, and ten (12.8\%) reported that they were immigrants to Iceland.

Length of professional experience ranged from 0 to 31 years, $\underline{M}=10.7$ and $\underline{\mathrm{SD}}=6.7$. Sixty-five $(82.3 \%)$ were solely working as occupational therapists, eight $(10.1 \%)$ were working in more than one field, three $(3.8 \%)$ were currently on a leave, and three $(3.8 \%)$ were not working in the occupational therapy field. Fifty-four $(67.5 \%)$ had paused from practice for more than six months. Forty-four (55\%) of them had paused because of maternity, $12(15 \%)$ due to upbringing of children, ten $(12.5 \%)$ for education, six $(7.5 \%)$ due to work in other fields, four (5\%) for other reasons, and two $(2.5 \%)$ due to illness.

Sixty-eight (85\%) had worked in more than one specialty area and 52 (76.5\%) of them had worked with adults having physical disabilities, 42 $(61.8 \%)$ with the elderly population, $39(57.4 \%)$ with adults having psychosocial problems, $33(48.5 \%)$ with children and adolescents, $20(29.4 \%)$ with health promotion/sickness prevention, 13 (19\%) with adults having 
development disabilities, $12(17.6 \%)$ in administration, and ten (14.7\%) in other areas.

The respondents were asked to indicate the one setting where they spent most of their working time. Thirty (39\%) spent most of their working time in a medical hospital, $21(27.3 \%)$ in a rehabilitation center, seven (9\%) in community care, five $(6.5 \%)$ in helping aid centers, three $(3.9 \%)$ in the school system, two (2.6\%) were working in an outpatient clinic and another two $(2.6 \%)$ in private practice while seven $(9 \%)$ were working in other settings. They were further asked to list all their work settings. Thirty-eight (49.4\%) reported working in medical hospitals, 27 (35\%) in rehabilitation centers, ten (13\%) in private practice, nine $(11.7 \%)$ were working in the school system, eight (10.4\%) in community care, seven (9\%) in helping aid centers, and nine (11.7\%) working in other workplaces.

The respondents were asked to indicate the one area of practice in which they spent most of their working time. Twenty-three (30\%) reported working with adults having physical disabilities, 14 (18\%) worked with children/adolescents, 11 (14.3\%) with adults having psychosocial problems, seven $(9 \%)$ with elderly, five $(6.5 \%)$ were administrators with more than ten staff members, four (5.2\%) worked in education, three (3.9\%) were administrators with five to ten staff members, two (2.6\%) were administrators with four staff members or less, two (2.6\%) worked with adults having developmental disabilities, one with health promotion/sickness prevention, and five (6.5\%) worked in other areas. They were further asked to list all their areas of practice. Forty-four (54.5\%) reported working with adults having physical disabilities, 34 (44\%) with adults having psychosocial problems, 28 (36.4\%) worked with children/adolescents, 26 (33.8\%) with elderly, 14 (18.2\%) in education, 12 (15.6\%) with health promotion/sickness prevention, eleven (14.3\%) in 
administration with four staff or less, ten (13\%) worked with adults having development disabilities, six $(7.8 \%)$ in administration with five to ten staff members, five $(6.5 \%)$ in administration with more than ten staff members, and $13(16.9 \%)$ reported other areas of practice.

Concerning main educational duties at work in addition to clinical work as occupational therapists, $14(18.7 \%)$ reported no educational duties, $27(36 \%)$ consulted with other professionals, 14 (18.7\%) supervised other staff, eight (10.7\%) educated staff members, six (8\%) supervised occupational therapists, and six (8\%) reported other educational duties. Concerning all educational duties, $35(46.7 \%)$ consulted with other professionals, 31 (41.3\%) educated staff members, 26 (33.3\%) supervised other staff, 11 (14.7\%) supervised occupational therapists, nine (12\%) supervised students in their own field, and thirteen (17.3\%) reported other educational duties.

Twenty-four (32\%) of the subjects worked with one to three occupational therapists, $14(18.7 \%)$ worked alone, 13 (17\%) worked with more than ten occupational therapists, $12(16 \%)$ worked with four to six occupational therapists, and $12(16 \%)$ worked with seven to nine occupational therapists. The range of working time as occupational therapists was from $20 \%$ to $100 \%$ (8 to 40 hours a week), $\underline{\mathrm{M}}=82.3, \underline{\mathrm{SD}}=21.1$. Fifty-two (68.4\%) worked 32 hours a week or more, 20 (26.3\%) worked 20-31 hours a week, four (5\%) worked less than 20 hours a week. Twenty-four (33\%) had income between 111 - 140 thousand kr., 21 (29\%) between $81-110$ thousand kr., 11 (15.3\%) between 141 - 170 thousand kr., nine (12.5\%) between 50 - 80 thousand kr., and seven (9.8\%) 201 thousand kr. or more. Thirty-five (46\%) worked full time, 14 (41\%) of them had an income between 111 - 140 thousand $\mathrm{kr}$., ten (28\%) between 141 - 170 thousand kr., four (12\%) between 81 - 110 thousand kr., four (12\%) between 171 - 200 thousand kr., 
and two (6\%) had an income of more than 200 thousand kr. Three (3.8\%) worked full time in other fields and their income ranged from $111-200$ thousand kr. Most of the occupational therapists that did additional work in other fields had an income of 50 thousand $\mathrm{kr}$. or less.

According to Etzioni's theory concerning the semi-professions, supervision, administration and directing are the most monetary rewarded tasks. In true professions however, task performance, not organizational position brings the main monetary rewards. Chi-Square analyses were used to see if this theory would apply for occupational therapists in Iceland and the analyses showed a significant difference in income by area of practice, $\underline{X}^{2}(2)=28.7, \underline{p}<.001$. Sixty-two percent of the administrators with five or more staff members had an income of 171 thousand $\mathrm{kr}$. or more a month, as compared to only four percent of those working as clinicians, while none of the teachers reached over 171 thousand $\mathrm{kr}$.

\section{Attitudes Toward Professionalism}

This section addresses research questions two and three on attitudes toward professionalism, in general, and differences among groups. The respondents displayed their interests in professional matters, continuing education and professional productivity. Their attitudes toward professionalism were measured on two different Likert scales from 1 to 5 . For one question, the respondents indicated whether or not the listed statements described them: $1=$ not at all, $2=$ rather poorly, $3=$ some, $4=$ rather well, or $5=$ very well. For the other question, the respondents indicated if they: $1=$ strongly disagreed, $2=$ mildly disagreed, $3=$ were neutral, $4=$ mildly agreed, or $5=$ strongly agreed to listed statements. Means and percentages are given on how the respondents answered on the Likert scales. Chi-Square analyses, t-tests and one-way ANOVAs were 
used when displaying differences among groups.

Professional Interests, Productivity and Commitment

Characteristics that have been connected to professionalism correspond to ongoing knowledge acquisition, devotion in teaching others, continually updating education and an ongoing sense of responsibility not only to clients but also to the profession.

Professional reading habits. Thirty-six $(45.6 \%)$ of the respondents reported reading occupational therapy journals once a month, 21 (26.6\%) twice a month, $12(15 \%)$ twice a year, and ten (12.7\%) at least once a week. When responding to how often they read other medical journals, 28 (35\%) once a month, $26(32.5 \%)$ reported twice a year, $18(22.5 \%)$ twice a month, six $(7.5 \%)$ once a week, and two $(2.5 \%)$ never. Concerning reading professional journals from other countries, 56 (71.8\%) reported reading occupational therapy journals from Denmark, 38 (48.7\%) from U.S.A., 23 (29.5\%) from Sweden, 16 (20.5\%) from Canada, 15 (19.2\%) from Norway, ten (12.8\%) from Great Britain, and four (5\%) from Australia. Seventy-six (97\%) read journals from foreign countries, 50 (64\%) read from two countries, 23 (29.5\%) from three countries, $11(14 \%)$ from four countries, and three (3.8\%) from five countries.

Professional productivity. Fifty-four percent of the occupational therapists had published one or more articles in the Icelandic Occupational Therapy Journal (see Table 2). Nineteen percent had written articles in other Icelandic professional journals, $32 \%$ in Icelandic newspapers, $12 \%$ in foreign professional journals, 33\% conducted workshops for occupational therapists, $10 \%$ appeared in TV or Radio, $42 \%$ had given presentations at meetings for professionals other than occupational therapists, $24 \%$ had given presentation at conferences, $10 \%$ of these were international. Ninety percent had participated in workshops, $49 \%$ of which were international, 
Table 2

Percentage of Occupational Therapists Engaged in Professional Activities for the Last Five Years $(n=77)$

$\%$

Professional productivity

\begin{tabular}{|c|}
\hline umber \\
\hline
\end{tabular}

Articles written

- in the Icelandic OT journal

- in professional journals in

$\begin{array}{rrrrrrr}46 & 28 & 10 & 10 & 4 & 1 & 1 \\ 81 & 10 & 5 & 3 & & 1 & \end{array}$

Iceland

- in newspapers in Iceland

$\begin{array}{lllll}68 & 20 & 4 & 4 & 4\end{array}$

- in foreign professional journals 88 11 1

Workshops conducted

- for OTs

$\begin{array}{llll}86 & 4 & 6 & 1\end{array}$

2 1a

- for other professionals

$\begin{array}{lllll}67 & 9 & 6 & 8 & 1\end{array}$

$3 \mathrm{lb}$

Presentations

- on TV/Radio

- in meetings for professionals

$\begin{array}{lll}90 & 8 & 2\end{array}$

$\begin{array}{llllllll}58 & 15 & 10 & 8 & 5 & 1 & 1 & 2\end{array}$ other than OTs

- in Icelandic conferences

$\begin{array}{llllll}76 & 10 & 5 & 4 & 1 & 3\end{array}$

- in international conferences $\quad \begin{array}{llllll}90 & 5 & 3 & 1 & 1\end{array}$

Participation

- in Icelandic workshops

- in international workshops

- in Icelandic seminars

- in international seminars)

$\begin{array}{rrrrrrrrrrrr}10 & & 8 & 8 & 1 & 7 & 10 & 4 & 8 & 4 & 10 & 30 \\ 51 & 18 & 18 & 4 & & 1 & 4 & & & & 1 & 3 \\ 28 & 11 & 14 & 13 & 10 & 5 & 4 & 3 & 1 & 1 & 4 & 6 \\ 63 & 18 & 8 & 8 & & 1 & 1 & & 1 & & & \end{array}$

Note: $1 \mathrm{a}=$ one respondent conducted 47 workshops. $1 \mathrm{~b}=$ one respondent conducted 30 workshops. 
and $72 \%$ participated in seminars, $37 \%$ of which were international.

Professional commitment. When asked if there was a need for a special "bridging course" for diploma level occupational therapists to achieve a BS degree, $56(70 \%)$ said yes, 18 (22.5\%) said no, and six (7.5\%) did not answer. When considering if they would be interested in taking such a course, $34(42.5 \%)$ were interested, $20(25 \%)$ were already holding a degree or studying, $19(24 \%)$ were not interested, and seven $(8.5 \%)$ did not answer the question. Sixty percent of those holding a diploma were personally interested in such a "bridging course." When considering if the therapists had adequate knowledge and skills to take on teaching roles, $57(71.3 \%)$ felt that they had adequate knowledge and skills to supervise students during fieldwork, $43(53.8 \%)$ to teach under supervision from a faculty member, 34 $(42.5 \%)$ to conduct research in the occupational therapy field and $14(17.5 \%)$ felt that they had adequate knowledge and skills to teach a course in an occupational therapy undergraduate program. Those who were interested in taking on such teaching duties were $56(70 \%)$ to supervise students in their fieldwork, $46(57.5 \%)$ to conduct research in the occupational therapy field, $30(37.5 \%)$ to teach a course under supervision and $11(13.8 \%)$ to teach a course.

Significant differences. When comparing professionalism by educational level, professional experience, and country of education, ChiSquare analyses showed significant differences by all three variables. Thirty-eight percent $(\underline{\mathrm{n}}=25$ ) of BS/MS therapists and MS students vs. only two percent $(\underline{n}=55)$ of those holding a diploma read occupational therapy journals at least once a week, $\underline{X}^{2}(3)=19.4, \underline{p}<.001$. Thirty-eight percent of BS/MS therapists and MS students vs. only $12 \%$ of those holding a diploma had published articles in journals other than occupational journals, $\underline{\mathrm{X}}^{2}(1)=7.2, \underline{\mathrm{p}}=.01$. Twenty-one percent of BS/MS therapists and MS 
students vs. just six percent of those holding a diploma had given presentations at international conferences, $\underline{X}^{2}(1)=4.1, \underline{p}=.04$. Forty-five percent of BS/MS therapists and MS students vs. just $22 \%$ of those holding a diploma had participated in international seminars, $\underline{X}^{2}(1)=4.5, \underline{p}=.04$. Regarding knowledge by education on the four teaching and research skills, $48 \%$ of BS/MS therapists and MS students considered themselves having adequate knowledge to teach a course in the occupational therapy undergraduate program as opposed to just four percent of those holding diploma, $\underline{\mathrm{X}}^{2}(1)=23.4, \underline{\mathrm{p}}<.001$. Eighty percent of BS/MS therapists and MS students considered themselves having adequate knowledge to teach a course in the occupational therapy undergraduate program with supervision from a faculty member as opposed to only $42 \%$ of those holding a diploma, $\underline{\mathrm{X}}^{2}(1)=10.1, \underline{\mathrm{p}}<.001$. Ninety-two percent of BS/MS therapists and MS students considered themselves having sufficient knowledge to supervise an occupational therapy student during fieldwork as opposed to just $62 \%$ of those holding a diploma, $\underline{X}^{2}(1)=7.6, \underline{p}=.01$. Eighty percent of BS/MS therapists and MS students considered themselves having sufficient knowledge to conduct research in the occupational therapy field compared to only $25 \%$ of those holding a diploma, $\underline{X}^{2}(1)=20.9, \mathrm{p}<.001$. Thirty-six percent of BS/MS therapists and MS students were interested in teaching a course while only four percent of those holding a diploma were interested, $\underline{\mathrm{X}}^{2}(1)=15.2, \underline{\mathrm{p}}<.001$. Sixty percent of BS/MS therapists and MS students were interested in teaching a course under supervision while only $27 \%$ of those holding diploma were interested, $\underline{X}^{2}(1)=7.9, \underline{p}=.005$.

When comparing professionalism by experience, $23 \%(\underline{\mathrm{n}}=30)$ of those with 12 years of experience or longer read occupational journals at least once a week, as compared to only $12 \%(\underline{\mathrm{n}}=25)$ of those having 6 to 11 years of experience, $\underline{\mathrm{X}}^{2}(6)=13.9, \underline{\mathrm{p}}=.03$. No one with five years experience or less 
$(\underline{\mathrm{n}}=19)$ read an occupational therapy journal at least once a week. Thirtyone percent of those with the longest experience had published articles in journals other than occupational journals as opposed to just $12 \%$ of those having 6 to 11 years of experience and only six percent of those with five years of experience or less, $\underline{X}^{2}(2)=5.8, \underline{p}=.05$. Twenty-eight percent of those with the longest experience had conducted workshops for occupational therapists as opposed to only eight percent of those having 6 to 11 years of experience, $\underline{\mathrm{X}}^{2}(2)=8.21, \underline{\mathrm{p}}=.02$. Those with five years experience or less had not conducted any workshops. Forty-one percent of those with longest experience had given presentations at conferences as opposed to $20 \%$ of those having 6 to 11 years of experience and only six percent of those with five years or less experience, $\underline{X}^{2}(2)=8.1, \underline{p}=.02$. One hundred percent of those with the longest experience and those having 6 to 11 years had participated in workshops while $72 \%$ of those with 5 years or less had participated, $\underline{X}^{2}(2)=14.1, \underline{p}<.001$. Eighty-six percent of those with the longest experience had participated in seminars compared to $80 \%$ of those having 6 to 11 years of experience and just $41 \%$ of those with the shortest experience, $\underline{X}^{2}(2)=11.3, \underline{p}<.001$. Fifty-five percent of those with the longest experience had participated in seminars internationally while $29 \%$ of those having 6 to 11 years of experience and $12 \%$ of them with five years or less had participated, $\underline{\mathrm{X}}^{2}(1)=4.5, \underline{\mathrm{p}}=.04$.

Concerning a need for a "bridging course," $78 \%$ of those with the shortest experience said there was a need for a bridging course, $83 \%$ of those with the longest experience said so while only $48 \%$ of those having experience 6 to 11 years agreed, $\underline{X}^{2}(4)=11.0, \underline{p}=.03$. Sixty-three percent of those with experience of 0 to 5 years were interested in such a course, $48 \%$ with experience 6 to 11 years, but only $33 \%$ with the longest experience were interested in such a course, $\underline{\mathrm{X}}^{2}(6)=12.9, \underline{\mathrm{p}}=.05$. Concerning knowledge to 
teach a course and supervise occupational therapy students, $63 \%$ of those that had the least experience considered themselves as having adequate knowledge to teach a course, as opposed to only $48 \%$ of those with 6 to 11 years and $33 \%$ with the longest experience, $\underline{X}^{2}(2)=5.9, \underline{p}=.05$. Eighty-three percent of those having the longest experience and $80 \%$ of those having 6 to 11 years considered themselves having adequate knowledge to supervise students during fieldwork as opposed to $47 \%$ of those having the least experience, $\underline{X}^{2}(2)=8.6, \underline{p}=.01$.

Concerning these professional issues by country of education, only one significant difference was found. Fifty percent of those that were educated in the U.S.A. and Canada $(\underline{\mathrm{n}}=6)$ had published articles in foreign journals within the last five years, compared to only $11 \%$ of those who were educated in the Nordic countries $(\underline{\mathrm{n}}=68), \underline{\mathrm{X}}^{2}(2)=8.5, \underline{\mathrm{p}}=.02$. None of whom were educated in the remaining countries $(\underline{n}=6)$ had published in foreign journals.

\section{Attitudes Toward Professional Commitment and Concerns}

Attitudes toward professional issues are shown in Table 3 as professional commitment and Table 4 as professional concerns. The number of subjects that responded to the questions are listed as well as means and percents of subjects selecting different options on the Likert scale. The respondents were willing to commit extra time for the advancement of the Occupational Therapy Association $(\underline{\mathrm{M}}=4.1) ; 79 \%$ answered that the statement described them "rather well" or "very well" (see Table 3). A majority felt that they had been taught the importance of life-long learning in school $(\underline{\mathrm{M}}=3.5) ; 59 \%$ responded "rather well" or "very well" and that they were quite active in the Occupational Therapy Association $(\underline{M}=3.3)$. When asked whether they could imagine themselves doing something other than occupational therapy in the future $(\underline{M}=3.0)$, 
Table 3

Means and Percentages Regarding Therapists' Attitudes Toward

Professional Commitment

Professional commitment

$\%$

$\begin{array}{lllllll}\underline{\mathrm{n}} & \underline{\mathrm{M}} & 1 & 2 & 3 & 4 & 5\end{array}$

I am prepared to commit extra

$80 \quad 4.1$

$\begin{array}{lllll}0 & 1 & 20 & 48 & 31\end{array}$

time for the advancement

of the OT Association

I am satisfied with my contribution

$\begin{array}{lllllll}79 & 4.0 & 0 & 5 & 12 & 63 & 20\end{array}$

to health care delivery as an OT

I was taught in school the

$80 \quad 3.5$

$\begin{array}{lllll}1 & 20 & 20 & 40 & 19\end{array}$

importance of life-long learning

I am actively involved in the

$\begin{array}{ll}79 & 3.3\end{array}$

$\begin{array}{lllll}11 & 14 & 20 & 41 & 14\end{array}$

OT Association

I can imagine myself doing

$\begin{array}{ll}78 & 3.0\end{array}$

$\begin{array}{lllll}10 & 26 & 36 & 13 & 15\end{array}$

something other than $\mathrm{OT}$ in the future

I feel that I have influence upon

$79 \quad 3.0$

$\begin{array}{lllll}15 & 13 & 33 & 32 & 7\end{array}$

the development of the OT profession

I am usually engaged in a committee

$\begin{array}{ll}78 & 2.6\end{array}$

$\begin{array}{lllll}37 & 19 & 12 & 13 & 19\end{array}$

within the OT Association

I do not participate in interest- groups

$\begin{array}{lllllll}79 & 2.6 & 24 & 31 & 20 & 10 & 15\end{array}$ in the OT Association

I feel that I am a professional

$79 \quad 2.5$

$\begin{array}{lllll}37 & 21 & 27 & 10 & 5\end{array}$ leader in the field of OT

Note. Options were: $1=$ not at all, 2 = rather poorly, $3=$ some, $4=$ rather well, 5 = very well. 
$26 \%$ responded "rather poorly" and $36 \%$ "some" to this statement.

Nevertheless, the majority were satisfied with their contributions to health care delivery $(\underline{\mathrm{M}}=4.0)$ and felt that they had somewhat influenced the development of the occupational therapy profession $(\underline{M}=3.0)$, although they did not consider themselves as leaders in the field $(\underline{M}=2.5)$.

Significant differences regarding professional commitment. T-tests showed significant differences regarding professional commitment by education on three statements. The first one was "I feel that I am a professional leader in the field of occupational therapy." Therapists holding a BS or MS, as well as those studying for MS ( $\underline{M}=2.8)$, agreed significantly more than therapists holding a diploma $(\underline{\mathrm{M}}=2.0), \underline{\mathrm{t}}(77)=3.11, \underline{\mathrm{p}}=.003$. The second one was "I am satisfied with my contribution to health care delivery as an occupational therapist." Therapists holding a BS or MS, as well as those studying for MS $(\underline{M}=4.2)$, agreed significantly more than therapists holding a diploma $(\underline{\mathrm{M}}=3.9), \underline{\mathrm{t}}(77)=2.16, \underline{\mathrm{p}}=.034$. The third one was "I am prepared to commit extra time for the advancement of the Occupational Therapy Association.” Therapists holding a BS or MS, as well as those studying for MS ( $\underline{\mathrm{M}}=4.4)$, agreed significantly more than therapists holding a diploma $(\underline{\mathrm{M}}=3.9), \underline{\mathrm{t}}(78)=2.60, \underline{\mathrm{p}}=.011$.

Analyses of variance showed significant differences regarding professional commitment by experience on two statements.

The first one was "I feel that I have influenced upon the development of the occupational therapy profession," $\underline{\mathrm{F}}(2,70)=11.50, \mathrm{p}<.001$. The most experienced therapists $(\underline{\mathrm{M}}=3.6)$ agreed significantly more than those with 6 to 11 years of experience $(\underline{M}=3.0)$ and more than those that had less than six years experience $(\underline{M}=2.2)$. There was also a significant difference between those with 6 to 11 years of experience and those that had less than six years experience. The second one was "I feel that I am a professional 
leader in the field of occupational therapy," $\underline{\mathrm{F}}(2,70)=5.79, \underline{\mathrm{p}}=.005$. The most experienced therapists agreed significantly more $(\underline{M}=2.9)$ than those with 6 to 11 years of experience $(\underline{M}=1.9)$ and those that had less than six years experience $(\underline{\mathrm{M}}=2.1)$.

Regarding professional concerns shown in Table 4, the respondents agreed that the prospects of occupational therapy in the future were positive $(\underline{\mathrm{M}}=4.4) ; 53 \%$ "strongly agreed." Their opinion was that the profession should aim to become autonomous in certain areas $(\underline{M}=4.0) ; 42 \%$ "strongly agreed" and that its services should be covered by social security $(\underline{M}=4.0)$; $38 \%$ of the respondents "strongly agreed." They found their colleagues competent in practice $(\underline{\mathrm{M}}=4.0) ; 73 \%$ "mildly agreed," but were neutral regarding differences between therapists educated in different countries $(\underline{M}=3.0) ; 35 \%$ chose "neutral." Fifty percent strongly disagreed $(\underline{M}=1.7)$ that the profession was becoming specialty based with no common generic philosophy to unite it; $42 \%$ strongly disagreed $(\underline{M}=2.0)$ that therapists should always have referrals from physicians. They also felt that the profession did not need to maintain the current relationship with the medical profession as a subordinate helping profession $(\underline{\mathrm{M}}=1.8) ; 42 \%$ "strongly disagreed" and the respondents did not find it difficult to convince others of the value of occupational therapy $(\underline{\mathrm{M}}=2.5)$.

Significant differences regarding professional concerns. There was a significant difference regarding professional concerns by professional experience, $\underline{\mathrm{F}}(2,69)=3.82, \underline{\mathrm{p}}=.027$ and country of education, $\underline{\mathrm{F}}(2,74)=4.15$, $\underline{p}=.020$ on the following statement, "I find there is a difference between therapists educated in different countries." Therapists with 6 to 11 years experience $(\underline{M}=3.3)$ agreed significantly more to the statement than those with the longest experience $(\underline{M}=2.6)$. Therapists educated in the Nordic countries $(\underline{M}=3.0)$ and the six subjects educated in the U.S.A. and in 
Table 4

Means and Percentages Regarding Attitudes Toward Professional

Concerns

Professional concerns

$\%$

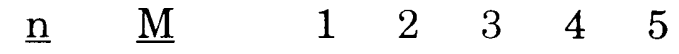

I feel that the prospects for OT

$\begin{array}{lllllll}78 & 4.4 & 0 & 3 & 6 & 38 & 53\end{array}$

in the future are positive

$\begin{array}{llllllll}\text { In my opinion, OTs should aim toward } & 78 & 4.0 & 1 & 1 & 17 & 39 & 42\end{array}$ becoming an autonomous profession

in certain areas to meet the

health care demands of the patients

In my opinion, OT services should

78

4.0

$\begin{array}{lllll}3 & 12 & 10 & 37 & 38\end{array}$

always be covered by social security

I feel that most OTs are competent in

78

4.0

$0 \quad 1$

$\begin{array}{lll}12 & 73 & 14\end{array}$ the practice of OT

I find that there is a difference

$77 \quad 3.0$

$\begin{array}{lllll}5 & 29 & 35 & 26 & 5\end{array}$

in practice between therapists

educated in different countries

I find it difficult to convince others

78

2.5

$10 \quad 55$

$\begin{array}{lll}15 & 17 & 3\end{array}$

of the value of OT

I think that OTs should always have

$78 \quad 2.0$

$\begin{array}{lllll}42 & 31 & 21 & 5 & 1\end{array}$

referrals from physicians

$\begin{array}{llllllll}\text { I feel that OTs should maintain their } & 77 & 1.8 & 42 & 39 & 18 & 1 & 0\end{array}$ relationship with the medical profession as a subordinate, helping profession

$\begin{array}{lllllllll}\text { I feel that OT is becoming a specialty } & 78 & 1.7 & 50 & 35 & 14 & 1 & 0\end{array}$ based profession with no common generic philosophy to unite it

Note: Options were: 1 = strongly disagree, 2 = mildly disagree, $3=$ neutral, $4=$ mildly agree, $5=$ strongly agree. 
Canada $(\underline{\mathrm{M}}=3.5)$ agreed more strongly than those six educated outside these countries $(\underline{\mathrm{M}}=2.0)$.

\section{Attitudes Regarding Educational Goals}

This section addresses research questions two and three on attitudes toward educational goals in general and differences among the independent variables. The attitudes were measured on a Likert scale from 1 to 5 . Respondents ranked preparation for practice from: $1=$ none, $2=$ poor, 3 = fair, 4 = good, 5 = excellent. Respondents ranked emphasis in the occupational therapy curriculum: 1 = none, 2 = very little, $3=$ average, $4=$ much, $5=$ very much and change needed in the profession from: $1=$ none, 2 = little, 3 = some, $4=$ much, $5=$ very much. Responding to statements concerning educational goals, the respondents indicated if they: 1 = strongly disagreed, $2=$ mildly disagreed, $3=$ were neutral, $4=$ mildly agreed, or $5=$ strongly agreed. Means and percentages were given on how the respondents answered on the Likert scales.

Finally, the respondents chose among 13 issues what they considered to be the five most important issues for the occupational therapy profession and the results are shown as percentages according to their importance. These items were ranged from 1 (lowest among the chosen five) to 5 (highest among the chosen five). T-tests and one-way ANOVAs were used when comparing mean differences between groups.

\section{Preparation for Practice}

Evaluation of how well education had prepared Icelandic occupational therapists for practice is shown in Table 5. The subjects ranked highest that their education had stimulated personal growth $(\underline{M}=3.9$ ). Ranked second was how their education had prepared them for using occupational therapy techniques $(\underline{\mathrm{M}}=3.7)$ and aspects of 
Table 5

Means and Percentages Regarding Attitudes Toward Preparation for

Occupational Therapy Practice

Preparation to practice

$\underline{\%}$

\begin{tabular}{llllllll} 
& $\underline{\mathrm{n}}$ & $\underline{\mathrm{M}}$ & 1 & 2 & 3 & 4 & 5 \\
\hline Personal development & 79 & 3.9 & 0 & 5 & 24 & 48 & 23 \\
Occupational therapy technique & 80 & 3.7 & 0 & 5 & 32 & 49 & 14 \\
Professionalization & 80 & 3.7 & 0 & 7 & 35 & 41 & 17 \\
Critical thinking & 80 & 3.6 & 0 & 9 & 37 & 39 & 15 \\
Clinical judgment & 80 & 3.6 & 1 & 9 & 31 & 48 & 11 \\
Occupational therapy theory & 80 & 3.4 & 1 & 21 & 30 & 31 & 17 \\
Reasoning & 78 & 3.0 & 0 & 24 & 48 & 26 & 2 \\
Basic science & 79 & 2.6 & 11 & 38 & 32 & 18 & 1 \\
Research & 80 & 2.3 & 21 & 33 & 40 & 6 & 0 \\
Management & 80 & 2.3 & 23 & 41 & 26 & 9 & 1 \\
\hline
\end{tabular}

Note. Options were: $1=$ none, $2=$ poor, $3=$ fair, $4=$ good, $5=$ excellent.

professionalization $(\underline{\mathrm{M}}=3.7)$. They considered themselves adequately prepared in critical thinking $(\underline{M}=3.6)$ and clinical judgment $(\underline{M}=3.6)$, but judged preparation in occupational therapy theory $(\underline{M}=3.4)$ and reasoning $(\underline{M}=3.0)$ no more than fair. Preparation for research $(\underline{M}=2.3)$, basic science $(\underline{M}=2.6)$ and management $(\underline{M}=2.3)$ were considered "poor" to "fair."

Significant differences. There were significant differences regarding preparation for management by education. The 25 therapists holding a BS or MS, as well as those studying for a MS, felt they were better prepared in management $(\underline{\mathrm{M}}=2.6)$ than those holding a diploma $(\underline{\mathrm{M}}=2.1)$, 
$\underline{\mathrm{t}}(78)=2.29, \underline{\mathrm{p}}=.025$.

There were significant differences regarding preparation for basic science, research and reasoning by experience. Therapists with the least experience felt they were better prepared in basic science $(\underline{M}=3.1)$ than those with longest experience $(\underline{\mathrm{M}}=2.3), \underline{\mathrm{F}}(2,70)=4.08, \underline{\mathrm{p}}=.021$. Those with the longest experience were significantly less prepared for research $(\underline{M}=$ 2.0) than those with experience from 6 to 11 years $(\underline{M}=2.5)$ and 0 to 5 years $(\underline{\mathrm{M}}=2.6), \underline{\mathrm{F}}(2,71)=4.53, \underline{\mathrm{p}}=.014$. Those with the longest experience were significantly less prepared for reasoning $(\underline{M}=2.8)$ than those with experience from 6 to 11 years $(\underline{\mathrm{M}}=3.3)$ and 0 to 5 years $(\underline{\mathrm{M}}=3.5), \underline{\mathrm{F}}(2,71)=$ $6.83, \underline{p}=.002$.

There were also significant differences concerning preparation for basic science, occupational therapy theory and management by country of education. The six therapists that were educated in the U.S.A. and Canada were significantly better prepared in basic science $(\underline{M}=4.0)$ than those educated in the Nordic countries $(\underline{\mathrm{M}}=2.5)$ and other countries $(\underline{\mathrm{M}}=2.2)$, $\underline{\mathrm{F}}(2,76)=8.88, \underline{\mathrm{p}}<.001$. Concerning preparation for occupational therapy theory, those who were educated in the U.S.A. and Canada were significantly better prepared $(\underline{\mathrm{M}}=4.5)$ than those educated in the Nordic countries $(\underline{\mathrm{M}}=3.3)$ and other countries $(\underline{\mathrm{M}}=3.0), \underline{\mathrm{F}}(2,77)=4.26, \underline{\mathrm{p}}=.018$. Regarding preparation for management, those who were educated in the U.S.A. and Canada were significantly better prepared $(\underline{\mathrm{M}}=3.7)$ than those educated in the Nordic countries $(\underline{\mathrm{M}}=2.2)$ and other countries $(\underline{\mathrm{M}}=2.0), \underline{\mathrm{F}}$ $(2,77)=8.74, \underline{\mathrm{p}}<.001$.

\section{Emphasis in Areas of Education}

The respondents' preferences regarding emphasis in education are shown in Table 6. They wanted the most emphasis on analytical skills $(\underline{M}=4.5) ; 59 \%$ chose "very much" and with secondary emphasis on 
Table 6

Means and Percentages Regarding Attitudes Toward Emphasis in

Occupational Therapy Education

Emphasized areas

$\%$

\begin{tabular}{lccccccc} 
& $\underline{\mathrm{n}}$ & $\underline{\mathrm{M}}$ & 1 & 2 & 3 & 4 & 5 \\
\hline Analytical skills & 79 & 4.5 & 0 & 0 & 9 & 32 & 59 \\
Theoretical knowledge & 79 & 4.5 & 0 & 1 & 5 & 39 & 55 \\
Research and analysis methods & 79 & 4.1 & 0 & 0 & 18 & 49 & 33 \\
Field work & 78 & 4.1 & 0 & 0 & 22 & 46 & 32 \\
Personal growth & 79 & 4.1 & 1 & 0 & 17 & 57 & 25 \\
Abstract ideas & 78 & 3.9 & 0 & 2 & 21 & 60 & 17 \\
Professional commitment & 77 & 3.8 & 3 & 0 & 35 & 36 & 26 \\
Experience in conducting research & 79 & 3.7 & 0 & 3 & 35 & 51 & 11 \\
Practical skills & 78 & 3.6 & 0 & 8 & 42 & 36 & 14 \\
Technical skills & 76 & 3.4 & 0 & 9 & 47 & 36 & 8 \\
Concrete principles & 73 & 3.3 & 0 & 12 & 48 & 33 & 7 \\
& & & & & & & \\
\hline
\end{tabular}

Note. Options were: $1=$ none, $2=$ very little, $3=$ average, $4=$ much, 5 = very much.

theoretical knowledge $(\underline{\mathrm{M}}=4.5), 55 \%$ chose "very much." Also highly regarded were research and analysis methods $(\underline{M}=4.1) ; 33 \%$ selected "very much," fieldwork $(\underline{M}=4.1) ; 32 \%$ selected "very much" and personal growth ( $\underline{\mathrm{M}}=4.1) ; 25 \%$ selected "very much." Ranked next was importance of abstract ideas $(\underline{M}=3.9)$, professional commitment $(\underline{M}=3.8)$ and experience in conducting research $(\underline{M}=3.7)$. The subjects had a rather neutral opinion concerning concrete principles $(\underline{\mathrm{M}}=3.3)$, technical skills $(\underline{\mathrm{M}}=3.4)$ and 
practical skills $(\underline{\mathrm{M}}=3.6)$.

Significant differences. There were significant differences regarding preferences of emphasis in areas of education by education level.

Therapists holding a BS or MS and MS students wanted significantly more emphasis on experience in conducting research $(\underline{M}=4.0)$ than those with a diploma $(\underline{\mathrm{M}}=3.6), \underline{\mathrm{t}}(77)=2.14, \underline{\mathrm{p}}=.036$. There were also significant differences regarding emphasis on analytical skills by experience.

Therapists with the longest experience $(\underline{\mathrm{M}}=4.8)$ wanted significantly more emphasis on analytical skills than those having experience 6 to 11 years $(\underline{\mathrm{M}}=4.4)$ and those with 0 to 5 years $(\underline{\mathrm{M}}=4.4), \underline{\mathrm{F}}(2,71)=3.74, \underline{\mathrm{p}}=.029$. Therapists with the longest experience valued personal growth $(\underline{\mathrm{M}}=4.3)$ significantly more than those with 6 to 11 years of experience $(\underline{\mathrm{M}}=3.8)$, $\underline{\mathrm{F}}(2,71)=3.44, \underline{\mathrm{p}}=.038$.

Preferences Regarding Changes in the Occupational Therapy Practice

The results revealed that the Icelandic occupational therapists feel that most change is needed regarding recognition by other health professionals $(\underline{\mathrm{M}}=4.5) ; 54 \%$ selected "very much" (see Table 7). Ranked second was the need for more research $(\underline{\mathrm{M}}=4.4) ; 53 \%$ selected "very much" and ranked third was the need for definite evidence of the effects of their services $(\underline{M}=4.4)$ with $39 \%$ choosing "very much." Recognition from social security came third $(\underline{\mathrm{M}}=4.2) ; 66 \%$ chose "very much" and next came the general public's recognition of the value of their service $(\underline{\mathrm{M}}=4.1) ; 41 \%$ chose "very much" and closely following behind was education $(\underline{\mathrm{M}}=4.1)$, $32 \%$ selected "very much," clear definition of occupational therapy service $(\underline{\mathrm{M}}=4.0) ; 27 \%$ "very much" and the process of service delivery $(\underline{\mathrm{M}}=3.8)$; with $21 \%$ stating "very much." When considering increasing use of complex techniques the respondents took a rather neutral stand $(\underline{\mathrm{M}}=2.7)$; $45 \%$ rated "some" and regarding development of technology $(\underline{M}=2.9), 48 \%$ 
Table 7

Means and Percentages Regarding Attitudes Toward Change in the Occupational Therapy Practice

Change needed in OT practice

$\%$

$\begin{array}{lllllll}\underline{\mathrm{n}} & \underline{\mathrm{M}} & 1 & 2 & 3 & 4 & 5\end{array}$

Recognition of the value of our service

$79 \quad 4.5$

$\begin{array}{lllll}0 & 3 & 14 & 29 & 54\end{array}$

by other health professionals

Research for practice

79

4.4

$\begin{array}{lllll}0 & 1 & 12 & 34 & 53\end{array}$

Definite evidence of the effects

$79 \quad 4.4$

$\begin{array}{lllll}0 & 3 & 20 & 38 & 39\end{array}$

of our service

Recognition of the value of our service

$79 \quad 4.2$

$\begin{array}{lllll}0 & 1 & 10 & 23 & 66\end{array}$ by social security

Recognition of the value of our service

79

4.1

$\begin{array}{llll}0 & 0 & 18 & 41\end{array}$

78

4.1

$\begin{array}{lllll}0 & 2 & 21 & 45 & 32\end{array}$

Clear definition of occupational

$77 \quad 4.0$

$\begin{array}{ll}1 & 8\end{array}$

therapy service

Process of service delivery

$\begin{array}{ll}76 & 3.8\end{array}$

$\begin{array}{lllll}0 & 3 & 33 & 43 & 21\end{array}$

Development of technology

$79 \quad 2.9$

$\begin{array}{lllll}3 & 27 & 48 & 20 & 2\end{array}$

Increase in use of complex techniques

$\begin{array}{ll}76 & 2.7\end{array}$

$\begin{array}{lllll}12 & 28 & 45 & 13 & 2\end{array}$

Note. Options were: $1=$ none, $2=$ little, $3=$ some, $4=$ much, $5=$ very much. 
rated "some."

Significant difference. There was a significant difference regarding the issue "definite evidence of the effect of our service" by country of education. The six therapists who were educated in other countries $(\underline{M}=5.0)$ wanted significantly more change in that area than those educated in the U.S.A and Canada $(\underline{\mathrm{M}}=4.0)$ and those educated in the Nordic countries $(\underline{\mathrm{M}}=4.1), \underline{\mathrm{F}}(2,76)=3.78, \underline{\mathrm{p}}=.027$.

Attitudes Toward Scope of Practice

The results revealed that $68 \%$ of the respondents "strongly agreed" that directed and purposeful activity, meaningful to the patient, ought to be the unique base of occupational therapy $(\underline{\mathrm{M}}=4.6)$ and $64 \%$ "strongly agreed" that the profession should be more active in promoting health and well being $(\underline{\mathrm{M}}=4.6)$ (see Table 8$)$. Furthermore, $54 \%$ "strongly agreed" that occupational therapy was a consciously planned progressive program of rest, play, occupation and exercise $(\underline{\mathrm{M}}=4.4)$ and $47 \%$ "mildly agreed" that occupational therapists should specialize within a certain population $(\underline{M}=3.6)$. Fifty-two percent "mildly agreed" that occupational therapists rely more on technique than theory $(\underline{\mathrm{M}}=3.5)$.

Significant differences. There was a significant difference regarding the statement, "I think that occupational therapists should develop treatment plans based on established frames of references" by education. The 24 therapists holding a BS or MS and the MS students agreed significantly more strongly $(\underline{\mathrm{M}}=4.3)$ than those holding a diploma $(\underline{\mathrm{M}}=3.8), \underline{\mathrm{t}}(76)=2.25, \underline{\mathrm{p}}=.028$.

\section{Attitudes Toward Educational Issues}

Table 9 presents educational concerns. Fifty-one percent "mildly agreed" and 35\% "strongly agreed" that development of a professional body of knowledge, unique to occupational therapy, was an important goal 
Table 8

Means and Percentages Regarding Attitudes Toward Scope of Practice

Scope of practice

$\%$

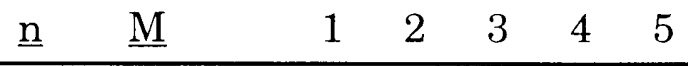

I think the unique base of OT is

$79 \quad 4.6$

$\begin{array}{lllll}1 & 0 & 1 & 30 & 68\end{array}$

directed and purposeful activity

meaningful to the patient

I feel that OTs should be more active

$\begin{array}{lllllll}78 & 4.6 & 0 & 0 & 3 & 33 & 64\end{array}$

in promoting health and well being

In my opinion, OT is a consciously

$79 \quad 4.4$

$\begin{array}{lllll}1 & 4 & 3 & 38 & 54\end{array}$

planned progressive program of rest,

play, occupation and exercise

I think OTs should develop treatment

$\begin{array}{ll}78 & 3.9\end{array}$

$\begin{array}{lllll}1 & 5 & 19 & 49 & 26\end{array}$

plans based on established

frames of references

In my opinion, OTs should specialize

$79 \quad 3.6$

$\begin{array}{llll}0 & 9 & 33 & 47\end{array}$

$77 \quad 3.5$

$\begin{array}{lllll}3 & 11 & 29 & 52 & 5\end{array}$

In my experience, OTs rely

more on technique than theory

Note. Options were: $1=$ strongly disagree, $2=$ mildly disagree, $3=$ neutral, $4=$ mildly agree, $5=$ strongly agree. 
Table 9

Means and Percentages Regarding Attitudes Toward Educational

Concerns

Educational concerns

$\%$

\begin{tabular}{lllllll}
$\underline{\mathrm{n}}$ & $\underline{\mathrm{M}}$ & 1 & 2 & 3 & 4 & 5 \\
\hline
\end{tabular}

I think that the development of a

$\begin{array}{lllllll}77 & 4.2 & 0 & 0 & 14 & 51 & 35\end{array}$

professional body of knowledge,

which is unique to OT, is an important

goal to achieve for the profession

I think that the Icelandic OT

$\begin{array}{lllllll}78 & 4.0 & 1 & 5 & 21 & 37 & 36\end{array}$

curriculum should emphasize the

study of philosophy and ethics to

aid the development of reasoning skills

In my opinion, emphasis on reasoning $\quad \begin{array}{llllllll}77 & 4.0 & 0 & 4 & 22 & 40 & 34\end{array}$ skills in the Icelandic OT curriculum

will impart significant improvements

in the quality of treatment

I feel that OT needs more research

$\begin{array}{lllllll}78 & 4.0 & 1 & 3 & 15 & 51 & 30\end{array}$

in order to validate practice

I think OT education needs to develop

78

a greater and clearer defined theoretical structure for the practice of OT

I feel that OT is less stimulating

$\begin{array}{lllllll}77 & 1.9 & 43 & 30 & 19 & 5 & 3\end{array}$

intellectually than I anticipated

I feel that OT is more of

$78 \quad 1.9$

$\begin{array}{lllll}42 & 31 & 21 & 5 & 1\end{array}$

an art than a science

Note. Options were: 1 = strongly disagree, $2=$ mildly disagree, $3=$ neutral, $4=$ mildly agree, $5=$ strongly agree. 
$(\underline{M}=4.2)$. Emphasis should also be on philosophy and ethics in the Icelandic occupational therapy curriculum to aid the development of reasoning skills to improve quality of treatment $(\underline{M}=4.0$ ). Fifty-one percent "mildly agreed" and 30\% "strongly agreed" that the profession needed more research in order to validate practice $(\mathrm{M}=4.0)$. Icelandic occupational therapists disagreed with the statements, "I feel that occupational therapy is more of an art than a science" $(M=1.9)$ and "I feel that occupational therapy is less stimulating than I anticipated" $\underline{\mathrm{M}}=1.9$ ).

Significant differences. A significant difference regarding educational concerns by education was found on the following statement: "I think that the Icelandic occupational therapy curriculum should emphasize the study of philosophy and ethics to aid the development of reasoning skills." Therapists holding a BS or MS and MS students agreed significantly more strongly $(\underline{\mathrm{M}}=4.4)$ than those holding a diploma $(\underline{\mathrm{M}}=$ $3.9), \underline{\mathrm{t}}(76)=2.32, \underline{\mathrm{p}}=.023$. Significant differences were also found regarding educational concerns by experience on two statements. The first one was, "I think that the development of a professional body of knowledge, which is unique to occupational therapy, is an important goal to achieve for the profession," $\underline{\mathrm{E}}(2,69)=4.02, \mathrm{p}=.022$. The therapists with the longest experience agreed significantly more strongly $(\underline{M}=4.5)$ than those with the least experiences $(\underline{M}=3.9)$. The second one was, "In my opinion, emphasis on reasoning skills in the Icelandic occupational therapy curriculum will impart significant improvements in the quality of treatment," $\underline{F}(2,70)=$ $7.11, \underline{p}=.002$. Therapists with the longest experience agreed significantly more strongly $(\underline{\mathrm{M}}=4.5)$ than those with the least experiences $(\underline{\mathrm{M}}=3.7)$. Those with 6 to 11 years of experience $(\underline{\mathrm{M}}=3.8)$ agreed significantly more strongly than those with the least experience $(\underline{\mathrm{M}}=3.7)$. 
Important Issues for the Occupational Therapy Profession

Table 10 displays that "theories explaining occupation in human beings" were chosen as most important (5) by twenty-eight (38\%) of the respondents $(\underline{\mathrm{M}}=3.5)$. Twenty $(27 \%)$ ranked "the role and mission of occupational therapy in health care" as the most important issue $(\underline{\mathrm{M}}=2.8)$, and third was "principles outlining the relationship of occupation to health" $(\underline{\mathrm{M}}=2.1)$, eleven $(15 \%)$ chose this issue as most important. "Specific treatment techniques" $\underline{\underline{M}}=0.4)$, "classification of diseases" $(\underline{\mathrm{M}}=0.2)$ and "history of occupational therapy" $(\underline{\mathrm{M}}=0.2)$ came last.

Significant differences. A significant difference was found concerning importance to the profession by experience. Therapists with experience 6 to 11 years $(\underline{\mathrm{M}}=2.5)$ and those with 12 years or more $(\underline{\mathrm{M}}=2.5)$ rated the issue "principles outlining the relationship of occupation to health" higher than those with less than six years of experience $(\underline{\mathrm{M}}=1.1), \underline{\mathrm{F}}$ $(2,66)=3.64, \underline{p}=.032$.

\section{Summary of Significant Differences Between Groups}

BS/MS therapists and MS students. BS/MS therapists and MS students read occupational therapy journals more frequently, published articles more often in journals other than occupational therapy journals, held presentations more often at international conferences, and participated more often at international seminars than therapists holding a diploma. They also considered themselves having adequate knowledge to supervise occupational therapy students, conduct research and teach in the occupational therapy undergraduate program while therapists holding a diploma evaluated themselves less capable in these fields. The BS/MS therapists and MS students were more interested in teaching in the Icelandic curriculum with or without supervision from a faculty member.

Table 11 displays that BS/MS therapists and MS students considered 
Table 10

Means and Percentages of Respondents' Choices for Important Issues for the Occupational Therapy Profession $(n=73)$

Importance for the OT profession

$\%$

M $\quad 1 \quad 2 \quad 2 \quad 3 \quad 4 \quad 5$

$\begin{array}{llllllll}\text { Theories explaining occupation in human beings } & 3.5 & 1 & 6 & 14 & 26 & 38\end{array}$

The role and mission of occupational therapy

$\begin{array}{llllll}2.8 & 8 & 15 & 15 & 15 & 27\end{array}$

Principles outlining the relationship of

$\begin{array}{llllll}2.1 & 7 & 9 & 9 & 21 & 15\end{array}$ occupation to health

Procedures for administering specific evaluations

$\begin{array}{llllll}1.2 & 11 & 16 & 4 & 14 & 1\end{array}$

Research comparing effectiveness of

$\begin{array}{llllll}1.2 & 11 & 14 & 18 & 4 & 1\end{array}$ different treatments in health care

Techniques of patient interaction

$\begin{array}{llllll}0.9 & 7 & 8 & 8 & 3 & 5\end{array}$

$\begin{array}{llllllll}\text { Program documentation skills (e.g., note writing) } & 0.6 & 19 & 8 & 4 & 1 & 1\end{array}$

Structure and function of the nervous-

$\begin{array}{llllll}0.5 & 3 & 4 & 4 & 4 & 3\end{array}$ and musculoskeletal system

Political and social contexts of health care delivery $\begin{array}{lllllll}0.5 & 7 & 5 & 5 & 4 & 0\end{array}$

Principles of supervision and administration $\quad \begin{array}{llllllll}0.5 & 14 & 7 & 7 & 0 & 0\end{array}$

Specific treatment techniques

$\begin{array}{llllll}0.4 & 9 & 7 & 4 & 0 & 1\end{array}$

History of occupational therapy

$\begin{array}{llllll}0.3 & 5 & 4 & 3 & 1 & 1\end{array}$

Classification of diseases

$\begin{array}{llllll}0.2 & 3 & 0 & 3 & 3 & 0\end{array}$

Note: The respondents chose among issues they considered to be the five most important issues for the occupational therapy profession and percentages are shown according to ranking of the issues, from 1 (lowest) to 5 (highest). 
Table 11

Significant Differences on Attitudes by Educational Level

Content area

Educational Level

BS/MS Diploma

$(\underline{\mathrm{n}}=25) \quad(\underline{\mathrm{n}}=55)$

$\underline{M} \quad \underline{M} \quad \underline{t} \quad \underline{p}$

Professionalism

I feel that I am a professional

$\begin{array}{llll}2.8 & 2.0 & 3.11 & .003\end{array}$

leader in the field of OT

I am satisfied with my contribution

4.2

3.9

2.16

.034

to health care delivery as an OT

I am prepared to commit extra time for

4.4

3.9

2.60

.011

the advancement of the OT association

Educational Goals

OT should develop treatment plans

4.3

3.8

2.25

.028

based on established frames of references

I think that the Icelandic OT

4.4

3.9

2.32

.023

curriculum should emphasize the study

of philosophy and ethics to aid the

development of reasoning skills

Preparation for practice

Management

2.6

2.1

2.29

.025

Emphasize in practice

Experience in conducting research

4.0

3.6

2.14

.036 
themselves being adequate leaders in the field, were satisfied with their contribution to health care and were prepared to commit substantial time for the advancement of the profession, while therapists holding a diploma reported less capabilities and interest in these issues. They also scored higher concerning preparation for management, necessity for more emphasis on occupational therapy students' experience in conducting research, necessity for the development of treatment plans based on established frames of references and that the Icelandic curriculum should emphasize the study of philosophy and ethics to aid the development of reasoning skills.

Professional experience. Therapists with a professional experience of 12 years or longer read occupational therapy journals most frequently, published more in journals other than occupational therapy journals, conducted workshops for occupational therapists more frequently, held presentations at conferences more frequently, participated more in workshops, domestic seminars and international seminars. Most of the experienced therapists considered themselves having sufficient knowledge to supervise students during fieldwork while fewer of the less experienced therapists evaluated themselves as having the required knowledge. The most experienced therapists were least interested in taking a "bridging course." They felt that they had influenced considerably upon the development of their profession and considered themselves leaders while those with 0 to 5 and 6 to 11 years of experience evaluated themselves as having fewer skills regarding this area (see Table 12). The most experienced therapists scored highest regarding the profession's need for development of a unique body of knowledge and emphasis on reasoning skills in the Icelandic curriculum. They were least prepared for practice in basic science and reasoning skills. They found it most important to 
Table 12

Significant Differences on Attitudes by Length of Experience

\begin{tabular}{lccccc}
\hline Content area & Years of Experience & & \\
& $0-5$ & $6-11$ & $>12$ & & \\
& $(\underline{\mathrm{n}}=19)$ & $(\underline{\mathrm{n}}=25)$ & $(\underline{\mathrm{n}}=30)$ & & \\
& $\underline{\mathrm{M}}$ & $\underline{\mathrm{M}}$ & $\underline{\mathrm{M}}$ & $\underline{\mathrm{F}}$ & $\underline{\mathrm{p}}$ \\
\hline
\end{tabular}

Professionalism

I feel that I have influence upon the

$\begin{array}{lllll}2.2 & 3.0 & 3.6 & 11.50 & .001\end{array}$

development of the OT profession

I feel that I am a professional leader

in the field of OT

I find there is a difference between

$\begin{array}{lll}3.1 & 3.3 & 2.6\end{array}$

$3.82 \quad .027$

therapists educated in different countries

Educational goals

I think that the development

$\begin{array}{lll}2.1 & 1.9 & 2.9\end{array}$

$5.79 \quad .005$

of a professional body of knowledge,

$\begin{array}{lllll}3.9 & 4.2 & 4.5 & 4.02 & .002\end{array}$

which is unique to OT, is an

important goal to

achieve for the profession

In my opinion, emphasis on reasoning

$\begin{array}{lll}3.7 & 3.8 & 4.5\end{array}$

$7.11 \quad .002$

skills in the Icelandic OT curriculum

will impart significant improvements

in the quality of treatment

Preparation for practice

Basic science

$\begin{array}{lllll}3.1 & 2.7 & 2.3 & 4.08 & .021\end{array}$

Research

$\begin{array}{lll}2.6 & 2.5 & 2.0\end{array}$

$4.53 \quad .014$

Reasoning

$\begin{array}{lllll}3.5 & 3.3 & 2.8 & 6.83 & .002\end{array}$

Emphasize in practice

Analytical skills

$\begin{array}{lll}4.4 & 4.4 & 4.8\end{array}$

Personal growth

$\begin{array}{lllll}4.2 & 3.8 & 4.3 & 3.44 & .038\end{array}$

Importance for the practice

Principles outlining the relationship

$\begin{array}{lllll}1.1 & 2.5 & 2.5 & 3.64 & .032\end{array}$

of occupation to health 
emphasize analytical skills and personal growth in the Icelandic curriculum.

Those with professional experience 6 to 11 years felt the least need for a "bridging course" to obtain a BS degree. They felt that they had adequate knowledge to supervise students during fieldwork, that they had influence upon the profession, and found teaching reasoning skills in the Icelandic curriculum more important than those with experience from 0 to 5 years. They felt more strongly that there was a difference between therapists educated in different countries than those with 12 years or more of experience.

Those with professional experience of 0 to 5 years were most interested in a "bridging course." In this group, there were more therapists who considered themselves as having knowledge to teach a course in the undergraduate curriculum than in the other two groups. However, fewer in this group felt that they had knowledge to supervise students during fieldwork than in the other groups. The least experienced therapists felt they were best prepared for basic science through their education and they considered "principles outlying the relationship of occupation to health" a less important issue for the profession than those with longer experience.

Country of education. Therapists educated in the U.S.A. and Canada published more in foreign journals than therapists educated in other countries. Table 13 shows that those that were educated in the U.S.A. and Canada and those educated in Scandinavia believed that there was a difference between therapists educated in different countries while those educated outside these countries did not believe this. Therapists educated in the U.S.A. and Canada also felt they were better prepared in basic science, occupational therapy theory and management than those therapists educated outside these two countries. Therapists educated elsewhere than 
Table 13

Significant Differences on Attitudes by Country of Education

\begin{tabular}{|c|c|c|c|c|}
\hline \multirow[t]{2}{*}{ Content area } & $\begin{array}{l}\text { Nordic } \\
\text { Countries } \\
\qquad(\underline{\mathrm{n}}=68)\end{array}$ & $\begin{array}{l}\text { USA/ } \\
\text { Canada } \\
(\underline{n}=6)\end{array}$ & $\begin{array}{l}\text { Other } \\
\text { Countries } \\
(\underline{n}=6)\end{array}$ & \\
\hline & $\underline{\mathrm{M}}$ & $\underline{M}$ & M & $\underline{p}$ \\
\hline
\end{tabular}

Professionalism

I find there is a difference between

$\begin{array}{lll}3.0 & 3.5 & 2.0\end{array}$

$2.74 \quad .020$

therapists educated in different countries

Preparation for practice

Basic science

$2.5 \quad 4.0 \quad 2.2$

$2.76 \quad .001$

Occupational therapy theory

$\begin{array}{lll}3.3 & 4.5 & 3.0\end{array}$

$2.77 \quad .018$

Management

$\begin{array}{lll}2.2 & 3.7 & 2.0\end{array}$

$2.77 \quad .001$

Change needed in practice

Definite evidence of the

$\begin{array}{lll}4.1 & 4.0 & 5.0\end{array}$

$\begin{array}{ll}2.76 & .027\end{array}$

effects of our service

the U.S.A., Canada and Scandinavia found change in the profession regarding definite evidence of the effects of occupational therapy services to be of greatest importance.

\section{Summary}

The results revealed that the typical Icelandic occupational therapist is a fairly young woman. Her experience in occupational therapy is around 11 years and she completed her education with a diploma in Denmark between 1981 and 1990. Her evaluation of how well education prepared her for practice ranks, personal growth, and therapy techniques highest. She works 36 to 40 hours a week together with other colleagues in medical hospitals or rehabilitation centers, treating a large variety of clients, mostly 
adults having physical disabilities. She reads occupational journals from Denmark or the U.S.A. once a month. She has written one article in the Icelandic journal during the past five years and participates yearly in national workshops and seminars.

The typical therapist is active in the occupational therapy association and is willing to take on duties for the advancement of occupational therapy. She thinks that there is a need for and is interested in participating in a bridging course to obtain a BS degree. She is interested in supervising students and conducting research in the field. She is satisfied with her work, optimistic concerning future perspective of the profession, wants the profession to become autonomous in certain areas and feels that occupational therapy services should be covered by social security. She values academic skills over technical ones, choosing analytical skills and theoretical knowledge as the most important educational issues for the Icelandic curriculum. Her suggestion for the most needed change in the profession is recognition by other health professionals. In her opinion, treatment should be based on occupational theory with emphasis on theories explaining occupation in human beings, philosophy, ethics, and research.

Icelandic occupational therapists showed a certain consistency regarding attitudes. However, t-tests and one-way ANOVAs revealed some significant differences, most often by professional experience, some by education level and a few by country of education. 


\section{CHAPTER V \\ Discussion \\ $\underline{\text { Research Questions }}$}

The Icelandic curriculum in occupational therapy was in its birth when this study emerged. The goal was to capture the main demographics of the Icelandic occupational therapists and their attitudes concerning professionalism and educational goals. The study further examined whether the educational level had an affect on their attitudes, as most of the therapists in Iceland hold diplomas and the new curriculum will provide a BS degree. Until now, Icelandic occupational therapists have studied abroad, the country of education was also of interest. Did different educational backgrounds affect their attitudes about professional issues? Furthermore, the study investigated whether professional experience influenced attitudes. The findings from this study are valuable for the profession at the present and can be used to monitor future changes.

The founders of the new curriculum in Iceland are emphasizing philosophy, occupational therapy theory, research methods and reasoning. During the last three years the Icelandic Occupational Therapy Association, along with the school committee, has made an extra effort to educate and update Icelandic practitioners regarding new theories and other developments in the profession. The results from this study also indicate the effect this campaign has had on the clinicians. If collaboration between the students and the clinicians is to succeed, they must not only respect each other, but also understand differences induced by alterations in education over time. If the occupational therapy students are to connect theory to practice during their fieldwork their clinicians' attitudes toward professional and educational issues are, therefore, of great concern.

With a response rate of $92 \%$, this study indicates that Icelandic 
occupational therapists are committed to their profession, welcoming new knowledge and responding to important issues for the profession. The results of the present study revealed that Icelandic occupational therapists want an academic curriculum with emphasis on research to validate practice. It shows that the Association has succeeded in preparing the practitioners for the new curriculum past all expectations. The majority of the clinicians are willing to take students in fieldwork and to participate in research. Those who have the skills are also willing to take on responsibilities and teach in the new curriculum. The Association and the faculty of the university now have great obligations to nurture these seeds of interest that they have implanted in the Icelandic therapists. The Association and the faculty of the university must provide opportunities for research with students as their collaborators. By establishing collaboration between the university and the clinics it should be possible to capture the current enthusiasm at the birth of the curriculum. The student and the practitioner can collaborate by contributing their skills in different areas. The clinicians have the experience and the knowledge of what is important and relevant to study at their workplace while the students can provide their skills in basic science and analysis methods.

Being such a young profession has both advantages and disadvantages. Being young makes anything possible and traditional barriers might often be overlooked or neglected, causing either positive or negative effects. New solutions can be achieved that might not have been discovered or obscured by traditional barriers and results can appear faster. However, enthusiastic occupational therapists could burn out easily, give up their efforts, or at worst leave the profession if their efforts are not recognized.

The data showed that among Icelandic occupational therapists there 
are individuals that consider themselves as leaders and show characteristics connected to professionalism. This applies mainly to the therapists with the longest experience. The resources of these founders of the Iceland profession should be utilized to stimulate leadership developments in the new generation of occupational therapists. A sponsorship should be built on a concept of intraprofessional and interprofessional support, as recommended by Rogers (1982). This support has been typically lacking in the female dominated professions. However, this alone will not be enough to solve the barriers connected to being a female dominated profession.

\section{Application of Theory}

\section{Professionalization}

According to Etzioni (1969), semi-professionals are characterized by the incompleteness of their knowledge base and weakness of their professional ideology. The practice of semi-professions does not have a unique theoretical base and theoretical knowledge. Technical skills of semiprofessionals are poorly defined. The period of training is relatively short, five years or less. Skills are more of a technical nature and there is a high rate of turnover among members and a lack of solidarity. The semiprofessions are often controlled by the established professions or bureaucracies. Special areas of competence are not well-defined and members can not claim monopoly on their work. Supervising, administrating and directing are the most monetary rewarded tasks for the semi-professionals. However, in true professions, (e.g., physicians) task performance, not organizational positions, brings the main monetary rewards.

The data from the present study showed that Icelandic occupational 
therapists have many characteristics of semi-professionals. They have a short period of training since the majority of them practice with a diploma. They consider that their profession relies more on technical skills than theoretical. They are controlled by the physicians since they need referrals to practice. The study showed that administrative tasks provided the highest income. On the other hand, their attitudes are toward professionalization, valuing, developing and validating an independent body of knowledge to support their practice. Their goals are pursuing professional status and they want competitive advantages, recognition for the value of their services and reimbursement from social security. They value academic skills over technical, emphasizing analytical skills, theoretical knowledge, research and analysis methods over technical skills and concrete principles. They want changes in the profession toward more research, clearer definitions of occupational therapy services, definite evidence of the effects of their services and recognition for the value of their services.

Professionalism. Icelandic occupational therapists actively attend workshops and seminars and contribute articles both to their own journal as well as others. They are also willing to spend extra time for the advantage of the occupational therapy profession, although they do not read much professional literature. They are active in the association, engaged in committees and interest groups. They take on educational duties along with their work as practitioners and are willing to take students and participate in research activities. They do not think that the profession is fragmenting into specialty areas although they agree that therapists should specialize. They think that their colleagues are competent and want autonomy in practice. Wages are lower than in male dominated professions with similar length of education. This is one of the largest obstacles for recruiting males 
in general and females that have greater demand for a higher income than the profession can currently offer.

Comparing the Study to Previous Studies

When comparing the present study to others, one must consider differences as to when they were conducted, as attitudes are generally affected by new developments in human theories and changes in health care priorities. The present study captures attitudes that Icelandic occupational therapists have today concerning professionalism and educational goals. Although the studies in comparison were conducted seven to 14 years ago, their target is on professionalism and educational concerns that still are in focus. The former studies compared differences between BS and MS students or BS and MS therapists; their aim was to identify difference between these educational levels. In Iceland the majority of therapists have diplomas, and fewer have a BS or MS. Therefore the present study combined BS and MS trained therapists as well as MS students into one group and compared it to therapists holding a diploma.

Gilkeson and Hanten (1984). Gilkeson and Hanten's study examined if there were any differences between baccalaureate and master's degree occupational therapists regarding professional activities and responsibilities other than direct patient care. They found no statistically significant differences between master's level and bachelor's level therapists. Both surveys revealed similar results regarding leave from work in the field and reasons why, maternity reported as the most common reason in both surveys. The average reading of occupational journals was not high in either study. Both showed that therapists were mainly working in hospitals and rehabilitation centers. In Iceland, 39\% are working in medical hospitals and 27\% in rehabilitation centers. Gilkeson and Hanten's study demonstrated that students with master's degrees showed more 
characteristics generally associated with professionalism, while the present study indicated significant differences between BS/MS and MS students compared to diploma therapists. BS/MS therapists and MS students read more, they published more in other journals than occupational ones, they participated and held presentations at conferences internationally more often, they were more interested in taking on teaching duties, were more satisfied with their contribution to health care delivery, considered themselves more as professional leaders and were prepared to spend more time working for the association than those holding a diploma.

Fifty-four percent of the Icelandic occupational therapists had published, during the last five years, between one and six articles in the Icelandic occupational therapy journal, $12 \%$ had published articles in foreign occupational therapy journals, $10 \%$ had held presentations at international conferences, $63 \%$ had participated at least once a year in workshops, $49 \%$ had participated in international conferences and $72 \%$ had attended seminars at least once. The majority of Icelandic therapists were actively involved in the occupational therapy association, served on committees and participated in interest groups. Five percent reported that their primary function was to teach and when asked for educational role at their work, only $19 \%$ reported that they had none, and $30 \%$ either educated or supervised other staff members. In Gilkeson and Hanten's study (1984), neither bachelors nor masters spent appreciable time in AOTA-related activities, professional growth activities or teaching roles. Though the results of the two studies are not directly comparable, they suggest that Icelandic occupational therapists are more active now than the research subjects in 1984 in Gilkeson and Hanten's study.

Clark et al. (1985). Clark et al. studied professional issues relating to professionalism, leadership, attitudes, and scholarly contributions between 
former basic master's and seniors who studied at one university. The master's group in Clark et al. study tended to agree more strongly $(\underline{M}=3.0$ ) than the seniors $(\underline{M}=2.7)$ with the statement, "In my experience, occupational therapists rely more on technique than theory." There was no significant difference between BS/MS and MS students vs. diploma therapists in the present study $(\underline{M}=3.5)$. The difference between the means for the two studies is explained by the fact that in Clark et al. (1985) used 1 to 4 Likert scale where "neutral" was not an option while in the present study neutral was one of the options on a scale ranging from 1 to 5 points. In Clark's et al. study, 76\% of the masters scored the options "mildly agree" and "strongly agree" while 59\% of the seniors did. In the present study $57 \%$ of all the therapists scored "mildly agree" and "strongly agree."

No significant differences were found between BS/MS and MS students vs. diploma therapists in the present study regarding the statement, "I feel that occupational therapy is more of an art than a science," $(\underline{M}=1.9)$. The present study had five options instead of four. In Clark et al., the majority of seniors disagreed $(\underline{\mathrm{M}}=2.1)$ with this statement, whereas the majority of the basic master's students agreed $(\underline{M}=2.5)$. In Clark's et al. study, $63 \%$ of the masters selected the options "mildly agree" and "strongly agree" while $28 \%$ of the seniors did. In the present study only six percent of all the therapists selected these two options. As for "strongly disagree" and "mildly disagree," $47 \%$ of the masters and $72 \%$ of the seniors scored these options in Clark's et al. study. In the present study, $73 \%$ of all therapists scored these two options, similar preferences to the seniors in Clark et al. study. The authors of the Clark et al. study explained that the differences between the groups was probably caused by the critical perspective the master's students are influenced by in graduate school and they consider the intuitive approach in human relations as the artistic 
portion part. Icelandic therapists' attitudes could be explained by the foundation of the occupational curriculum. The discussions around the new Icelandic curriculum has been about theories, science, research and evidence that occupational therapy does count. The artistic portion might therefore, have been suffocated for some time.

In Clark's et al. study there were significant differences in response to the statement, "I think occupational therapists should develop treatment plans based on established frames of references." The masters agreed significantly more $(\underline{M}=3.5)$ than the seniors $(\underline{M}=3.0)$ on a four point scale. The overall mean score in the present study was $(\underline{M}=3.9)$ on a five point scale, and there was a significant mean difference between BS/MS therapists and MS students $(\underline{M}=4.3)$ who selected higher than the diploma therapists $(\underline{M}=3.8)$. In Clark's et al. study, $87 \%$ masters and $75 \%$ of the seniors selected the two opinions "mildly agree" and "strongly agree" to the above statement. In the present study, $75 \%$ of all therapists scored these two options, again, a more similar response to seniors in Clark et al. study.

When comparing scores in Clark's et al. study regarding professional productivity, $87.5 \%$ of the masters and $92.1 \%$ of the seniors had participated in continuing education, $18.8 \%$ of the masters and $9.4 \%$ of the seniors had published in occupational therapy journals. In the present study, $90 \%$ had participated in workshops and $54 \%$ of all therapists had published in the Occupational Therapy Journal in Iceland. In Clark's et al. study, masters made greater scholarly contributions than seniors, for example, three percent of the seniors had published in journals other than the American Journal of Occupational Therapy, in contrast to nine percent of the masters. In the present study, $19 \%$ had written in other than the Occupational Therapy Journal and $12 \%$ in foreign journals. There were significant differences concerning publishing articles in other than 
occupational therapy journals with BS/MS therapists/MS students publishing more than those therapists that held diplomas. In Clark's et al. study, $20.6 \%$ of the seniors and $37.5 \%$ of the masters had held presentations at professional conferences. In the present study, $24 \%$ of the Icelandic therapists had held presentations at professional conferences and, regarding presentations at conferences internationally, BS/MS therapists/MS students presented significantly more often than the diploma therapists.

Regarding professional productivity, Icelandic therapists are more similar to the seniors than to masters in Clark's et al. study. However, Icelandic occupational therapists were more active than both seniors and masters in Clark's et al. study regarding publishing in other than occupational therapy journals. Part of the explanation for the difference is the fact that the Icelandic Occupational Therapy Journal is only issued twice a year so those who want to publish more often must publish in foreign journals or journals other than occupational therapy journals. Another factor is that Icelandic occupational therapists have been encouraged by the association to submit articles due to the foundation of the new curriculum.

Barris and Kielhofner (1985). Barris and Kielhofner's study revealed differences in preference among occupational therapy students. Those that were studying at an undergraduate level had low preference for abstract learning and high preference for concrete learning. In the present study, theoretical knowledge and analytical skills were selected as the areas that should be given most the emphasis in the Icelandic education program $(\underline{M}=4.5)$. The Icelandic occupational therapists had high preferences for abstract learning and low for concrete learning, despite that $69 \%$ of the population has only the diploma as the highest educational level. 
Regarding this, the whole population of the Icelandic occupational therapists were more similar in their preference to those that were studying for a master's degree than those who were studying for a baccalaureate degree in the U.S.A. In Fleming and Piedmont's study (1989), therapists with higher educational degrees wanted greater emphasis on research, theory, and clinical judgment; whereas, those with lower degrees felt a need to increase therapists' proficiency in applied skills, for example, in specific occupational therapy techniques. In the present study, therapists had generally similar preferences to those with higher educational degrees as shown in Fleming and Piedmont's study, with the only significant difference being that BS/MS and MS students in the present study wanted more emphasis on experience in conducting research than the therapists holding a diploma.

In the present study, respondents ranked in order of importance for the profession: "theories explaining occupations in human beings," "the role of occupational therapy in health care" and "principles outlining the relationship of occupation to health." In the present study, no significant differences were found between BS/MS therapists/MS students and diploma therapists on important issues for the occupational therapy profession. In the Barris and Kielhofner study (1985), those that were studying at a undergraduate level gave greater priority to learning about procedures for administering evaluations and the structure and function of internal bodily systems; whereas, the graduate level students placed a greater priority on the importance of learning about research on treatment efficacy and on the relationship between occupation and health. Regarding this, the whole population of Icelandic occupational therapists' priorities were more similar in their priorities to the graduate level students in the U.S.A than to baccalaureate level students. These differences between the two studies 
might again be affected by the foundation of the Icelandic curriculum, since the attitudes of the Icelandic occupational therapists might have been influenced by the discussions around the development of the new Icelandic program.

Fleming and Piedmont (1989). Respondents in the present study indicated no area in which they felt especially well prepared or stimulated as a result of their education. The results from Fleming and Piedmont's study (1989) were similar to the present study. The main contrast in the two studies were preparation in basic science. Fleming and Piedmont's study reported $\underline{\mathrm{M}}=3.7$ compared to the present study which reported $\underline{\mathrm{M}}=2.6$. Regarding personal development, Fleming and Piedmont's study reported $\underline{M}=3.2$ compared to $\underline{M}=3.9$ in the present study.

The present study analyzed differences in preparation by educational level, professional experience and country of education. The findings showed significant differences in all three areas. There were significant differences regarding preparation for management by education. The therapists holding a BS or MS, as well as those studying for the MS, felt they were better prepared for management than those holding diplomas. Regarding preparation for basic science, research and reasoning, the study showed that those that had experience from 0 to 5 years felt best prepared and those that had experience from 6 to 11 years felt they were better prepared than those with 12 years or longer experience. There were also significant differences concerning preparation for basic science, occupational therapy theory and management by country of education. Therapists that were educated in North America felt better prepared for basic science, occupational therapy theory, and management than those educated in other countries. These findings indicate that occupational therapy curricula has improved through the years in preparing their 
students for basic science, research and reasoning skills. The U.S.A. is a leading country in many areas and many theorists and ambitious individuals within occupational therapy are from the United States. They are concerned that if the profession is to grow, it needs an educational system that generates creative clinicians, skillful researchers and leaders with political exposure. The occupational therapy schools are obviously trying to following some of these recommendations, as the findings in the present study show better preparation in basic science, research and reasoning skills among younger therapists than the more experienced.

Both the Fleming and Piedmont study and the present study examined the subjects' opinions on what changes are most needed in occupational therapy practice. The difference in mean scores between the two studies ranged from none to 0.7 . Icelandic therapists found it most important to change the "recognition of the value of our service by other health professionals" $(\underline{M}=4.5)$. In Fleming and Piedmont's study, this issue was ranked fifth $(\underline{\mathrm{M}}=4.4)$. Therapists in Fleming and Piedmont's study ranked "recognition of the value of our service by the third party payers" first ( $\underline{M}=4.7)$. In the present study this issue was ranked fourth $(\underline{M}=4.2)$. Ranked second and third in the present study were "research for practice" and "definite evidence of the effects of our service" (both $\underline{M}=4.4$ ). In Fleming and Piedmont's study, "recognition of the value of our service by the general public" and "clear definition of occupational therapy service" (both $\underline{M}=4.5$ ) were ranked second. The differences between the two studies are probably mainly explained by the differences between health care systems in the two countries. Icelandic occupational therapists do not have to spend energy on reimbursement, leading their focus more toward the need to gain recognition from other professionals. Again, the discussion related to the founding of the new curriculum in Iceland may have outlined 
the need for research and evidence of occupational therapy's value.

Other studies. Vogel (1991) studied the perceived role of the practitioner, comparing three groups: educators, practitioners and students. Her findings were that all therapists agreed that occupational therapy services should be covered by third-party payers. The same result was found in Fleming and Piedmont's (1989) study and in the present study. Therapists in all surveys were concerned about the lack of recognition of the value of occupational therapy services by the third-party payers. In all three surveys, the respondents were not concerned about the profession being in imminent danger of fragmenting into groups of loosely related technical specialties, despite the fact that the profession has become more specialized. According to Bell and Bell (1972), Rogers and Mann (1980a, 1980b), Clark et al (1984), therapists with master's degrees demonstrated more characteristics generally associated with professionalism. The present study showed similar results although the groups were not directly comparable. Results from Van Deusen's (1985, 1986) studies showed that theory development are related to level of education and length of professional experience. Davidson's (1981) suggested that theory valuing had a developmental sequence. Results from Van Deusen's $(1985,1986)$ studies and the present study indicate that both longevity of practice as well as level of education are associated with priorities for theory development. The present study was similar to Taylor and Mitchell's study (1990) showing that occupational therapists strongly believe in the importance of research in the profession, although they don't practice it. The former studies compared differences between BS and MS students or BS and MS therapists to identify difference between these educational levels. The present study combined BS and MS therapists, as well as MS students, into one group and compared it to therapists holding a 
diploma.

\section{Implications of the Study}

The study should be very representative since $92 \%$ of the total occupational therapy population in Iceland responded. The results show the importance of providing Icelandic occupational therapy practitioners with the opportunity to take part in research and to capture their current enthusiasm. The communication between the clinicians and the faculty at the University of Akureyri will be essential to how the curriculum succeeds. Icelandic occupational therapists have until now had the privilege to be within short distances of one another, able to attend domestic meetings and seminars without traveling. Since the majority of therapists are still living in the Reykjavík area while the school is now set in the North of Iceland, there is a risk that communication between clinicians and the faculty might suffer. New technical devices will hopefully compensate for this. The positive effect of the program being located in the North is that occupational therapy will gain a stronger position against other health professions there. The society is much smaller, including the health sector, and the competition to other health professions, therefore are not nearly as prominent as in the Reykjavík area. The conditions for growth are excellent in Akureyri and occupational therapists will probably have greater opportunities to develop and try out new ideas and techniques there than in Reykjavík. The Icelandic curriculum can not compete with the advantage of existing programs in the U.S.A., but it can surely follow close behind and may take the leadership for the Nordic countries, trying out new ideas and raising the status of occupational therapy. 


\section{Limitations of the Study}

The small size of the Icelandic occupational therapy population is of concern when comparing different groups by education and country of education. The three groups: Diploma, BS therapists and MS therapists could not be directly compared due to small sample size. Instead, BS and MS therapists and those studying for MS degrees were grouped together and compared to diploma therapists. There were also too few subjects for a precise evaluation of whether or not country of education affected attitudes. There were only five therapists educated in the U.S.A., one in Canada, five in European countries other than Scandinavia and one from another country. Analyses were done despite small numbers of subjects in two of the groups due to extensive interest in the issue, especially for countries far apart. Results of those analyses are, therefore, to be taken with caution. The study could have looked into differences between therapists educated in the three Scandinavian countries: Denmark, Sweden and Norway. The same problem would have applied to some extent though, since the majority of the Icelandic occupational therapy population are educated in Denmark. The findings apply to the practice of occupational therapy in Iceland, any inferences about relevance to other countries must be made with caution.

\section{Further Studies}

This study will serve as a foundation for future studies on Icelandic occupational therapists and provide reference data for later comparison. A similar study could be conducted in the future to monitor possible changes in demographics and attitudes concerning professionalism and educational goals within the new generation of occupational therapists. The following could be addressed in future studies: Does the Icelandic occupational therapy profession succeed in pursuing the profession further 
in the areas of research and recognition? Does the Icelandic curriculum prepare students better in areas like research, reasoning and occupational theory? How will professionalization succeed in the Icelandic occupational therapy profession in the future? Comparison could be done between the Icelandic and foreign curricula.

\section{Conclusion}

This study indicates that the most experienced therapists considered themselves as leaders. Some of them might not be willing to struggle in the front line anymore, but could still be a valuable force to supervise or sponsor young practitioners and support the Icelandic curriculum in many ways. They have valuable experience that a young profession cannot be without, knowing that the right timing, extra effort and risk must be a part of the growth process. This study shows that the great effort of the Occupational Therapy Association and the school committee in Iceland, the support from Fulbright Professor Gail Hills and the involved staff and faculty at Florida International University have affected not only the attitudes of the potential teachers in the Icelandic curriculum but also the attitudes of the Icelandic occupational therapy profession. 


\section{List of References}

Adamson, B., Sinclair-Legge, G., Cusick., \& Nordholm, L. (1994). Attitudes, values and orientation to professional practice: A study of Australian occupational therapists. British Journal of Occupational Therapy, 57, 476-480.

Allen, A. S., \& Cruickshank, D. R. (1977). Perceived problems of occupational therapists: A subset of professional curriculum. American Journal of Occupational Therapy, 31, 557-564.

Ambrosi, E., \& Schwartz, K. (1995a). The profession's image, 1917-1925, Part I: Occupational therapy as represented in the media. American Journal of Occupational Therapy, 47, 715-719.

Ambrosi, E., \& Schwartz, K. (1995b). The profession's image, 1917-1925, Part II: Occupational therapy as represented in the media. American Journal of Occupational Therapy, 49, 828-832.

American Occupational Therapy Association (AOTA) (1991). Essentials and guidelines for an accredited educational program for the occupational therapist. American Journal of Occupational Therapy, 45, 1077-1084.

Avi-Itzhak, T. E., \& Ben-Shem, I. (1993). Work values of freshmen in allied health and helping professions: A comparative study. The Occupational Therapy Journal of Research, 13, 253-269.

Bailey, D. M. (1988). Occupational therapy administrators and clinicians: Differences in demographics and values. The Occupational Therapy Journal of Research, 8, 299-315.

Barris, R. (1984). Toward an image of one's own: Sources of variation in the role of occupational therapists in psychosocial practice. The Occupational Therapy Journal of Research, 4, 3-23. 
Barris, R., \& Kielhofner, G. (1985). Generating and using knowledge in occupational therapy: Implications for professional education.

The Occupational Therapy Journal of Research, 5, 113-123.

Baum, C., \& Law, M. (1997). Occupational therapy practice: Focusing on occupational performance. American Journal of Occupational Therapy, $\underline{51}, 277-288$.

Beckman, S. (1990). Professionalization: Borderline authority and autonomy in work. In Burrage, M., \& Thorstendahl, R. (Eds.), Professions in theory and history: Rethinking the study of the professions (pp. 115-138). New Dehli: SAGA publications.

Bell, B. D., \& Bell, J. K. (1972). Professionalism as a multidimensional perspective. American Journal of Occupational Therapy, 26, 391-398.

Bellner, A. (1995). Working conditions influencing professionalization of occupational and physical therapists, part 1: A quantitative perspective. Scandinavian Journal of Occupational Therapy, 5 , $145-152$.

Bellner, A. (1996). The impact of educational level on occupational and physical therapists' perception of professional status. The Occupational Therapy Journal of Research, 6, 147-165.

Bordieri, J. E. (1988). Job satisfaction of occupational therapists: Supervisors and managers versus direct service staff. The Occupational Therapy Journal of Research, 8, 155-153.

Breines, E. B. (1988). The issue Is - Redefining professionalism for occupational therapy. American Journal of Occupational Therapy,42, 5557.

Brollier, C. (1985a). A multivariate predictive study of staff OTR Job satisfaction: Some results of importance to psychosocial occupational 
therapy. The Occupational Therapy Journal of Research, 5, 13-27.

Brollier, C. (1985b). Managerial leadership and staff OTR job satisfaction. The Occupational Therapy Journal of Research, 5, 170-184.

Brollier, C., Bender, D., Cyranowski, J., \& Velletri, C. M. (1986). A pilot study of burnout among hospital-based occupational therapists. The Occupational Therapy Journal of Research, 6, 287-299.

Brown, J. (1992). The definition of a profession. New Jersey: Princeton University Press.

Bruhn, J. G. (1991). Occupational therapy in the 21st century: An outsider's view. American Journal of Occupational Therapy, 45, 775780.

Burke, J. P., \& DePoy, E. (1991). An emerging view of mastery, excellence, and leadership in occupational therapy practice. American Journal of Occupational Therapy, 45, 1027-1032.

Colman, W. (1990). Evolving educational practices in occupational therapy: The war emergency courses, 1936-1954. American Journal of Occupational Therapy, 44, 1028-1036.

Colman, W. (1992). Maintaining autonomy: The struggle between occupational therapy and physical medicine. American Journal of Occupational Therapy, 46, 63-70.

Collins, R. (1990). Market closure and the conflict theory of the professions. In Burrage, M., \& Thorstendahl, R. (Eds.), Professions in theory and history: Rethinking the study of the professions (pp. 24-43). New Dehli: SAGA publications.

Cowie, A. P. (Ed.). (1989). Oxford advanced learners dictionary of current English (4rd ed.). Oxford: Oxford University Press.

Christiansen, C. H. (1983). Editorial: Research: An economic imperative. The Occupational Therapy Journal of Research, 3, 195-198. 
Clark, C., Corcoran, M., \& Gitlin, L. (1995). An exploratory study of how occupational therapists develop therapeutic relationships with family caregivers. American Journal of Occupational Therapy, 49, 587-594.

Clark, F., Sharrott, G., Hill, D. J., \& Campell, S. (1985). A comparison of impact of undergraduate and graduate education on professional productivity. American Journal of Occupational Therapy, 39, 155-162.

Cottrell, R. F. (1990). Perceived competence among occupational therapists in mental health. American Journal of Occupational Therapy, 44, 118-124.

Creek, J., \& Ormston, C. (1996). The essential elements of professional motivation. British Journal of Occupational Therapy, 59, 7-10.

Davidson, H. A. (1981). Commentary: 'Occupational therapy theory development: Knowledge and values held by recent graduates.' The Occupational Therapy Journal of Research, 1, 94-96.

Davis, G.. L., \& Bordieri, J. E. (1988). Perceived autonomy and job satisfaction in occupational therapists. American Journal of Occupational Therapy, 42, 591-595.

Dudek-Shriber, L. (1997). Leadership qualities of occupational therapy department program directors and the organizational health of their departments. American Journal of Occupational Therapy, 51, 369-377.

DePoy, E. (1990). Mastery in clinical occupational therapy. American Journal of Occupational Therapy, 44, 415-422.

DePoy, E., \& Merill, S.C. (1988). Value acquisition in an occupational therapy curriculum. The Occupational Therapy Journal of Research, 8 , 259-274.

Duncombe, L., \& Howe, M. (1985). Group work in occupational therapy: A survey of practice. American Journal of Occupational Therapy, 
39, 163-170.

Duncombe, L., \& Howe, M. (1995). Group treatment goals, task, and economic implications. American Journal of Occupational Therapy, 49, 199-205.

Eberhardt, K., \& Mayberry, W. (1995). Factors influencing entry-level occupational therapists' attitudes toward persons with disabilities. American Journal of Occupational Therapy, 49, 629-636.

Engelhart, H. T. (1983). Occupational therapists as technologists and custodians of meaning. In G. Kielhofner (Ed.), Health through occupation: Theory and practice in occupational therapy (pp. 139-145). Philadelphia: F.A. Davis.

Engquist, D., Short-DeGraff, M., Gliner, J., \& Oltjenbruns, K. (1997). Occupational therapists' beliefs and practices with regard to spirituality and therapy. American Journal of Occupational Therapy, 51, 173-180.

Elzinga, A. (1990). The knowledge aspect of professionalization the case of science-based nursing education in Sweden. In Torstendahl, R., \& Burrage, M. (Eds.), The formation of professions: Knowledge, state and strategy (pp. 151-173) New Dehli: SAGA publications.

Etzioni, A. (Ed.) (1969). The semi-professions and their organizations: Teachers, nurses, social workers. New York: Free Press.

Ezersky, S., Havazelet, L., Scott, A. H., \& Zettler, C. L. (1989). Specialty choice in occupational therapy. American Journal of Occupational Therapy, 43, 227-233.

Fidler, G. (1979). Professional or nonprofessional. In Occupational therapy: $2001 \mathrm{AD}$. (pp. 31-36). Rockville, MD: AOTA.

Finlay, L. (1997). Good patients and bad patients: How occupational therapists view their patients/clients. British Journal of Occupational Therapy, 60, 440- 446. 
Fleming. M. H. (1985). Questionnaire No. 2. Unpublished manuscript.

Fleming, M. H., Johnson, J. A., Marina, M., Spergel, E. L., \& Townsend, B. (1986, February). Interim report II of entry level study. Committee American Occupational Therapy Association.

Fleming, M. H., \& Piedmont, R. L. (1989). The relationship of academic degree and years in practice to occupational therapists' perceptions of the status of the profession and educational preparation. The Occupational Therapy Journal of Research, 9, 101-113.

Flexner, S. B., \& Hauck, L. C. (1987). The random house dictionary of the English language (2nd ed.). New York: Random House.

Florian, V., Sheffer, M., \& Sachs, D. (1985). Time allocation patterns of occupational therapists in Israel: Implication for job satisfaction. American Journal of Occupational Therapy, 39, 392-396.

Freidson, E. (1983). The theory of professions: State of art. In Dingwall, R., \& Lewis, P. (Eds.) (1983). The sociology of the professions: Lawyers, doctors and others (pp. 19-37). London: The Macmillan Press.

Funk \& Wagnalls (Eds.) (1964). Britannica world language (Vol. 1.). New York: Funk \& Wagnalls Company.

Gape, N., \& Hewin, P. (1995). A matter of degree: Has occupational therapy graduated as a profession? British Journal of Occupational Therapy, 58, 50-54.

Gillette, N., \& Kielhofner, G. (1979). The impact of specialization on the professionalization and survival of occupational therapy. American Journal of Occupational Therapy, 33, 20-28.

Gilkeson, G. E., \& Hanten, W. P. (1984). A comparative analysis of occupational therapy graduates from baccalaureate and entry-level master's degree programs. The Occupational Therapy Journal of 
Research, 4, 67-91.

Graham, J., \& Timewell, E. (1990). The perceived status of occupational therapy: Myth versus reality. Australian Occupational Therapy Journal, 37, 50-56.

Green, S. (1991a). Shaking our foundations, part 1: Occupational therapy - its path to professionalization. British Journal of Occupational Therapy, 54, 11-12.

Green, S. (1991b). Shaking our foundations, part 2: Into the future. British Journal of Occupational Therapy, 54, 53-56.

Griffin, S. (1988). Conflicts in professional practice. Australian Occupational Therapy Journal, 35, 9-18.

Gunnarsson, Th. (1997). Gód tengsl milli Háskólans á Akureyri og atvinnulífsins í landinu. [Good connection between the University at Akureyri and the workingmarket]. Idjthjálfinn, 2, 7-9.

Hagedorn, R. (1995). The Casson Memorial Lecture 1995: An emergent profession - a personal perspective. British Journal of Occupational Therapy, 58, 324- 331.

Halldórsdóttir, S. (1997). Idjuthjálfun er thjódhagslega hagkvæm. [Occupational therapy is economic for the society]. Idjuthjálfinn, 2, 10-12.

Hasselkus, B. R., \& Dickie, V. A. (1990). Themes of meaning: Occupational therapists' perspectives on practice. The Occupational Therapy Journal of Research, 10, 195-205.

Hasselkus, B. R., \& Dickie, V. A. (1994). Doing occupational therapy: Dimensions of satisfaction and dissatisfaction. American Journal of Occupational Therapy, 48, 145-154.

Health Statistics (1995). Health Statistics in the Nordic countries. Health Statistics. Köbenhavn: Nordisk Medisinalstatistish committee. Humphry, R., González, S., \& Taylor, E. (1993). Family involvement 
in practice: Issues and attitudes. American Journal of Occupational Therapy, 47, 587-593.

Irvine, R. \& Graham, J. (1994). Deconstructing the concept of profession: A prerequisite to carving a niche in a changing world. Australian Occupational Therapy Journal, 41, 9-18.

Jacobs, K. (1994). Flow and the occupational therapy practitioner. American Journal of Occupational Therapy, 48, 989-996.

Javetz, R., \& Katz, N. (1989). Knowledgeability of theories of occupational therapy practitioners in Israel. American Journal of Occupational Therapy,43, 664-675.

Jeffery, B., \& Hicks, C. (1997). The impact of counselling skills training on the interpersonal skills of the undergraduate occupational therapy students. British Journal of Occupational Therapy, 60, 395- 406.

Jenkins, M., \& Brotherton, C. (1995a). In search of a theoretical framework for practice, Part l. British Journal of Occupational Therapy, $\underline{58}, 280-284$.

Jenkins, M., \& Brotherton, C. (1995b). In search of a theoretical framework for practice, Part ll. British Journal of Occupational Therapy, $\underline{58,} 332-336$.

Kaur, D., Seager, M., \& Orrell, M. (1996). Occupation or therapy? The attitudes of mental health professionals. British Journal of Occupational Therapy, 59, 319- 322 .

Katz, G. M. (1982). Terminal and instrumental values of beginning occupational therapy students. The Occupational Therapy Journal of Research, 2, 89-102.

Katz, N., \& Heimann, N. (1991). Learning style of students and practitioners in five health professions. The Occupational Therapy Journal of Research, 11, 238-244. 
Kelly, G. (1996). Feminist or feminine? The feminine principle in occupational therapy. British Journal of Occupational Therapy, 59, 2-6.

Kielhofner, G. (1992). Conceptual foundations of occupational therapy. Philadelphia: F. A. Davis Company.

Kielhofner, G., \& Burke, J. (1977). Occupational therapy after 60 years: An account of changing identity and knowledge. American Journal of Occupational Therapy, 31, 657-689.

Lee, T. M., Paterson, J. G., \& Chan, C. C. (1994). The effect of occupational therapy education on students' perceived attitudes toward persons with disabilities. American Journal of Occupational Therapy, 48, 633-638.

Lehmann, L. (1973). Occupational therapists: Attitudes toward role autonomy. American Journal of Occupational Therapy, 27, 384-391.

Lyons, M. (1991). Enabling or disabling? Students' attitudes toward persons with disabilities. American Journal of Occupational Therapy, 45, 311-316.

Lyons, M. (1997). Understanding professional behavior: Experiences of occupational therapy students in mental heath settings. American Journal of Occupational Therapy, 51, 686-692.

Lyons, M. \& Hayes, R. (1993). Student perceptions of persons with psychiatric and other disorders. American Journal of Occupational Therapy, 47, 541-548.

Lög idjuthjálfsfélags Íslands. (1977, December). [Authorization of occupational therapy: Laws of occupational therapy practice]. Starfsréttindi idjuthjálfa. Bessastadir: Ísland.

Madigan, M. J. (1985). Characteristics of students occupational therapy educational programs. American Journal of Occupational Therapy, $39,41-48$. 
Madill, H. M., Brintnell, E. S., Stewin, L. L. Fritzsimmons, G. W., \& Macnab, D. (1986). Occupational therapy career patterns in profile. Canadian Journal of Occupational Therapy, 53, 89-95.

Madill, H. M., Fritzsimmons, G. W., Macnab, D., Stewin, L. L., Brintnell, E. S., \& Casserly, M. (1986). Work related issues in occupational therapy: Your values do count. Canadian Journal of Occupational Therapy, $\underline{53}, 13-18$.

Mathewson, M. (1975). Female and married: Damaging to the therapy profession? American Journal of Occupational Therapy, 29, 601605 .

Mattingly, C., \& Fleming, M. (1994). Clinical reasoning: Forms of inquiry in a therapeutic practice. Philadelphia: F.A. Davis Company.

McClain, L., McKinney, J., \& Ralston, J. (1992). Occupational therapists in private practice. American Journal of Occupational Therapy, 46, 613-618.

Miller, R. (1982). Application of role and role conflict theory to administration in occupational therapy education. Occupational Therapy Journal of Research, 2, 27-38.

Miller, R. (1992). Interwoven threads: Occupational therapy, feminism, and holistic health. American Journal of Occupational Therapy, $\underline{46}, 1013-1019$.

Mocellin, G. (1996a). Occupational therapy: A critical overview, Part I. British Journal of Occupational Therapy, 58, 502- 506.

Mocellin, G. (1996b). Occupational therapy: A critical overview, Part II. British Journal of Occupational Therapy, 59, 11- 16.

Moll, S., \& Cook, J. (1997). "Doing” in mental health practice: Therapists' beliefs about why it works. American Journal of Occupational Therapy, 51, 662-670. 
Moser, C. A., \& Kalton, G. (1971). Survey methods in social investigation (2nd ed.). Glasgow: The University Press.

Mosey, A. C. (1981). Occupational therapy: Configuration of a profession. New York: Raven Press.

Mountain, G. (1997). A review of the literature in the British Journal of Occupational Therapy 1989-1996. British Journal of Occupational Therapy, 60, 430- 435 .

Munoz, J. P., Lawlor, M., \& Kielhofner, G. (1993). Use of the model of human occupation: A survey of therapists in psychiatric practice. The Occupational Therapy Journal of Research, 13, 117-139.

Neistadt, M. (1992). The classroom as clinic: Applications for a method of teaching clinical reasoning. American Journal of Occupational Therapy, 46, 814-819.

Neistadt, M., \& Smith, R. (1997). Teaching diagnostic reasoning: Using a classroom-as-clinic methodology with videotapes. American Journal of Occupational Therapy, 51, 360-368.

Nelson, D. (1997). Why the profession of occuptional therpy will flourish in the 21st century. American Journal of Occupational Therapy, $\underline{51}, 11-24$.

Nordic Medico Statistical Committee (NOMESCO) (1996). Health Statistics in the Nordic Countries, 1994. 47:1996.

Ottenbacher, K., \& Short, M. G. (1982). Publication trends in occupational therapy. The Occupational Therapy Journal of Research, 2, 80-88.

Pálmadóttir, G. (1996a, Mars). Idjuthjálfun á Íslandi í 20 ár: [Occupational therapy in Iceland for 20 years]. Paper presented on the annual meeting of the Icelandic Occupational Therapy Association 20th birthday. Reykjavík: Iceland. 
Pálmadóttir, G. (1996b). Occupational therapy education program in Iceland: Needs and development. World Federation of Occupational Therapists, 33, 19-23.

Pálmadóttir, G. (1997). Idjuthjálfun verdur íslensk frædigrein: Stada og thróun - nám á idjuthjálfunarbraut háskólans á Akureyri [Occupational therapy in Icelandic developing their own professional body of knowledge]. Idjuthjálfinn, 2, 14-19.

Parham, D. (1985). Academic reward structures and occupational therapy faculty, part I: Characteristics of faculty. The Occupational Therapy Journal of Research, 5, 83- 100.

Parham, D. (1987). Nationally Speaking - Toward professionalism: The reflective therapist. American Journal of Occupational Therapy, 41, $555-561$.

Pierce, D., Jackson, J., Rogosky-Grassi, M., Thompson, M. E., \& Menninger, B. (1987). The possible effects of a change to master's entry level in occupational therapy. American Journal of Occupational Therapy, 41, 658-666.

Pierce, E. R. (1984). The liberal arts connection. American Journal of Occupational Therapy, 38, 237-244.

Ottenbacher, K. (1990). Occupational therapy curricula and practice: Skill based or knowledge based. The Occupational Therapy Journal of Research, 10, 7-11.

Rogers, J. C. (1982). Sponsorship: Developing leaders for occupational therapy. American Journal of Occupational Therapy, 36, 309313.

Rogers, J. C., \& Mann, W. C. (1980a). Relationship between professional productivity and educational level part 1. Review of the literature and methodology. American Journal of Occupational Therapy, 
34, 378-392.

Rogers, J. C., \& Mann, W. C. (1980b). Relationship between professional productivity and educational level part 2. Result and discussion. American Journal of Occupational Therapy, 34, 460-468.

Rozier, C. K., Gilkeson, G. E., \& Hamilton, B. L. (1992). Why students choose occupational therapy as a career. American Journal of Occupational Therapy, 46, 626-632.

Rugg, S. (1996). The transition of junior occupational therapists to clinical practice: Report of a preliminary study. British Journal of Occupational Therapy, 59, 165- 168.

Sabari, J. S. (1985). Professional socialization: Implications for occupational therapy education. American Journal of Occupational Therapy, 39, 96-102.

Scott, W. E. (1985). Variables that contribute to leadership among female occupational therapists. American Journal of Occupational Therapy, 39, 379-385.

Schemm, R., \& Bross, T. (1995). Mentorship experiences in a group of occupational therapy leaders. American Journal of Occupational Therapy, 49,32-37.

Schlenz, K., Guthrie, M., \& Dudgeon, B. (1995). Burnout in occupational therapists and physical therapists working in head injury rehabilitation. American Journal of Occupational Therapy, 49, 986-993.

Schön, D. (1987). Educating the reflective practitioner.

San Francisco: Jossey-Bass

Schuman, H., \& Presser, S. (1981). Questions and answers in attitudes surveys. New York: Academic Press.

Schwarz, N., \& Sudan, S. (Eds.) (1996). Answering questions: Methodology for determining cognitive and communicative process in 
survey research. San Francisco: Jossey-Bass Publishers.

Selander, S. (1990). Associative strategies in the process of professional strategies and scientification of occupations. In Burrage, M., \& Thorstendahl, R. (Eds.), Professions in theory and history: Rethinking the study of the professions (pp. 139-146). New Dehli: SAGA Publications.

Sieg, K. W. (1986). Chairing the academic occupational therapy department: A job analysis. American Journal of Occupational Therapy, 40, 89-95.

Storm, W. (1990). The relationship of educational level to the development and dissemination of knowledge by occupational therapists. American Journal of Occupational Therapy, 44, 39-46.

Strong, J., Gilbert, J., Cassidy, S., \& Bennett, S. (1995). Expert clinicians' and students' views on clinical reasoning in occupational therapy. British Journal of Occupational Therapy, 58, 119 -122.

Taylor, E. A., Mitchell, M. (1990). Research attitudes and activities of occupational therapy clinicians. American Journal of Occupational Therapy, 44, 350-355.

Taylor, E. A., Madill, H. M., \& Macnab, D. (1990). Values, salience, and job satisfaction: Male and female occupational therapists' responses. The Occupational Therapy Journal of Research, 10, 131-143.

Taylor, J. (1995). A different voice in occupational therapy. British Journal of Occupational Therapy, 58, 170- 173.

Teske, Y. R., \& Spelbring, L. M. (1983). Future impact on occupational therapy from current changes in higher education. American Journal of Occupational Therapy, 37, 667-672.

Tompson, M. M., \& Ryan, A. G. (1996). The influence of fieldwork on the professional socialization of occupational therapy students.

British Journal of Occupational Therapy, 59, 65-70. 
Tryssenaar, J. (1997). Clinical interpretation of "understanding professional behavior experiences of occupational therapy students in mental health settings". American Journal of Occupational Therapy, 51, 693-695.

Tyrrell, J., \& Smith, H. (1996). Levels of psychological distress among occupational therapy students. British Journal of Occupational Therapy, $\underline{59}, 365-371$.

University of Iceland. (1995). Information booklet. Reykjavík: Information Office and Public Relations Committee.

Yerxa, E. J. (1975). Nationally Speaking - On being a member of a "feminine" profession. American Journal of Occupational Therapy, 29, 597-598.

Yerxa, E. J. (1982). The issue - A response to testing and measurement in occupational therapy: A review of current practice with special emphasis on the southern California sensory integration tests. American Journal of Occupational Therapy, 36, 399-404.

Yerxa, E. J. (1983). Audacious values: The energy source of occupational therapy practice, In G. Kielhofner (Ed.), Health through occupation: Theory and practice in occupational therapy (pp. 149-162). Philadelphia: F.A. Davis.

Yerxa, E. J. (1987). Research: The key to the development of occupational therapy as an academic discipline. American Journal of Occupational Therapy, 41, 415-419.

Yerxa, E. J. (1991). Nationally Speaking - Occupational therapy: An endangered species or an academic discipline in the 21 st century? American Journal of Occupational Therapy, 45, 8, 680-685.

Yerxa, E. J. (1995). Who is the keeper of occupational therapy's practice and knowledge? American Journal of Occupational Therapy, 49 
295-299.

Yerxa, E. J., \& Sharrott, G. (1986). Liberal arts: The foundation for occupational therapy education. American Journal of Occupational Therapy, 40, 153-159.

Van Deusen, J. (1981). Occupational therapy theory development: Knowledge and values held by recent graduates. The Occupational Therapy Journal of Research, 1, 79-93.

Van Deusen, J. (1985 ). Relationship of occupational therapists' education and experience to perceived value of theory development. The Occupational Therapy Journal of Research, 5, 223-231.

Van Deusen, J. (1986). Occupational therapy theory: Values held by undergraduate students. The Occupational Therapy Journal of Research, 6, 115-122.

Van Deusen, J. (1993). Enhancing the research image of occupational therapy. American Journal of Occupational Therapy, 47, 181-183.

Van Deusen, J. (1995). What is the role of the occupational therapist in managed care? American Journal of Occupational Therapy, 49, 833-834.

Vogel, K. A. (1991). Perception of practitioners, educators, and students concerning the role of the occupational therapy practitioner. American Journal of Occupational Therapy, 45, 130-136.

Wallis, D., \& Hutchings, S. (1990). The attainment of professional attitudes: the use of group work in clinical and school based settings. British Journal of Occupational Therapy, 53, 48-52.

Wallis, M. (1987). 'Profession' and 'professionalism' and the emerging profession of occupational therapy, part I. British Journal of Occupational Therapy, 50, 262- 263.

West, W. (1992). Ten milestone issues in AOTA history. American 
Journal of Occupational Therapy, 46, 1066-1074. 
APPENDIX 
Dear Colleague:

As you probably know, the initial preparations for the Bachelor's program in occupational therapy have been going on for several years. However, it was not until Dr. Gail Hills visited Iceland in spring 1995 on a Fulbright fellowship that the program development moved forward. She worked on the development of the Icelandic occupational therapy program with the school committee and the association. This fall, we finally saw the, effort of their tremendous work when the University of Akureyri opened its doors and the occupational therapy program became a reality.

During Dr. Gail Hills' stay she also initiated a Master's program with seven Icelandic occupational therapists, including me, intended to prepare potential teachers for the program. This is a collaboration between Florida International University and the University of Iceland. The enclosed survey is an important part of my thesis, and I need your valuable input to be able to accomplish my master's degree. When you have completed this questionnaire you have made a valuable contribution to the Icelandic occupational therapy program and to the Icelandic Occupational Therapy Association.

All information will be handled confidentially and you are not supposed to identify yourself by name. The data will only be reported as group data.

The purpose of the survey is to gather initial data on Icelandic occupational therapists. A perspective on the current state of our profession regarding professional issues and the development of the academic program will be of great significance now when we are in our first stage of the curriculum development. The data might be annually updated to observe changes and development within our profession. I hope that the survey will encourage a dialogue regarding professional issues between clinicians and educators.

To obtain valid results, it is important that you answer all the questions. We are few, everyone counts! Please return the questionnaire no later than the 20th of February.

Thank you very much,

Elín Ebba Ásmundsdóttir 


\section{Icelandic occupational therapists' attitudes toward educational and professional issues}

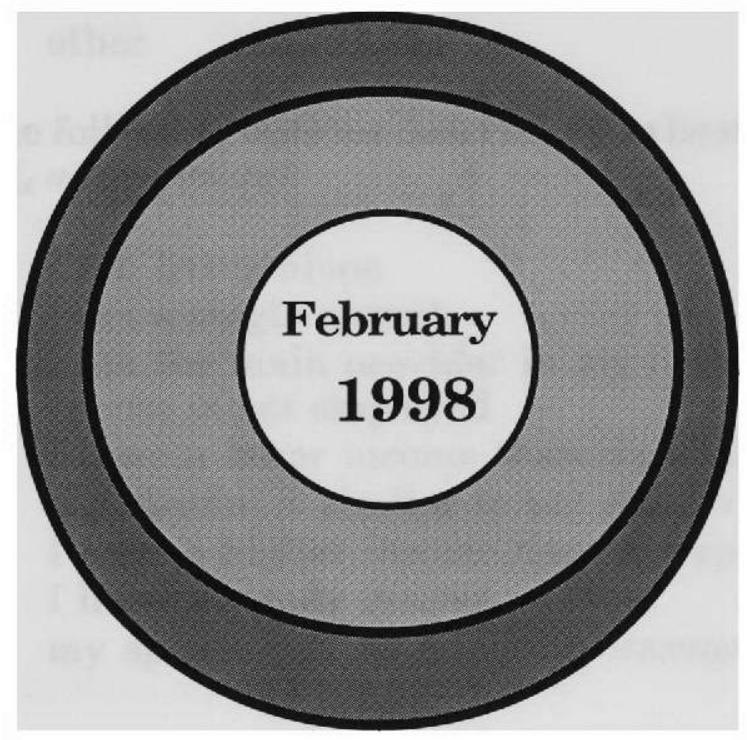

Thank you for taking time to participate in this survey

It is important that you answer all questions If a question does not quite fit your situation, just pick the best choice 


\section{FIRST SECTION}

Background (Questions 1- 22)

1. What is your age?

$\begin{array}{ll}\square & \text { younger than } 30 \text { years } \\ \square & 30 \text { years to } 39 \text { years } \\ \square & \text { 40 years to } 49 \text { years } \\ \square & 50 \text { years to } 59 \text { years } \\ \square & \text { 60 years and older }\end{array}$

2. What is your current marital status?

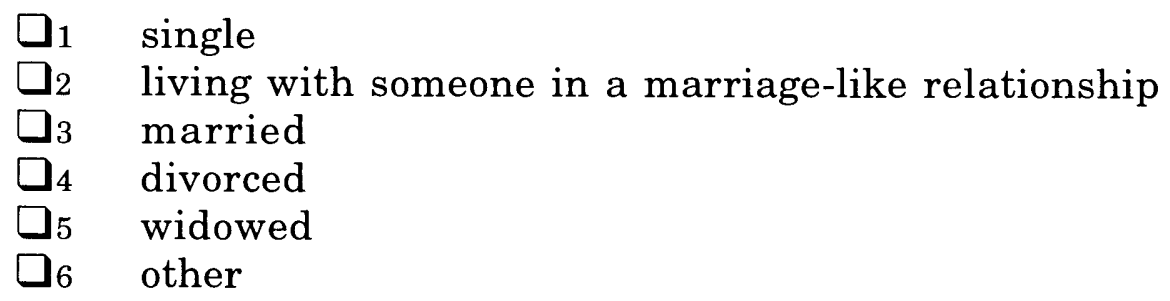

3. Which of the following options describes you best? (Check $\underline{\mathbf{A L} L}$ appropriate)

$\begin{array}{ll}\square_{1} & \text { I am living alone } \\ \square_{2} & \text { I am a single parent } \\ \square_{3} & \text { I am the main provider in my household, since my } \\ & \text { spouse is not employed } \\ \square_{4} & \text { I have a lower income than my spouse } \\ \square_{5} & \text { my income is similar to my spouse's } \\ \square_{6} & \text { I have a higher income than my spouse } \\ \square_{7} & \text { I have a steady income } \\ \square_{8} & \text { my spouse has an irregular income }\end{array}$

\section{What are your caregiving duties?}

(Check $\mathbf{A L L}$ appropriate, and fill in the number and ages of children in the empty lines)

$\begin{array}{ll}\square_{1} & \text { none } \\ \square_{2} & \text { I am a parent to child(ren) the age(s) of } \\ \square_{3} & \begin{array}{l}\text { I have } \\ \text { grandchild(ren) }\end{array} \\ \square_{4} & \begin{array}{l}\text { I give care to a relative at least once a week } \\ \square_{5}\end{array} \\ \begin{array}{l}\text { I have other time consuming caregiving duties } \\ \text { specify }\end{array}\end{array}$


5. What were your reasons for coming back to Iceland after your education was completed? (Check $\underline{A L L}$ the appropriate boxes and write number 1 next to the most important reason, 2 next to the second most important reason, and onward)

_. $\square_{1}$ as an immigrant to Iceland this question does not apply to me

_- - $\square_{2}$ there was an occupational therapy position waiting for my return

_. $\quad \square_{3} \quad$ my spouse did not get employment where I graduated

$\square_{4} \quad$ I could not get work as an occupational therapist where I graduated

_- $\square_{5}$ patriotism/family affairs

$\square_{6} \quad$ I always intended coming back to Iceland

- $\square_{7}$ other reasons $=>$ specify

6. How long have you been working as an occupational therapist? years

7. When did you graduate as an occupational therapist?

$\begin{array}{ll}\square_{1} & 1960 \text { or before } \\ \square_{2} & 1961 \text { to } 1970 \\ \square_{3} & 1971 \text { to } 1980 \\ \square_{4} & 1981 \text { to } 1990 \\ \square_{5} & 1991 \text { or later }\end{array}$

8. From which country did you graduate?

$\begin{array}{ll}\square_{1} & \text { Denmark } \\ \square_{2} & \text { Sweden } \\ \square_{3} & \text { Norway } \\ \square_{4} & \text { another European country } \\ \square_{5} & \text { USA } \\ \square_{6} & \text { Canada } \\ \square_{7} & \text { other countries }=>\text { specify }\end{array}$


9. What education do you have? (Check $\underline{\mathbf{A L L}}$ appropriate)

$\square$ program degree/diploma in occupational therapy

$\square_{2} \quad$ bachelors in occupational therapy

$\square_{3}$ bachelors in a profession other than occupational therapy

$\square 4$ master's degree in occupational therapy

$\square 5$ master's degree in a profession other than occupational therapy

$\square 6$ currently studyingfor master's degree in occupational therapy

$\square_{7} \quad$ studying for master's in another field

$\square_{8}$ doctorate

$\square 9$ other special education $=>$ specify

10. What is your employment status?

$\square$ I am working as an occupational therapist

$\square_{2}$ I work as an occupational therapist, but I am currently on a leave

$\square_{3} \quad$ I am working as an occupational therapist along with other paid work

$\square$ I am working in fields other than occupational therapy $=>$ go to question 17

$\square 5 \quad$ I keep house $=>$ go to question 17

11. What is your current work setting? (Check $\underline{A L L}$ the appropriate boxes and write no 1 next to the item you spent most of your time doing, 2 next to what comes second, and onward)

$\begin{array}{ll}\square_{1} & \text { medical hospital } \\ \square_{2} & \text { rehabilitation center } \\ \square_{3} & \text { outpatient clinic } \\ \square_{4} & \text { community care/organization } \\ \square_{5} & \text { school system } \\ \square_{6} & \text { helping aid center } \\ \square_{7} & \text { common workplace } \\ \square_{8} & \text { private practice } \\ \square 9 & \text { other => specify }\end{array}$


12. What percentage of time do you work as an occupational therapist? $\%$

13. How many occupational therapists do you work with besides yourself?

$\begin{array}{ll}\square & \text { none } \\ \square_{2} & 1-3 \\ \square_{3} & 4-6 \\ \square_{4} & 7-9 \\ \square & \text { more than } 10\end{array}$

14. What is your current area of practice? (Check $\underline{A L L}$ the appropriate boxes and write no. 1 next to the item you spent most of your time doing, 2 next to what comes second, and onward)

\begin{tabular}{|c|c|c|}
\hline & $\sqcup_{1}$ & $\begin{array}{l}\text { occupational therapy for children/adolescents } \\
\text { (until } 16 \text { years of age) }\end{array}$ \\
\hline & $\square_{2}$ & occupational therapy for adults with physical disabilities \\
\hline & $\square_{3}$ & $\begin{array}{l}\text { occupational therapy for adults with psychosocial } \\
\text { problems }\end{array}$ \\
\hline & $\square_{4}$ & $\begin{array}{l}\text { occupational therapy for adults with development } \\
\text { disabilities }\end{array}$ \\
\hline & $\square_{5}$ & occupational therapy for the elderly \\
\hline & $\square_{6}$ & $\begin{array}{l}\text { health promotion and sickness prevention for people } \\
\text { with normal abilities }\end{array}$ \\
\hline & & education \\
\hline & & administration with 4 staff members or less \\
\hline & & administration with $5-10$ staff members \\
\hline & $\square$ & administration with more than 10 staff members \\
\hline & & other areas $=>$ specify \\
\hline
\end{tabular}

15. What educational roles do you practise in addition to your clinical work as an occupational therapist?

(Check $\underline{\boldsymbol{A L L}}$ the appropriate boxes and write no. 1 next to the item you spent most of your time doing, 2 next to what comes second, and onward)

$\begin{array}{lll}-- & \square_{1} & \text { none } \\ --- & \square_{2} & \text { consulting other professionals } \\ --- & \square_{3} & \text { supervising occupational therapists } \\ --- & \square_{4} & \text { supervising other staff members } \\ --- & \square_{5} & \text { educating staff members } \\ --- & \square_{6} & \text { supervising occupational therapy students } \\ --- & \square_{7} & \text { other educational duties }=>\text { specify }\end{array}$


16. What is your average monthly income as an occupational therapist?

$\begin{array}{ll}\square_{1} & 50 \text { thousand kroners or less } \\ \square_{2} & 51-80 \text { thousand kroners } \\ \square_{3} & 81-110 \text { thousand kroners } \\ \square_{4} & 111-140 \text { thousand kroners } \\ \square_{5} & 141-170 \text { thousand kroners } \\ \square & 171-200 \text { thousand kroners } \\ \square 7 & 201-230 \text { thousand kroners } \\ \square & 231 \text { thousand kroners or more }\end{array}$

17. Have you paused from occupational therapy work for more than 6 consecutive months at any time?

$\begin{array}{ll}\square_{1} & \text { yes } \\ \square_{2} & \text { no => go to question number } 19\end{array}$

18. For what reasons? (Check $\underline{\boldsymbol{A L L}}$ appropriate)

\begin{tabular}{|c|c|c|}
\hline$\square_{1}$ & maternity $=>$ & how often? \\
\hline$\square_{2}$ & upbringing of children $=>$ & how often? \\
\hline$\square_{3}$ & illness $=>$ & how often? \\
\hline$\square_{4}$ & education $=>$ & how often? \\
\hline$\square_{5}$ & other occupations $=>$ & how often? \\
\hline$\square_{7}$ & illness within family $=>$ & how often? \\
\hline & $\begin{aligned} \text { other reasons } & => \\
& =>\text { specify }\end{aligned}$ & how often? \\
\hline
\end{tabular}

19. Have you worked in more than one specialty area of occupational therapy?

$\begin{array}{ll}\square_{1} & \text { yes } \\ \square_{2} & \text { no => go to question } 21\end{array}$ 
20. What specialty areas of occupational therapy have you worked in? (Check $\underline{A L L}$ appropriate)

$\square_{1}$ occupational therapy for children/adolescents (until 16 years of age)

$\square 2$ occupational therapy for adults with physical disabilities

$\square_{3}$ occupational therapy for adults with psychosocial problems

$\square 4$ occupational therapy for adults with development disabilities

$\square_{5}$ occupational therapy for the elderly

$\square 6$ health promotion and sickness prevention for people with normal abilities

education

$\square_{8}$ administration

$\square 9$ other areas $\Rightarrow$ specify

21. What percentage of time do you work in other areas than occupational therapy? $\%$

22. What is your total monthly income for work other than occupational therapy including freelance and other irregular work?

$\begin{array}{ll}\square_{1} & \text { none } \\ \square_{2} & 50 \text { thousand kroners or less } \\ \square_{3} & 51-80 \text { thousand kroners } \\ \square_{4} & 81-110 \text { thousand kroners } \\ \square_{5} & 111-140 \text { thousand kroners } \\ \square_{6} & 141-170 \text { thousand kroners } \\ \square_{7} & 171-200 \text { thousand kroners } \\ \square_{8} & 201-230 \text { thousand kroners } \\ \square 9 & 231 \text { thousand kroners or more }\end{array}$

This is the end of section one 
Educational issues (Questions 23 - 24)

23. How well did your occupational therapy education prepare and stimulate you in the following areas?

(Circle the appropriate numbers 1 to 5 for each area a to $j$ )

none poor fair good excellent
a. basic science

$\begin{array}{lllll}1 & 2 & 3 & 4 & 5\end{array}$

b. occupational therapy theory

$\begin{array}{lllll}1 & 2 & 3 & 4 & 5\end{array}$

c. occupational therapy technique

$\begin{array}{lllll}1 & 2 & 3 & 4 & 5\end{array}$

d. critical thinking

$\begin{array}{lllll}1 & 2 & 3 & 4 & 5\end{array}$

e. research

$\begin{array}{lllll}1 & 2 & 3 & 4 & 5\end{array}$

f. clinical judgment

$\begin{array}{lllll}1 & 2 & 3 & 4 & 5\end{array}$

g. management

$\begin{array}{lllll}1 & 2 & 3 & 4 & 5\end{array}$

h. personal development

$\begin{array}{lllll}1 & 2 & 3 & 4 & 5\end{array}$

i. professionalization

$\begin{array}{lllll}1 & 2 & 3 & 4 & 5\end{array}$

j. reasoning

$\begin{array}{lllll}1 & 2 & 3 & 4 & 5\end{array}$


24. How much emphasis do you think the following areas should be given in our Icelandic occupational therapy education?

(Circle the appropriate numbers 1 to 5 for each area a to $k$ )

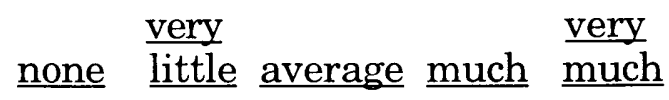

a. technical skills

b. theoretical knowledge

c. abstract ideas

d. concrete principles

e. analytical skills

f. practical skills

g. personal growth

h. professional commitment

i. field work

j. experience in conducting research

k. research and analysis methods

1

1

1

1

1

1

1

12

12

12

1

1

1

$\begin{array}{llll}2 & 3 & 4 & 5\end{array}$

This is the end of section two 


\section{THIRD SECTION}

Professional activity (Questions 25 - 28)

25. How often do you read occupational therapy journals?

(Check ONLY one)

$\square_{1}$ at least once a week

$\square_{2}$ at least twice a month

$\square 3$ at least once a month

$\square$ at least twice a year

$\square 5$ never $=>$ go to question 27

26. From which countries are the occupational therapy journals you read? (Check $\underline{\boldsymbol{A L L}}$ appropriate)

$\begin{array}{ll}\square_{1} & \text { Denmark } \\ \square_{2} & \text { Norway } \\ \square_{3} & \text { Sweden } \\ \square_{4} & \text { United States } \\ \square_{5} & \text { Great Britain } \\ \square_{6} & \text { Canada } \\ \square_{7} & \text { Australia } \\ \square_{8} & \text { other countries }=>\text { specify }\end{array}$

27. How often do you read other medical journals other than occupational therapy journals? (Check ONLY one)

$\square_{1}$ at least once a week

$\square_{2}$ at least twice a month

$\square_{3}$ at least once a month

$\square_{4}$ at least twice a year

口5 never 
28. How often have you been occupied with the following activities related to occupational therapy or other professional matters from January 1st, 1993 to the present?

(Fill in the appropriate numbers on the spaces)

a. I have written articles in the Icelandic occupational therapy journal times

b. I have written articles in Icelandic other professional journals __ times

c. I have written articles in the daily newspapers times

d. I have written articles in foreign professional journals times

e. I have conducted workshops for occupational therapists times

f. I have conducted workshops for other health professionals or for the public times

g. I have appeared on TV as a professional times

h. I have given presentations at meetings for professionals other than occupational therapists times

i. I have given presentations at conferences __ times, of these international

j. I have participated in workshops __ times, of these international

k. I have participated in seminars times, of these international

This is the end section three 
Professional issues (Questions 29 - 38)

29. How much change do you think is needed in the following areas of occupational therapy practice?

(Circle the appropriate numbers 1 to 5 for each area a to j)

$$
\underline{\text { none little }} \underline{\text { some }} \underline{\text { much }} \underline{\underline{\text { very }}}
$$
a. increase in use of complex techniques
12
3
4
5
b. development of technology
12
34
5
c. process of service delivery

12
3
4
5
d. clear definition of occupational therapy service

$\begin{array}{lllll}1 & 2 & 3 & 4 & 5\end{array}$
e. education for practice

$\begin{array}{ll}1 & 2 \\ 1 & 2\end{array}$

34
5
f. definite evidence of the effects of our service
g. recognition of the value of our

12 service by other health professionals
h. recognition of the value of our
1 service by social security
i. recognition of the value of our

12

3
4
5
service by the general public
j. research for practice

$\begin{array}{lllll}1 & 2 & 3 & 4 & 5\end{array}$


30. How well do the following statements describe you?

(Circle the appropriate numbers 1 to 5 for each statement a to i)

$$
\begin{array}{ll}
\text { not all pather } & \underline{\text { rather }} \text { very } \\
\text { poorly } & \underline{\text { well }} \text { well }
\end{array}
$$
a. I am actively involved in the
Occupational Therapy Association

$\begin{array}{lllll}1 & 2 & 3 & 4 & 5\end{array}$

b. I am usually engaged in a committee within the Occupational Therapy Association

c. I do not participate in interest groups in the Occupational Therapy Association

d. I can imagine myself doing 12 34 5 something other than occupational therapy in the future

e. I feel that I have influence upon the development of the occupational therapy profession

f. I feel that I am a professional leader in the field of occupational therapy

g. I was taught in school the 12

3
4 5 importance of life-long learning

h. I am satisfied with my contribution to health care delivery as an occupational therapist

i. I am prepared to commit extra 1 2 3 time for the advancement of the Occupational Therapy Association 
31. How well do the following statements describe your opinion? (Circle the appropriate numbers 1 to 5 for each item a to f)

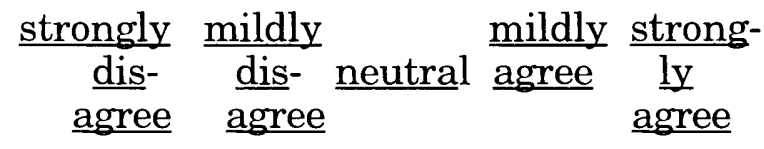
a. I feel that occupational therapists should be more active in
12
3
4
5 promoting health and well being

b. In my opinion, occupational therapists should specialize $\begin{array}{lllll}1 & 2 & 3 & 4 & 5\end{array}$ within a certain population

c. I think occupational therapists should develop treatment plans based on established frames of references

d. In my experience, occupational therapists rely more on technique than theory

$\begin{array}{lllll}1 & 2 & 3 & 4 & 5\end{array}$

e. I think the unique base of 12 34 5 occupational therapy is directed and purposeful activity meaningful to the patient

f. In my opinion occupational

12

34
5 therapy is a consciously planned progressive program of rest, play, occupation and exercise 
32. How well do the following statements describe your opinion? (Circle the appropriate numbers 1 to 5 for each item a to g)

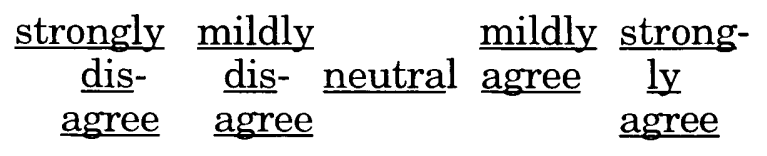
a. I feel that occupational therapy

$\begin{array}{lllll}1 & 2 & 3 & 4 & 5\end{array}$
b. I feel that occupational therapy

$\begin{array}{lllll}1 & 2 & 3 & 4 & 5\end{array}$

c. I think occupational therapy education needs to develop a 12

3

4

5 greater and clearer defined theoretical structure for the practice of occupational therapy

d. I think that the development of a professional body of knowledge, which is unique to occupational therapy, is an important goal to achieve for the profession

e. I feel that occupational therapy is less stimulating intellectually than I anticipated

f. I think that the Icelandic occupational therapy curriculum should emphasize the study of philosophy and ethics to aid the development of reasoning skills

g. In my opinion, emphasis on reasoning skills in the Icelandic occupational therapy curriculum will impart significant improvements in the quality of treatment 
33. How well do the following statements describe your opinion?

(Circle the appropriate numbers 1 to 5 for each item a to i)

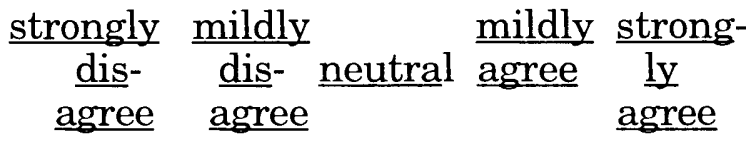
a. I feel that occupational therapy
12
3
4
5
is becoming a specialty based
profession with no common
generic philosophy to unite it

b. I find that there is a difference in practice between therapists

$\begin{array}{lllll}1 & 2 & 3 & 4 & 5\end{array}$

educated in different countries

c. I feel that most occupational

therapists are competent in the

practice of occupational therapy

d. I find it difficult to convince others

1

of the value of occupational therapy

e. I feel that the prospects for

12

2

3

4

5

occupational therapy in the

future are positive

f. In my opinion, occupational therapy services should

12

3

4

5

always be covered by social security

g. I feel that occupational therapists should maintain their current relationship with the medical profession as a subordinate, helping profession

h. I think that occupational therapists should always have referrals from physicians

i. In my opinion, occupational 1 12 3 45 therapy should aim toward becoming an autonomous profession in certain areas to meet the health care demands of the patients 
34. The Icelandic occupational therapy program will be a four year undergraduate program. Completion will be attainment of a BS degree. In your opinion is there any need for a special "bridging course" for occupational therapists who have graduated with a diploma to achieve a BS degree?

$\begin{array}{ll}\square_{1} & \text { yes } \\ \square_{2} & \text { no }\end{array}$

35. Would you be interested in such a "bridging course" if available?

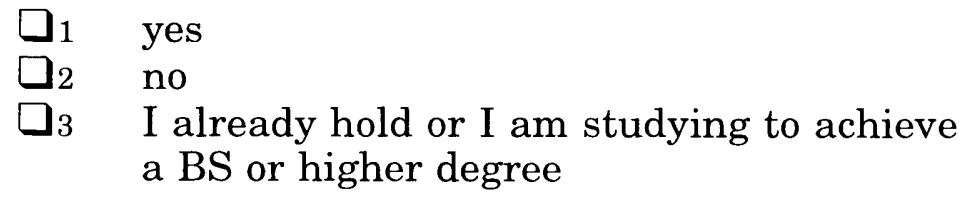

36. Do you consider yourself as having adequate knowledge and skills to:

(Check $\underline{\text { ALL }}$ appropriate)

$\square_{1}$ teach a course in the occupational therapy undergraduate program

$\square_{2}$ teach a course in the occupational therapy undergraduate program with supervision of a faculty member

$\square_{3} \quad$ supervise an occupational therapy student during fieldwork

$\square_{4}$ conduct research in the occupational therapy field

37. Would you be interested in:

(Check $\underline{\text { ALL }}$ appropriate)

$\square 1$ teaching a course in the occupational therapy undergraduate program

$\square 2$ teaching a course in the occupational therapy undergraduate program with supervision of a faculty member

$\square 3$ supervising an occupational therapy student during fieldwork

$\square$ conducting research in the occupational therapy field 
38. Which of the following issues do you consider most important for the occupational therapy profession? (Choose what you consider to be the FIVE most important issues and rank order them according to their importance. Write the number 1 next to the issue you find most important, 2 next to what comes second and onward so that the number 5 indicates the least important of the 5 chosen issues)

-_- techniques of patient interaction

(i.e., interviewing, setting limits)

procedures for administering specific evaluations

political and social contexts of health care delivery

theories explaining occupation in human beings

classification of diseases

structure and function of the nervous-

and musculoskeletal system

research comparing effectiveness of

different treatments

the role and mission of occupational therapy

in health care

history of occupational therapy

specific treatment techniques

principles of supervision and administration

program documentation skills (e.g., note writing)

principles outlining the relationship of occupation to health

This is end of section four 


\section{Additional information}

39. Please comment if you have something more to share that you think is of importance for the occupational therapy profession

40. Please share if you have any comments or ideas concerning the Icelandic occupational therapy curriculum

41. Please comment if you have ideas on how continuing education in occupational therapy can be provided 